\title{
Mouse Models of Polyglutamine Diseases: Review and Data Table. Part I
}

\author{
Maciej Figiel • Wojciech J. Szlachcic • \\ Pawel M. Switonski • Agnieszka Gabka • \\ Wlodzimierz J. Krzyzosiak
}

Received: 22 April 2012 / Accepted: 29 July 2012 / Published online: 7 September 2012

(C) The Author(s) 2012. This article is published with open access at Springerlink.com

\begin{abstract}
Polyglutamine (polyQ) disorders share many similarities, such as a common mutation type in unrelated human causative genes, neurological character, and certain aspects of pathogenesis, including morphological and physiological neuronal alterations. The similarities in pathogenesis have been confirmed by findings that some experimental in vivo therapy approaches are effective in multiple models of polyQ disorders. Additionally, mouse models of polyQ diseases are often highly similar between diseases with respect to behavior and the features of the disease. The common features shared by polyQ mouse models may facilitate the investigation of polyQ disorders and may help researchers explore the mechanisms of these diseases in a broader context. To provide this context and to promote the understanding of polyQ disorders, we have collected and analyzed research data about the characterization and treatment of mouse models of polyQ diseases and organized them into two complementary Excel data tables. The data table that is presented in this review (Part I) covers the behavioral, molecular, cellular, and anatomic characteristics of polyQ mice and contains the most current knowledge about polyQ mouse models. The structure of this data table is designed in such a way that it can be filtered to allow for the immediate retrieval of the data corresponding to a single
\end{abstract}

Electronic supplementary material The online version of this article (doi:10.1007/s12035-012-8315-4) contains supplementary material, which is available to authorized users.

M. Figiel $(\bowtie) \cdot$ W. J. Szlachcic · P. M. Switonski · A. Gabka •

W. J. Krzyzosiak

Institute of Bioorganic Chemistry, Polish Academy of Sciences,

Noskowskiego 12/14,

61-704 Poznan, Poland

e-mail: mfigiel@ibch.poznan.pl mouse model or to compare the shared and unique aspects of many polyQ models. The second data table, which is presented in another publication (Part II), covers therapeutic research in mouse models by summarizing all of the therapeutic strategies employed in the treatment of polyQ disorders, phenotypes that are used to examine the effects of the therapy, and therapeutic outcomes.

Keywords Polyglutamine $\cdot$ Mouse models $\cdot$ Huntington's disease $\cdot$ Spinocerebellar ataxia $\cdot$ DRPLA $\cdot$ SBMA

\section{Introduction}

The polyglutamine (polyQ) family of disorders comprises nine diseases, including Huntington's disease (HD) [1]; spinal and bulbar muscular atrophy, X-linked 1 (SMAX1/ SBMA) [2, 3]; six spinocerebellar ataxias (SCA) type 1 [4], type 2 [5], Machado-Joseph disease (MJD/SCA3) [6], type 6 [7], type 7 [8], and type 17 [9, 10]; and dentatorubralpallidoluysian atrophy (DRPLA) [11, 12]. The polyQ diseases have multiple commonalities [13]. PolyQ diseases are all neurological disorders, and their pathology is mainly related to dysfunction or even a loss of neurons in the central nervous system (CNS). Recently, the non-neuronal pathology has been increasingly recognized and investigated. The polyQ diseases are caused by an unusual type of mutation, namely, the expansion of CAG repeats in the coding region of causative genes that are otherwise structurally unrelated. The presence of one mutant allele containing a CAG repeat number that exceeds a pathologic threshold is sufficient to cause the disease; therefore, all of these diseases are dominantly inherited. One exception is SMAX1/SBMA, which is 
linked to the androgen receptor (AR) gene on the X chromosome; thus, one affected allele in female patients may cause no (or only mild) symptoms compared to male patients.

In all of the polyQ diseases, the number of CAG repeats is dynamic and can expand or contract from generation to generation. The presence of a mutant allele leads to the production of a pathogenic protein containing an expanded polyQ tract that alters the properties and activity of the affected protein. The disease mechanism may include a gain and/or loss of function in the mutant protein, which becomes toxic to cells. The severity of the disease symptoms increases markedly with an increasing number of CAG repeats and the resulting number of glutamines in causative proteins; however, the naturally occurring low number of CAG repeats in the causative genes encodes polyQ stretches in their respective proteins without evoking any signs of a disease. Another feature that is common to the polyQ disorders is that many mouse models of polyQ diseases share common phenotypes, and this phenomenon resembles the situation in patients wherein many SCA disorders are clinically indistinguishable based on a neurological examination alone. These similar features led to the hypothesis that all polyQ disorders are in fact one disease that may have a common treatment. However, the extent to which this is true is limited because each disease possesses unique features as a result of the protein context of the polyQ mutation. Because the polyQ diseases (including their respective mouse models) are similar, understanding the mechanisms and pathogenesis of one disease or mouse model may contribute to our understanding of the mechanisms of other diseases.

The first transgenic animal that was generated as a model of a polyQ disorder and that showed the disease was the B05 SCA1 model mouse [14]. To date, more than 100 polyQ mouse models have been created, although some diseases are overrepresented (e.g., HD) [15] and others are underrepresented (e.g., SCA6) [16, 17] (Supp.
Fig. 1). At this stage, finding, comparing, and translating the information between diseases are difficult without using special tools such as a database or sortable list. Therefore, we collected and integrated the body of data regarding disease onset and progression and therapeutic approaches in mouse models of the various polyQ diseases by creating an Excel data table (referred to as the data table). The data table is attached to this publication as supplementary material and covers the behavioral, molecular, cellular, and anatomic characteristics of polyQ mice in 21 columns and over 2,000 records (Fig. 1).

The structure of our data table comprises two informal groups of data. The first group of data consists of $11 \mathrm{col}-$ umns that describe the general features of each mouse model, such as the disease that was modeled; references; the practical name of the mouse as used in the original publication; the model type; the genetic background of the mouse; and the data regarding the transgenic construct, including the promoter, transgenic sequence, and the number of CAG $(\mathrm{Q})$ repeats within the structure of the transgene. The second group consists of nine columns that contain data characterizing the disease models by phenotypes divided into general phenotypes, phenotypes, detailed phenotypes, the methods that were used to detect the phenotypes, the affected brain regions or other tissues (if applicable), the age of the earliest and latest detection of the phenotype, and a quantification of the phenotype (if data are available) expressed as a percent decrease or increase relative to nontransgenic animals. The last column contains various comments that refine or add more details to other columns and provides additional references. Supplementary Table 1 summarizes the contents of the columns in the data table.

The data for the data table come from almost 290 carefully selected research articles that report the generation and/ or characterization of transgenic animals. In this review, in addition to constructing the data table, we provide a "classic" text overview of polyQ mouse models. This review

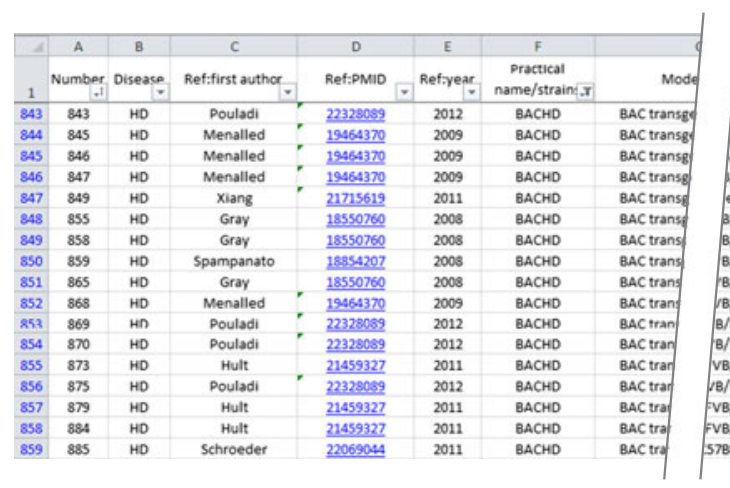

Fig. 1 The data table is an electronic resource that collects the behavioral, molecular, cellular, and anatomic characteristics of polyQ mice. The figure demonstrates only a small fragment of the data table, and

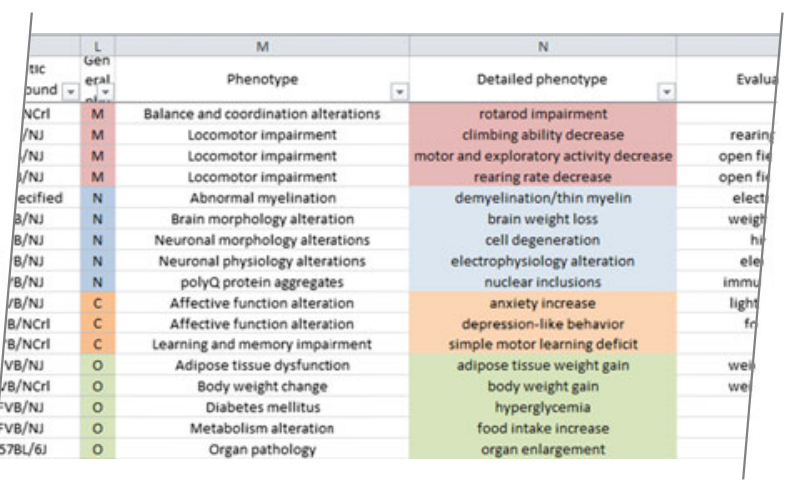

the selection of records for this figure is accidental. The full data table comprises over 2,000 records and 21 columns 
quotes a fairly complete set of scientific publications describing polyQ mouse model generation and characterization; however, many important works, particularly those in which no mouse models were directly investigated, were omitted due to space constraints. Therapeutic research using polyQ mouse models is included in our companion review (Part II), which summarizes the preclinical therapeutic strategies employed in polyQ disorders. We believe that this combination of text and table reviews can provide the most comprehensive overview of in vivo research on polyQ disorders.

Although the initial studies in which transgenic mice were created and characterized were very sparse and often inaccurate, the characterization of the disease phenotypes that are present in polyQ transgenic mice evolved rapidly as researchers learned what to look for in polyQ models. Unfortunately, the lack of guidelines, protocols or a systematic list of phenotypes that can aid in and standardize the characterization of polyQ mouse models remains a general issue within the field of polyQ and neurological disease research. A useful resource is the Mouse Genome Informatics (MGI) database (http://www.informatics.jax. org), which provides the Mammalian Phenotype Browser (MPB) [18]. The MPB contains very broad lists of phenotypes for all forms of disease models. The disadvantage of this solution is that it does not offer the subset of phenotypes that are specific to polyQ or neurological diseases. In addition, some phenotypes (such as the cognitive phenotypes observed in the R6/2 model) are not listed, and it contains only a partial list of transgenic animals and variants. For example, the MPB contains 7 models of SCA3, whereas our data table contains 14 mouse models and variants of SCA3. Additionally, our data table contains more precise information regarding phenotype timelines.

The current lack of both a coherent set of phenotypes and a list of polyQ mouse models delays the gathering of new information from mouse models, which makes it difficult to compare information among models and to compare information from mouse models with human patients. More precise characterization of polyQ disease models and the exchange of data from various disease models may accelerate the discovery of disease mechanisms and effective therapeutic strategies.

\section{Mouse Models of PolyQ Disorders}

\section{HD Mouse Models}

The HTT gene contains 67 exons spanning $169 \mathrm{~kb}$ and encodes a 3142-aa protein (huntingtin) from a 13-kb transcript. Because the CAG expansion is located in the first exon of the HTT gene, it is possible to generate simple transgenic models that express short fragments of the HTT gene containing the promoter, exon 1 and intron $1[19,20]$, short fragments of cDNA [21-24] or the full-length cDNA [25] driven by a non-native promoter. Other transgenic models have been generated by introducing the entire HTT gene with a yeast or bacterial artificial chromosome (YAC or BAC, respectively) [26-30]. Another strategy for overcoming the size of the HTT gene is using the mouse gene as a framework and introducing a CAG repeat tract [31] or CAG repeats in a chimeric human exon 1 [32-34] using a knock-in technique. In addition, both conditional and reversible HD models have been created to demonstrate the cell- and brain region-specific effects of mutant huntingtin or its fragments [35-37]. To date, the size of the HTT gene has hindered the creation of a "whole-gene-humanized" targeted knock-in mouse model of HD.

\section{R6/2 Mouse Models}

The first genetic model of HD was serendipitously created in 1996 by Bates and coworkers while studying the CAG instability in the HTT gene [19]. Three different transgenic lines - R6/1 (116 CAG), R6/2 (144 CAG) and homozygous R6/5 (128-156 CAG) - exhibit progressive neurological phenotypes. Because the R6/2 line shows instability of the repeat tract, variants containing 200-249, 250-299, 300$349,350-399$ and $>400$ CAG repeats have been created by breeding [38]. Interestingly, the disease is mitigated by an increase in the number of CAG repeats [38, 39].

The R6/2 line exhibits the most severe and rapid onset of motor and cognitive phenotypes among all of the available HD mice and is the most commonly studied model of this disease [40]. The R6/1 is a late-onset HD model [41] that often complements the use of $\mathrm{R} 6 / 2$ in therapeutic approaches (Part II).

Young R6/2 mice are indistinguishable from wild-type (WT) animals by home cage observation, but early tests reveal that the transgenic animals exhibit cognitive deficits as early as 3.5 weeks prior to the onset of overt motor abnormalities [42-46] (Table 5 and the data table). Cognitive deficits in R6/2 comprise spatial (hippocampaldependent) and non-spatial (striatal-dependent) learning and memory, and such impairments are very similar to those observed in HD patients [46-50]. The motor abnormalities appear over the subsequent weeks, and their severity and frequency increase until they finally develop into the evident neurological signs of repetitive movements, wide-based gait, epileptic seizures and sudden involuntary movements of the whole body that may be the mouse equivalent of the chorea observed in HD patients [19, 42, 44, 45]. In addition, progressive body-weight loss is observed until death, which occurs prematurely between 13 and 15 weeks of age [44], but the lifespan of the animal increases with an increasing number of CAG repeats $[38,39]$. 
The neurodegeneration in R6/2 mice has been intensively studied, revealing pathological changes in neuronal morphology, such as the presence of nonapoptotic dark neurons in specific areas of the brain [51, 52]. Striatal medium-sized spiny neurons (MSNs) exhibit electrophysiological changes in addition to altered morphology [53-55]. The models of polyQ diseases and patients contain neuronal intranuclear inclusions (NIIs) that can also be identified in R6/2 as early as postnatal day 1 in various brain regions [44, 56-58]. The R6/2 brain progressively loses weight $[44,59,60]$, but not as a result of neuronal loss in the striatum, because neuronal death was not observed [52, 61]. However, Stack and colleagues [44] observed a $25 \%$ reduction in the number of striatal neurons and also detected reactive gliosis in R6/2 animals. This finding was later confirmed by another group [62]. Despite these results, the findings from R6/2 mice largely support the hypothesis that neuronal dysfunction (rather than neuronal loss) is responsible for the onset of neurological phenotypes. If the mice were to live beyond 13 weeks of age, they may eventually show a larger reduction in the number of MSNs.

Mutant huntingtin is also expressed in the retinas of R6/2 and R6/1 mice, which leads to pronounced vision deficiencies and retinal degeneration [63]. This huntingtin effect cannot be observed unless the background strain does not contain the $r d$ mutation responsible for retinal degeneration (see "Mouse genetic background"). A map of the neuropathology of R6/2 mice can be found in Fig. 2.

R6/2 mice also exhibit severe non-neurological abnormalities, which are summarized in detail in Table 6 and the data table. Like HD patients, some R6/2 mice develop diabetes [64-66] and insulin resistance as a consequence of hypothalamic-pituitary-adrenal axis dysregulation [67]. Moreover, R6/2 mice exhibit cardiac dysfunction, which leads to severe cardiac failure; this finding is consistent with the early onset cardiovascular disease that occurs in HD patients [68]. Another non-neurological abnormality in R6/2 mice, which makes them difficult to maintain, is the prominent atrophy of their reproductive organs [19]. In addition, the circadian rhythms of R6/2 mice are altered [69, 70].

Taken together, the R6/2 models have demonstrated the multitude of phenotypes that can also be detected in HD patients and have established the role of mutant huntingtin exon 1 in the pathogenesis of HD.

\section{N171-82Q Mouse Models}

The N171-82Q transgenic model, which expresses the Nterminal fragment of the human huntingtin protein, was created in Borchelt's laboratory [21]. The transgene molecule comprises the first 171 amino acids, but it contains a stretch of 82 glutamines instead of the 23 glutamines that are present in the reference sequence $[21,71]$.
N171-82Q mice exhibit a neurological phenotype that is rapidly progressive but slower than that of $\mathrm{R} 6 / 2$ animals. The disease progresses to the evident loss of coordination, hypokinesis, motor and learning deficits, and it ends in premature death [21, 72-74].

As in the R6/2 mice, the NIIs of mutant huntingtin are present in neurons in many brain regions (see the data table) $[21,52,75,76]$. N171-82Q mice exhibit progressive neurodegeneration that manifests in brain atrophy [77-80] and reactive gliosis [52]. Importantly, the degenerating neurons in N171-82Q animals die from apoptotic processes [52], whereas apoptosis is not detected in degenerating neurons of R6/2 mice. Another marked difference from the R6/2 model is the evident loss of medium spiny neurons in the striata $[80,81]$. However, the spectrum of disease phenotypes in N171-82Q mice is generally in line with those in the $\mathrm{R} 6 / 2$ mice. Because the transgene and protein are longer in N171-82Q mice, the model contributed to the discussion about the significance of transgene and protein length, as well as the putative cleavage of huntingtin in the pathogenesis of HD [71]. A map of the neuropathology of N171-82Q mice can be found in Fig. 2.

\section{Transgenic YAC HD Models}

A range of HD mouse models was produced in Hayden's laboratory by introducing the human HTT gene using YAC. The models are named after the number of consecutive CAG repeats in the HTT gene and include the YAC18, YAC46, YAC72, and YAC128 lines [28]. YAC72 mice exhibit a mild disease course and also show NMDA receptor (NMDAR) abnormalities and impairment of mitochondrial metabolism [29, 82-85]. The YAC128 model was generated to further investigate $\mathrm{HD}$ and to produce a more severe disease phenotype than that of the YAC72 model [30]. YAC128 mice exhibit a progressive deterioration in rotarod performance, a biphasic activity profile that manifests as a transition from a hyperkinetic to a hypokinetic phenotype (detailed onset and progression of disease in YAC128 mice listed in Table 5 and the data table) [86, 87]. Cognitive abnormalities manifest as cognitive rigidity, as well as spatial and procedural learning deficits; therefore, both the hippocampal and striatal memory systems are affected. These changes precede the onset of motor deficits and resemble the cognitive impairments seen in patients [88-91].

In YAC128 animals, neurodegeneration is detected late, but the loss of striatal and cortical neurons is evident [30, 86 , 92, 93]. The neuronal NIIs, as well as the extranuclear inclusions, in YAC128 mice are visible by light microscopy well after the development of the histological and behavioral abnormalities [20,94]. For a map of neuropathology in the YAC128 model, see Fig. 2. 
Fig. 2 Diagrams of neuropathology in the brain, spinal cord, and retina of selected mouse models of Huntington's disease. Seven neuropathology phenotypes, namely, neuronal loss, neuronal morphology alterations, neuronal physiology alterations, glia abnormalities, retinopathy, neurogenesis impairment, and abnormal myelination, were selected, along with the localization available for these phenotypes in CNS region column of the data table. The brain regions involved in the selected neuropathology phenotypes for R6/2, N171-82Q, CAG140, Hdh(CAG)150,

YAC128, and BACHD models were marked with colors on a schematic sagittal section of the mouse brain. Brain regions were color-coded using colors from the Allen Brain Atlas [374]. The main brain regions involved in the HD models are the striatum (STR) and cerebral cortex (CTX). The R6/2 and YAC128 models also show involvement of the hippocampus $(H P)$ as a region of "neurogenesis impairment" $[375,376]$; the deficit is also observed in the piriform cortex (CTX, bottom part) [377] and olfactory bulb $(O B)$ [378] of the R6/2 mice. Moreover, R6/2 neuropathology is observed in the hypothalamus $(H Y)$, cerebellum $(C B)$, spinal cord $(S C)$, and retina of the eye (RETINA). The cerebral cortex $(C T X)$ is not involved in the selected neuropathology phenotypes in the Hdh (CAG)150 knock-in. As in R6/2 animals, abnormal myelination has been detected in the corpus callosum $(C C)$ and striatum $(S T R)$ of BACHD animals
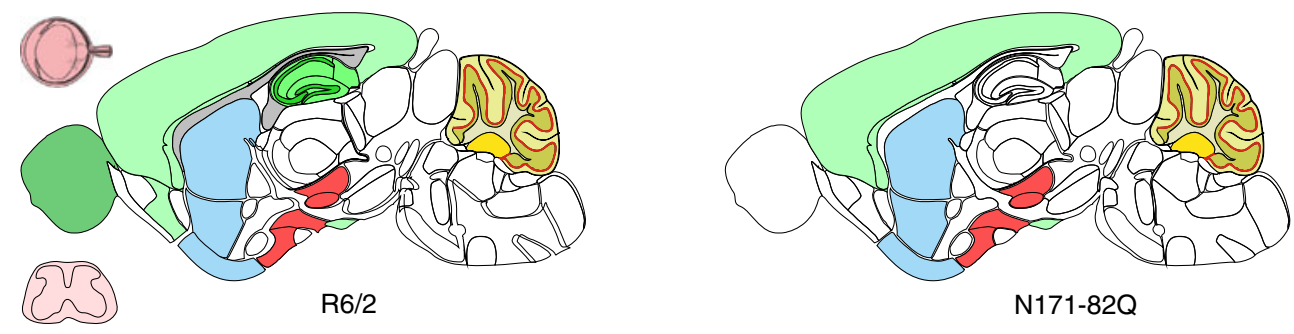

OB CTX CC STR HY HP CB RETINA SC

Observed phenotype Abnormal myelination

\begin{tabular}{|c|c|c|c|c|c|c|c|c|c|c|c|}
\hline & & + & & & & & Abnormal myelination & & & & \\
\hline & + & + & & + & & & Glial abnormalities & & + & & \\
\hline+ & + & & & + & & & Neurogenesis impairment & & & & \\
\hline+ & & + & + & & & & Neuronal loss & + & + & + & \\
\hline & + & + & + & + & + & + & Neuronal morphology alteration & + & + & + & \\
\hline & + & + & & + & + & + & Neuronal physiology alteration & + & + & & + \\
\hline & & & & & & & Retinopathy & & & & \\
\hline
\end{tabular}
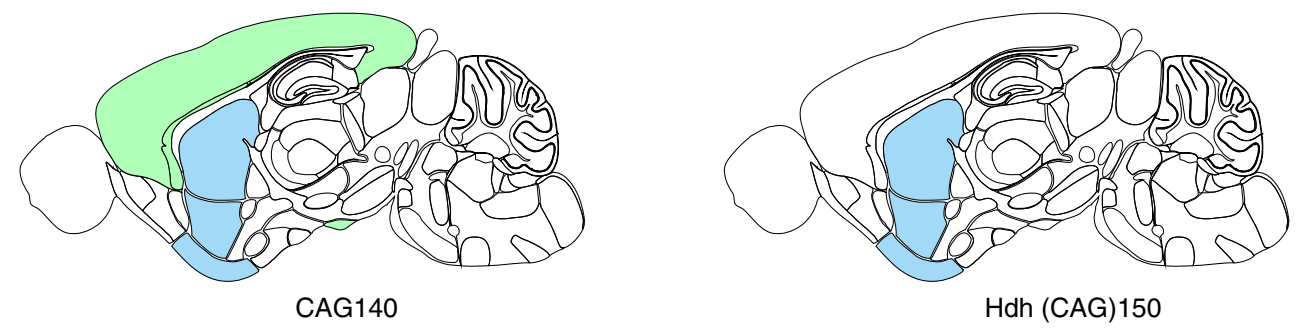

Hdh (CAG) 150

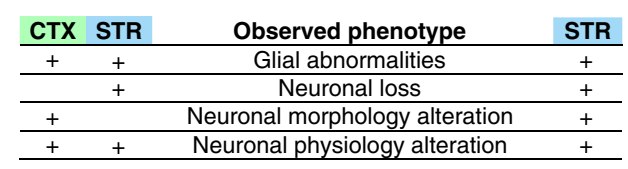

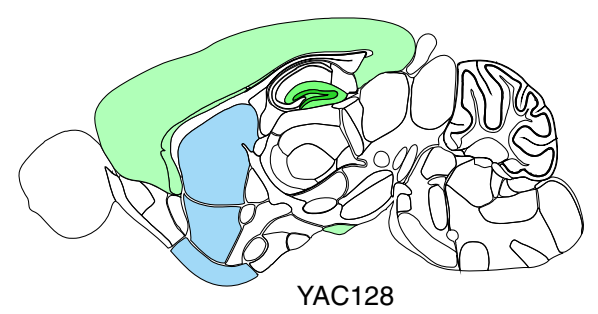

YAC128

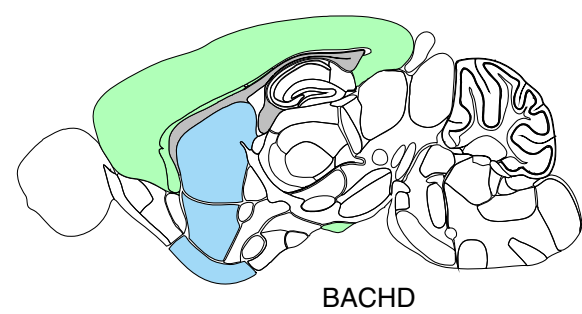

BACHD

\begin{tabular}{|c|c|c|c|c|c|c|}
\hline CTX & STR & HP & Observed phenotype & CTX & CC & STR \\
\hline & & & Abnormal myelination & & + & + \\
\hline \multirow[t]{3}{*}{+} & + & & Glial abnormalities & & & \\
\hline & + & & Neuronal loss & & & \\
\hline & + & & Neuronal morphology alteration & + & & + \\
\hline \multirow[t]{2}{*}{+} & + & & Neuronal physiology alteration & + & & + \\
\hline & & + & Neurogenesis impairment & & & \\
\hline
\end{tabular}

A long-debated feature of nearly every HD model is the resistance to excitotoxicity following the injection of quinolinic acid (QUIN). Interestingly, in the YAC models, the animals first develop an increased susceptibility to excitotoxicity and later develop a resistance to it. This is in contrast to the fast-occurring resistance seen in the R6/2 and N171-82Q models [95-100]. The transition from susceptibility to resistance most likely results from progressing neuronal dysfunction in the cortex and striatum that finally leads to a severe loss of connectivity between these brain structures [101-106]. It is possible that increased NMDAR-mediated currents in the MSNs compensate for a mild loss of corticostriatal connectivity during the early stage of HD in YAC128 mice. The increased currents in the MSNs probably result from elevated NMDAR protein levels [84, 107], which may be the reason behind the increased susceptibility to excitotoxicity after challenging the YAC128 brains with QUIN. The later resistance may develop after severe loss of corticostriatal connectivity, loss of spines, and reduction in the level of NMDAR expression. This problem is also discussed in our Part II review. 


\section{Knock-in HD Models}

The R6 and N171-82Q models exhibit a severe, highly progressive HD phenotype but do not always reflect the real expression pattern of human HTT or the underlying molecular basis of the disease. To address this issue, knock-in mice with a wide range of CAG repeats (50-200; see the data table) were created. For instance, the 50, 92, and 111 CAG stretches were knocked-in by replacing exon 1 of the mouse $H t t$ gene with a hybrid mouse/human sequence [108, 109]. HdhQ92 and HdhQ111 mice have both intergenerational and somatic repeat instability [109], showing a very mild phenotype that appears almost exclusively when homozygous $[110,111]$. Although the deficits in the acoustic startle response and cognitive deficits are detected around 4 months, motor impairments were not detected before 24 months $[32,45,112]$. The cognitive deficits include changes in procedural learning and alternation learning [110, 113-116]. The NIIs are detectable in various brain regions and are composed of the N-terminal fragments of the HTT protein [117, 118]. Similar knock-in CAG71 and CAG94 animals with mild phenotypes were created by Chesselet's group $[119,120]$ and have been recapitulated by the creation of a CAG140 model [33] in which the course of the disease is slightly accelerated. The disease progression is somewhere between those of the BACHD and YAC128 models, and the model also exhibits the biphasic behavior common for many HD models (Table 5 and the data table). The mice have abnormal balance and coordination [33, 121-123] as well as increased anxiety and motor learning deficits. At the level of the brain tissue, a reduction in striatal volume, the loss of striatal neurons and the presence of NIIs in striatum parallel a progressive reduction of DARPP-32 expression in the MSNs [33, 122]. A map of the neuropathology of CAG140 mice can be found in Fig. 2.

A two-step gene targeting strategy was used by Detloff's group to create HD knock-in $\mathrm{Hdh}(\mathrm{CAG}) 150$ mice with CAG expansions that were inserted into the pure mouse $H t t$ gene sequence [31]. Longitudinal studies of homozygous animals revealed that this model has a mild phenotype characterized by late-onset decreases in motor activity [124] along with cognitive deterioration $[125,126]$ and neuropathology [124, 127]. Recently, a knock-in HdhQ200 mouse with 200 CAG repeats was created that presents a slightly accelerated phenotype compared to that of the $\mathrm{Hdh}$ (CAG)150 mice [128].

\section{Transgenic BACHD Model}

The BACHD model was created using the entire human HD gene located in a $250-\mathrm{kb}$ genomic fragment modified by inserting a $\mathrm{CAA} / \mathrm{CAG}$ mixed sequence encoding the tract of 97 glutamines [27]. Unlike the pure CAG sequence, the
CAA/CAG mixed sequence is genetically more stable and therefore suitable for testing whether the somatic instability of CAG repeats is essential for pathogenic processes in HD. Indeed, the BACHD mice show the same stable length of the mixed $\mathrm{CAA} / \mathrm{CAG}$ tract in both maternal and paternal transmission, as well as in aged brain regions, including the striatum, cortex, and cerebellum. However, the stability of the mixed CAA/CAG tract does not prevent pathogenesis in the BACHD mice, and neuronal dysfunction clearly occurs long before neuronal degeneration is observed. For instance, the motor deficits are evident as early as 4 weeks, and increased anxiety manifests at 12 weeks of age [27, 45]. Although the neuropathological changes in electrophysiology can also be identified at 12 weeks $[129,130]$, the evidence of neurodegeneration is observed at 12 months in the form of atrophy of the cortex and striatum. As in the R6/ 2 mice, the BACHD mice have neuronal dark cell degeneration in the striatum [27]. Interestingly, the BACHD animals essentially lack NIIs; instead, they show the presence of extranuclear aggregates (neuropil aggregates) in the cortex and the striatum [27]. A map of the neuropathology of BACHD mice can be found in Fig. 2.

Information about other HD models that are not directly reviewed in the text is provided in Table 1.

\section{SCA1 Mouse Models}

\section{SCA1 Pcp2/L7 Promoter-Based Models}

The SCA1 mouse model (called B05) was created using the full-length $A T X N 1$ cDNA with $82 \mathrm{CAG}$ repeats. The Purkinje cell (PC) protein $2(P c p 2 / \mathrm{L} 7)$ promoter limits the transgene expression to cerebellar PCs. The ataxin-1 mRNA content is massive due to the occurrence of approximately 30 copies of the transgene at a single integration site [14]. Voluminous but cell-population-limited transgene expression results in the close reproduction of the ataxic phenotype in mice but the absence of a decreased lifespan [131]. Cerebellar neuropathology develops prior to the onset of ataxia and involves strong and unusual morphological [131] and electrophysiological alterations in PCs [132, 133], as well as the presence of NIIs in $90 \%$ of PCs [134]. Morphology alterations are accompanied by strong gliosis and the loss of PCs [131]. The B05 mice also exhibit changes in cerebellar gene expression [135] and signaling [136] as well as biochemical changes, similar to those of SCA1 patients [137].

A limitation of the B05 model is the use of the Pcp2 promoter, which induces an ataxin-1 protein expression pattern that is inconsistent with the expression pattern of the native protein. High overexpression of the mutant protein in PCs results in abnormalities such as vacuolization and heterotopy of PCs; these features are not present in SCA1 patients. 
Table 1 Other transgenic mouse models of HD

\begin{tabular}{|c|c|c|c|c|}
\hline Model name & Promoter & $\begin{array}{l}\text { CAG } \\
\text { number }\end{array}$ & Properties & References \\
\hline D9-N171-98Q & mDarpp-32 & 98 & Cell-autonomous MSNs dysfunction, mild phenotype & {$[23]$} \\
\hline HD48, HD89 & CMV & 48,89 & $\begin{array}{l}\text { Full HTT cDNA; relatively slow, biphasic phenotype; decreased lifespan; } \\
\text { neuronal loss, clasping and circling behavior }\end{array}$ & {$[25,300]$} \\
\hline HD 100 & rat Eno2 & 100 & Neuron-specific model; corticostriatal pathway impairment & {$[273,313]$} \\
\hline $\begin{array}{l}\text { HD150QG, } \\
\text { HD 190QG }\end{array}$ & HTT (1 kb of 5'UTR) & 150,190 & $\begin{array}{l}\text { EGFP-HTT model; R6-like phenotype; decreased life span; possible } \\
\text { attenuating effect of eGFP on disease severity }\end{array}$ & [311] \\
\hline NLS144, NES144 & HTT (1 kb of 5'UTR) & 143 & $\begin{array}{l}\text { Modified R6/2 constructs with either NLS or NES signals produce } \\
\text { accelerated and ameliorated phenotypes, respectively }\end{array}$ & [276] \\
\hline Htt-160Q & GFAP (Gfa2) & 160 & $\begin{array}{l}\text { Glia-specific expression of N-terminal HTT; decreased lifespan; } \\
\text { non-cell-autonomous mechanism of HD pathogenesis }\end{array}$ & {$[231]$} \\
\hline NLS-N171-82Q & $\operatorname{PrP}$ & 82 & NLS signal ameliorates the phenotype of N171 mice & [22] \\
\hline N118-82Q & $\operatorname{PrP}$ & 82 & $\begin{array}{l}\text { Shorter N-terminal HTT fragment; N171-like phenotype with earlier } \\
\text { premature death }\end{array}$ & {$[24]$} \\
\hline N586-82Q/K14-eGFP & $\operatorname{PrP}$ & 82 & $\begin{array}{l}\text { N-terminal HTT (equivalent to caspase- } 6 \text { clevage product); phenotype } \\
\text { milder than N171 with unexpected cerebellar pathology, dyskinesia and } \\
\text { ataxia; frequent cytoplasmic aggregates }\end{array}$ & {$[236]$} \\
\hline N586-82Q & $\operatorname{PrP}$ & 82 & N-terminal HTT (equivalent to caspase- 6 clevage product) & [237] \\
\hline shortstop & HTT & 120 & N-terminal YAC model; no disease phenotype; NIIs present & {$[20]$} \\
\hline $\begin{array}{l}\text { BACHD-SD, } \\
\text { BACHD-SA }\end{array}$ & HTT & $97^{\mathrm{a}}$ & $\begin{array}{l}\text { Mutation of HTT at serines } 13 \text { and } 16 \text { to either phosphomimetic (SD) } \\
\text { or phosphoresistant (SA) version; mice with normal and BACHD-like } \\
\text { phenotype, respectively }\end{array}$ & [239] \\
\hline HD94 & CamKII $\alpha$ & 94 & $\begin{array}{l}\text { Forebrain-specific conditional (dox-regulated) model; reversal of NIIs } \\
\text { and HD-like phenotype upon HTT expression turn off }\end{array}$ & [35] \\
\hline $\begin{array}{l}\text { Prp-tTA-6/iFL148Q- } \\
\quad 69\end{array}$ & $\operatorname{PrP}$ & 148 & $\begin{array}{l}\text { Conditional model; full-length HTT; phenotype similar to other } \\
\text { N-terminal models, but slower disease progression rate; decreased } \\
\text { lifespan }\end{array}$ & [37] \\
\hline RosaHD/Dlx5/6-Cre & Rosa26/Dlx5/6 & 103 & $\begin{array}{l}\text { Restriction of HTT expression to MSNs; changes in NMDA receptor- } \\
\text { mediated currents; no other neurological phenotypes }\end{array}$ & [233] \\
\hline RosaHD/Emx1-Cre & Rosa26/Emx1 & 103 & $\begin{array}{l}\text { Restriction of HTT expression to cortical pyramidal neurons; no } \\
\text { neurological phenotype; polyQ nuclear accumulation }\end{array}$ & {$[36]$} \\
\hline RosaHD/Nestin-Cre & Rosa26/Nestin & 103 & $\begin{array}{l}\text { Restriction of HTT expression to neurons; evident neuropathology; } \\
\text { locomotor activity decrease }\end{array}$ & {$[36]$} \\
\hline
\end{tabular}

${ }^{a}$ Mixed CAA/CAG repeats

The variants of the B05 model enhanced our knowledge of the mechanisms of SCA1 by elucidating the role of ataxin-1 phosphorylation at $\mathrm{S} 776[138,139]$ and the role of the ataxin-1 NLS signal in the disease pathogenesis [140, 141]. The use of the conditional B05 variants also confirmed that the SCA1-like phenotype can be reversed upon doxycycline treatment [142-144].

\section{SCA1 Knock-in Model}

Knock-in models of SCA1 were created by the targeted insertion of chimeric mouse/human exon 8 with 78 and 154 CAG repeats into one allele of the Atxn1 locus [145-147]. Mice containing 78Q in ataxin-1 develop neither ataxic behavior nor a neuropathological phenotype [145]. In contrast, mice containing $154 \mathrm{Q}\left(\mathrm{Scal}^{154 \mathrm{Q} / 2 \mathrm{Q}}\right)$ develop ataxia that resembles SCA1 in human patients. Other phenotypes of $S c a 1^{154 \mathrm{Q} / 2 \mathrm{Q}}$ mice include growth retardation, muscle atrophy, kyphosis, and clasping. In addition, the cognitive deficits in $S c a 1^{154 Q / 2 Q}$ occur before the onset of ataxia and are likely associated with hippocampal dysfunction [146, 148]. The progressive respiratory dysfunction, which is also observed in human patients, is probably the direct cause of premature death in these mice [149].

The NIIs are formed more frequently throughout the brains of $S c a 1^{154 \mathrm{Q} / 2 \mathrm{Q}}$ mice than in SCA1 patients, probably because of the much longer polyQ tract in the mouse transgene. Interestingly, neurons that are less affected or unaffected exhibit more NIIs and gain NIIs at a faster rate [146]. The mice show pronounced brain atrophy, as well as the loss and degeneration of PCs [150]. However, in contrast to the B05 model, no vacuoles or heterotopic PCs can be detected [146]. Figure 3 contains a map of the neuropathology of $S c a 1^{154 \mathrm{Q} / 2 \mathrm{Q}}$ model.

\section{SCA2 Mouse Models}

Cell-specific transgenic models of SCA2 were created using the Pcp2 (L7) promoter-driven full-length ATXN2 cDNA 
Fig. 3 Diagrams of neuropathology of the brain, spinal cord, and retina in polyQ models that use native promoters. As in Fig. 2, the selected phenotypes and brain regions were marked with colors on a schematic sagittal section of the mouse brain. The polyQ models selected for this figure were the SCA1 154Q, SCA3 MJD84.2, SBMA AR100, DRPLA Q129, and SCA7 266Q models that were created using the mouse or human versions of native promoters. The exception to this scheme is the SCA17 nestin-TBP model, in which the native TBP promoter drives expression only in neurons. The SCA3 MJD84.2 and DRPLA Q129 models with native promoters demonstrate the involvement of various and partially overlapping brain regions. The neuropathology is localized in the cerebral cortex $(C T X)$, pons $(P)$, midbrain $(M B)$, and cerebellum $(C B)$ for MJD84.2 animals and in the cerebral cortex $(C T X)$, pallidum $(P A L)$, hippocampus $(H P)$, medulla oblongata $(M Y)$, corpus callosum $(C C)$, and cerebellum $(C B)$ for the DRPLA Q129 model. These neuropathology patterns also resemble the patterns that are present in human patients. Abnormal myelination in MJD84.2 animals is observed in the dorsal root ganglia $(D R G)$ and sciatic nerve, both of which belong to the peripheral nervous system (PNS)
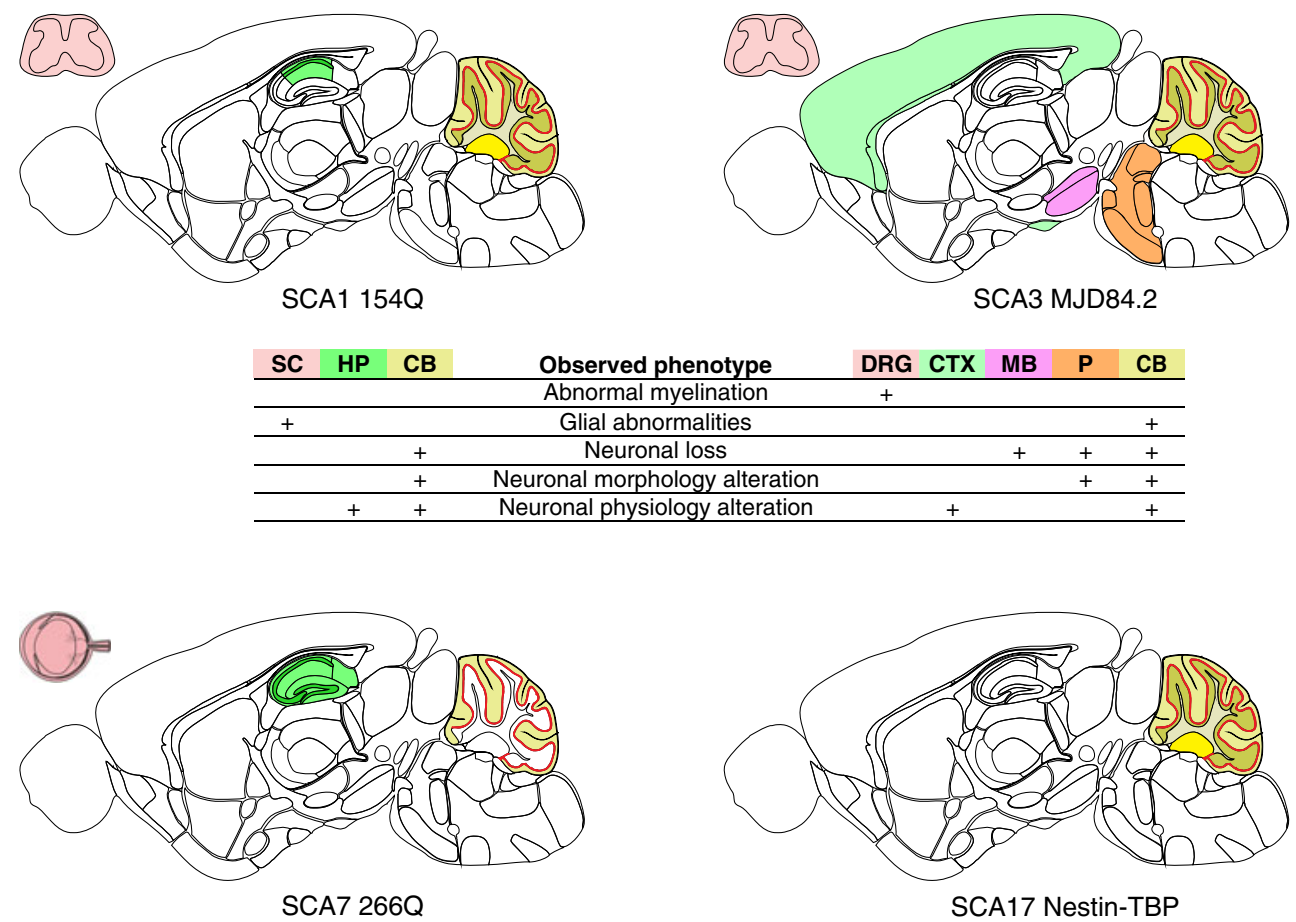

\begin{tabular}{ccccc} 
RETINA & HP & CB & Observed phenotype & CB \\
\hline+ & & + & Glial abnormalities & + \\
\hline+ & & & Neuronal loss & + \\
\hline+ & & + & Neuronal morphology alteration & + \\
\hline & + & & Neuronal physiology alteration & \\
\hline+ & & & Retinopathy & \\
\hline
\end{tabular}
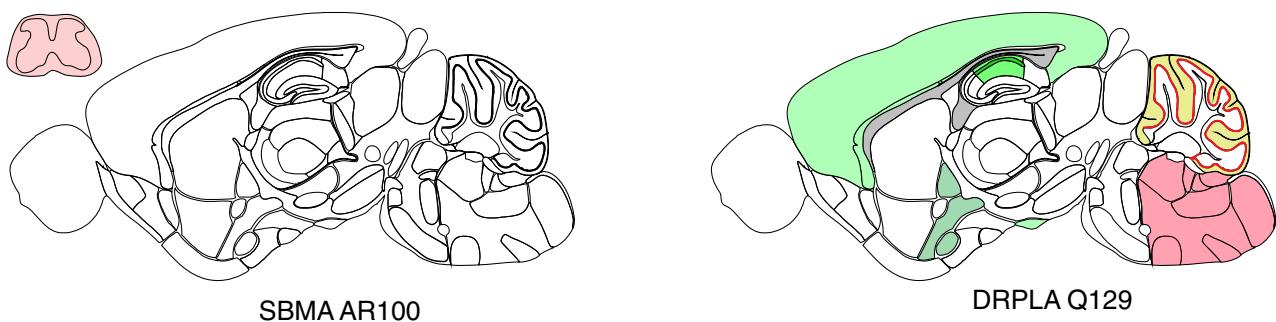

\begin{tabular}{ccccccccc} 
SC & Observed phenotype & CTX & CC & PAL & HP & CB & MY \\
\hline+ & Neuronal morphology alteration & + & + & & & & + & + \\
\hline+ & Neuronal physiology alteration & & & & + & + & + & \\
\hline
\end{tabular} that contained $58(58 \mathrm{Q}-5 \mathrm{~B})$ or $22(22 \mathrm{Q}) \mathrm{CAG}$ repeats. The 58Q-5B mice show mild and slowly progressing neurobehavioral dysfunctions and neuropathology including deficits in walking and coordination as well as the presence of clasping behavior [151]. The neuropathology involves the atrophy and loss (50\%) of PCs [152]. The mice show ubiquitin-negative microaggregates in the cytoplasm, but NIIs are not observed [151].

Another SCA2 model (75Q-SCA2) was created using the full-length human ataxin-2 cDNA driven by the human ATXN2 promoter and containing $75 \mathrm{CAG}$ repeats. The expression of this transgene is ubiquitous and is detected in the brain, liver, and skeletal muscle. The phenotype appears to be slightly accelerated compared to that of the $58 \mathrm{Q}-5 \mathrm{~B}$ mice [153].

\section{SCA3 Mouse Models}

\section{SCA3 Pcp2/L7 Promoter-Based Models}

The first attempt to create $\mathrm{SCA} 3$ transgenic mice revealed that using the Pcp 2 (L7) promoter and full-length ATXN3 79 CAG cDNA does not result in a disease phenotype in the PCs. Surprisingly, the presence of the C-terminal part of mutant ataxin-3 containing $79 \mathrm{Q}$ in the $\mathrm{PCs}$ was able to evoke a severe ataxic phenotype and cerebellar degeneration. This difference 
in phenotypes between the full-length and truncated ataxin-3 lines is probably due to a lack of ataxin-3 polyQ cleavage in the PCs [154].

A similar model was created by Torashima et al. [155] in which a C-terminal ataxin-3 fragment (exons 10-11 of ATXN3 mRNA) containing 69 CAGs driven by the $P c p 2$ (L7) promoter is expressed. The mice exhibit a neurobehavioral phenotype consisting of ataxia and cerebellar atrophy with heterotopic positioning of the PCs in the molecular layer and a shrunken dendritic tree.

\section{SCA3 PrP Promoter-Based Models}

The prion protein $(\mathrm{PrP})$ promoter is employed in SCA3 models that express the full-length ATXN3 cDNA but contain various numbers of CAG repeats. The first PrP/SCA3 hemizygous mouse with ataxin-3 containing 71 glutamines (the Q71-B and Q71-C mouse lines) exhibited no phenotype. A phenotype that is reminiscent of SCA3 appears in homozygous transgenic animals, but homozygosity renders the animals infertile [156, 157]. The homozygous mice show posture abnormalities, muscle wasting, seizures, and progressive, ataxia-like motor dysfunction [156]. The Q71$\mathrm{C}$ homozygotes mice show no neuronal loss in the dentate nuclei but have a loss of tyrosine hydroxylase positive neurons only in the substantia nigra [156]. Notably, the MJD patients show severe neuronal loss in various brain regions, and this feature is better reproduced in the MJD84.2 YAC model (see below and in the data table). The apparent reason for the discrepancy between the phenotypes of the hemizygous and homozygous mice is the difference in the concentrations of the toxic mutant ataxin-3 cleavage fragment in the brain [156]. In an attempt to prevent the cleavage of toxic polyQ from ataxin-3, the authors created the Q71 transgene, which lacks residues 190-220. Unfortunately, these deltaQ71 mice have both the cleavage fragment and exhibit an accelerated disease progression with an earlier premature death compared to the Q71 mice [158].

Another group created animals similar to Q71 with 15, 70 (70.61 mouse line), and 148 polyQ tracts in ataxin-3, but with a shorter version $(1.1 \mathrm{~kb})$ of the murine PrP promoter. The 70.61 line develops a mild to severe phenotype with ataxia and premature death [159]. Interestingly, later studies of the 70.61 line report a much milder phenotype and no reduction in the lifespan of the animals [160]. In the 148Q lines, the disease progression leads to decreased fertility and the death of all animals by 3 months of age. In both the 70.61 and 148Q lines, ubiquitin-positive inclusions are seen in many brain regions.

The subcellular localization of mutant ataxin-3 is an important aspect in the disease pathogenesis. Mice that express the nuclear export signal (NES)-tagged $148 \mathrm{Q}$ protein have normal lifespans with either nonexistent or very mild phenotypes. In contrast, the nuclear localization signal (NLS)-tagged 148Q mice exhibit a more severe phenotype than the 148Q mice [159]. Interestingly, the NES construct was unable to prevent the neurological phenotype in a double transgenic crossbreed of 70.61/NES.148 mice, which exhibit an aggravated ataxic phenotype [161].

Mutant ataxin-3 with 79 CAG repeats driven by the PrP promoter also results in a late phenotype in mice. The transgene is expressed in the brain areas that are involved in SCA3 pathology but not in PCs $[162,163]$.

\section{The MJD-84.2 YAC Model}

The mouse model that most closely mimics SCA3 was created using a 250-kb YAC construct that contains $50 \mathrm{~kb}$ of the human ATXN3 gene flanked by $30-$ and $170-\mathrm{kb}$ genomic sequences [164]. This indicates that MJD-84.2 YAC may in fact be transgenic for other human genes, and the possible candidates are TRIP11 and NDUFB1. The animals that were generated include lines with $15,67,72$, and $84 \mathrm{Q}$ that vary in the age of onset and the severity of disease but generally present mild phenotypes. The neurobehavioral dysfunctions that are observed in the lines include an abnormal gait (mild to severe), mild tremor, hypoactivity, and limb clasping [164]. The pattern of neuropathology primarily includes NIIs formation, neuronal loss and gliosis of the dentate nucleus, pontine nuclei, and substantia nigra, along with visible myelination defects in peripheral nervous system $[164,165]$. The cerebellar cortex, which is less affected in SCA3 patients than in SCA1 patients, is atrophic with Purkinje cell loss, dysfunction, and degeneration $[164,166]$. Figure 3 contains a map of the neuropathology of MJD84.2 mice.

\section{Other SCA3 Models}

In contrast to $\mathrm{PrP} /$ ataxin-3 with 148Q [164], the mice that express ataxin-3 with a $148 \mathrm{Q}$ tract driven by the huntingtin promoter show only mild behavioral and motor changes [167]. A mild phenotype without an altered lifespan has been observed in mice expressing 94Q or $83 \mathrm{Q}$ in ataxin-3 driven by the cytomegalovirus (CMV) promoter [168]. Our group has attempted to generate a SCA3 knock-in model, but a functionally inactive allele was generated in the mice instead, resulting in a functional ataxin-3 knock-out [169].

\section{SCA6 Mouse Models}

Creating a SCA6 knock-in mouse model may be challenging because the mouse homolog of the human calcium channel gene $C A C N A 1$ lacks a CAG tract. The first attempt to generate a knock-in model of SCA6 (Q13/Q28) produced mice that were viable and healthy [16]. Thus, the range of 
expansions that causes SCA6 in human patients is probably insufficient for mice. Next, Watase et al. [17] created a model using targeted insertions of $84 \mathrm{Q}$ together with their flanking sequence into exon 47 of the mouse Cacnal gene. The heterozygous $\mathrm{Sca}^{84 \mathrm{Q} /+}$ and homozygous $\mathrm{Sca} 6^{84 \mathrm{Q} / 84 \mathrm{Q}}$ are only mildly affected, with no detected neuropathology except for the presence of cytoplasmic inclusions in the PCs of 22-month-old $\mathrm{Sca}^{84 \mathrm{Q} / 84 \mathrm{Q}}$ mice and decreased $\mathrm{Ca}_{\mathrm{v}} 2.1$ protein expression that is accompanied by a reduced calcium current. The presence of the reduction in the $\mathrm{Ca}^{2+}$ current is not dependent on the number of CAG repeats in Cacnal because a reduced $\mathrm{Ca}^{2+}$ current is also evident in homozygous animals containing 14Q and 34Q [17].

\section{SCA7 Mouse Models}

SCA7 is a very rare disease, but its modeling in mice generates systemic and complex phenotypes that reveal information significant for the entire polyQ research field. Moreover, the SCA7 mice provide an important model for polyQ nonautonomous pathogenesis of neurons, revealing the role of astrocytes and glutamate toxicity.

\section{Cell-specific SCA7 Models with Pcp2/L7, Rhodopsin, and GFAP Promoters}

The first SCA7 mice were cell-specific models that expressed an expanded ataxin-7 protein that contained a 90Q expansion either in the PCs using the $P c p 2$ promoter (strain P7E) or exclusively in the retina using the rhodopsin promoter (strain R7E) [170]. P7E.B mice contain 10-50 copies of the transgene and show only some defects in motor performance and learning. In this model, human ataxin-7 translocates to the nucleus of the PCs [171] and eventually forms large perinucleolar aggregates. The neuropathology involves the degeneration of PCs and deep cerebellar nuclei [170]. R7E transgenic mice develop a phenotype earlier than P7E mice, with a pathology that includes NII formation, retinal photoreceptor dysfunction, and neurodegeneration [170, 172-174]. One possible reason for the retinopathy in these mice is the toxicity of the expanded polyQ tracts that deregulate rod differentiation genes [175].

The GFAP (Gfa2) promoter [176] restricts the expression of a transgene to astrocytes within the brain, including the cerebellar subpopulation of astrocytes called Bergmann glia. A Gfa2-SCA7-90Q mouse model expressing ataxin-7 with a 90Q exhibits an ataxic phenotype and PC degeneration [177]. The mice develop an abnormal gait and poor coordination but do not die prematurely. Neuropathological analysis revealed dark cell degeneration of PCs and the formation of NII and abnormal radial processes in the
Bergmann glia. Dark cell degeneration is indicative of glutamatergic excitotoxicity, which corresponds to the $20-25 \%$ decrease in glutamate uptake that is observed in cerebellar slices from Gfa2-SCA7-90Q mice. This decrease in glutamate uptake likely results from the dysfunction of the Bergmann glia, which express the GLT-1 and GLAST glutamate transporters. The authors postulated that the non-cellautonomous, excitotoxicity-mediated pathology of PCs leads to the development of ataxia in SCA7 [177]. Thus, a potential therapeutic strategy for SCA7 (and also for HD) is to increase the expression of glutamate transporters in the brain. We have identified PACAP, TGF- $\alpha$, and EGF as potent positive regulators of both GLAST and GLT-1 glutamate transporters $[178,179]$.

\section{SCA7 PrP Promoter-Based Models}

The PrP-SCA7-c92Q is the PrP polyQ model, expressing human ATXN7 cDNA with 92 CAG repeats [180]. The animals show smaller body size, clasping, and premature death, and these features are characteristic for other PrP polyQ models. These mice are well-characterized and present an interesting systemic phenotype that includes ataxia, retinopathy, motility dysfunctions, non-cell-autonomous neurodegeneration of PCs and Bergmann glia pathology [181-183].

\section{SCA7 Knock-in Model}

Knock-in SCA7 266Q/5Q mice were created by inserting the human exon 3 of ATXN7 containing 266 CAG repeats [184], which is in the repeat number range that is present in patients with juvenile-onset SCA7. Similar to pediatric patients, the mice develop a rapidly progressive complex phenotype that includes ataxia, myoclonic seizures, strong retinopathy leading to blindness and additionally posture abnormalities and, later, infertility. In the end stage of the disease, the mice are hypoactive and die at 19-20 weeks of age (7-8 weeks as homozygous) [184]. Interestingly, despite the ubiquitous expression of ataxin-7 266Q, the only abnormal neuronal morphology in the cerebellum is a decrease in the sizes of the PCs, whereas the dendritic trees and number of cells appear to be normal $[184,185]$. More severe abnormalities are observed in the Bergmann glia, which also express the mutant ataxin-7 [177] (for a map of neuropathology, see Fig. 3). Aggregates are present in the glial cells and later in the PCs and hippocampal CA1 pyramidal neurons. In the retina, the inclusions appear first in the cones and interneurons of the outer and inner nuclear layers, respectively, and later in the rods and ganglion cells [173, 184].

The SCA7 models that utilize the platelet-derived growth factor (PDGF) promoter $[171,186]$ and the BAC models [187] are listed in the data table. 


\section{SCA17 Mouse Models}

The first SCA17 mouse model expresses the full-length human TATA-box binding protein (hTBP) with either 71 or $105 \mathrm{CAG} / \mathrm{CAA}$ repeats in the mRNA under the control of the PrP promoter [188]. The phenotype is observed early and featured by low weight, ataxia, and a reduced lifespan. The mice are hypoactive and develop seizures, tremors and kyphosis. The hTBP transgene is expressed widely in neurons throughout the brain [188]; however, the PrP promoter is not permissive for expression in PCs but can be expressed in astrocytes [189]. Therefore, the transgene expression that was detected in the Purkinje layer is most likely located in the Bergmann glia. The PCs exhibited axon degeneration, demyelination, vacuolization, and a dark-cell degeneration phenotype that was also present in neurons in the granule layer. Large NIIs are visible in the granule neurons and contain the N-terminal part of hTBP with a polyQ expansion [190].

The SCA17 mouse model named L7-hTBP was generated using the shorter fragment of the $P c p 2$ (L7) promoter with a full-length $T B P$ cDNA containing 109 mixed CAA/ CAG repeats [191]. The L7-hTBP mice express the transgene in the PCs of the cerebellum, but unlike with the regular Pcp2 promoter, the expression is present in other brain regions including the brainstem, cerebral cortex, and hippocampus. Interestingly, the neuronal cell losses occur not only in the same brain regions but also in the striatum, pallidum, and hypothalamus. The animals do not exhibit reduced lifespans, but they show clear and early evidence of ataxia [191].

The first SCA17 knock-in model contains a chimeric mouse TBP exon 2 with 105 CAG repeats. However, the chimeric allele is inactive because of the floxed stop codon [192]. This kind of construct allows for endogenous (mouse promoter) and cell-specific expression of the mutant TBP that was demonstrated by neuronal expression using the Nestin-Cre mice [192]. The phenotype in the nestin-TBP knock-in mice is very mild, and the most distinctive phenotype, observed regardless of the ages of the mice, is a loss of nest-building behavior like that previously observed in an autistic mouse model [193]. Figure 3 contains a map of the neuropathology of the Nestin-Cre mice.

\section{DRPLA Mouse Models}

The first mouse model of DRPLA (AT-FL-65Q) [194] is a PrP promoter-driven transgenic mouse line that expresses ATN1 cDNA with either 24Q or 65Q. The AT-FL-65Q model develops a phenotype that consists of ataxia, tremors, aggression, and decreased breeding efficiency. The model has contributed important knowledge about the processing of mutant atrophin-1 protein in patients and mice. The transgenic atrophin-1 proteins with $65 \mathrm{Q}$ or $26 \mathrm{Q}$ undergo proteolytic cleavage, and the resulting $120-\mathrm{kDa}$ fragments containing the mutant polyQ tracts accumulate in the nucleus, whereas the endogenous and 26Q atrophin-1 proteins are mostly cytosolic [194].

A similar but slightly more severe phenotype than that of the PrP mouse was observed for a pan-neuronal model of DRPLA using ATN1 cDNA with 118 CAG repeats driven by a rat neuron-specific enolase (NSE) promoter [195].

DRPLA models with the entire ATN1 gene and 76-78 CAG repeats were generated using the SuperCos 1 cosmid vector, but the expression of this transgene produces no obvious disease phenotype in these mice [196]. Later, intensive breeding of these mice [196] resulted in the creation of extremely expanded mosaic mice that have been bred to Q129 mice [197, 198]. Further related substrains with 113 and 96 CAG repeats were generated from Q129 strain [199].

The Q129 mouse phenotype is severe and highly complex; it features many aspects of the disease physiology and is similar to juvenile-onset DRPLA. In brief, the animals develop ataxia, myoclonic movements, and tactile-induced and spontaneous epilepsy [198]. These animals have severe brain atrophy manifesting as degeneration of dendrites and dendritic spines, presence of widespread NIIs and physiological changes in neurons, as recorded by electrophysiology [196]; however, a loss of neurons has not been observed [197] (for a map of neuropathology, see Fig. 3). Additional abnormalities in $129 \mathrm{Q}$ mice include polyuria and diabetes [198].

\section{SBMA Mouse Models}

The initial attempts at generating an SBMA model produced mice with no phenotype $[200,201]$ or mice that lacked many of the features of the SBMA disease [202]. Neither the neurofilament light chain (NFL) promoterdriven model (NFL112) nor the PrP promoter-driven model (PrP112), which has a truncated form of the androgen receptor (AR), is able to reproduce the full SBMA disease phenotype.

\section{SBMA Models Generated with AR Promoters}

The AR-239Q mouse was the first mouse model that recapitulated many SBMA features [203]. These mice demonstrate that the $239 \mathrm{CAG}$ repeats and the resulting protein composed exclusively of glutamines under the control of the human AR promoter are sufficient to evoke SBMA-like hind limb weakness and incoordination. The expression of the transgene and NIIs formation is evident in the brain, spinal cord, pituitary, lung, eye, and skin, all of which exhibit endogenous AR expression in mice [203]. 
The transgenic mouse lines have smaller brains, but there is no evidence of neuronal loss [203], which indicates that neuronal dysfunction is responsible for the pathogenesis observed in this mouse model.

A YAC construct containing a 450-kb genomic fragment that included the 100-kb human AR gene [201] with 100 CAG repeats was used to generate the SBMA AR100 model [204]. The model was able to reproduce the fact that the development of SBMA is sex-dependent. The AR100 males exhibit impaired mobility, hind limb atrophy, and occasional hind limb paralysis, while the female mice are only mildly affected. Anatomically, the muscle atrophy is likely caused by muscle denervation resulting from a very low number of motor neurons present in the lumbar spinal cord of the YAC animals [204, 205]. Males (but not females) have decreased expression of the VEGF164 protein isoform that is important for motor neuron survival [206]. Interestingly, the loss of endogenous $\mathrm{AR}$ expression aggravated the phenotype in the AR100 mice [207].

An SMBA knock-in mouse model was generated by replacing the 1,340-bp coding sequence of mouse AR exon 1 with a human exon 1 sequence containing 113 CAGs [208]. The AR113Q males are infertile and exhibit testicular atrophy, decreased body weight, and weak forelimbs [208, 209]. The muscle weakness and occurrence of early death in AR113Q are androgen-dependent, as confirmed by castration and testosterone supplementation experiments [209]. Moreover, the mice exhibit myopathic changes that are similar to those observed in SBMA patients. The myopathy is associated with the loss of chloride channel (CLCN1) protein expression in muscles, which can be rescued by castration [209]. Moreover, Ranganathan et al. [210] provided evidence for mitochondrial dysfunction in the AR113Q knock-in mouse model.

\section{SBMA Models Generated with Nonendogenous Promoters}

Multiple SBMA models were created using the full-length $A R$ cDNA driven by a CMV (AR120 mouse) [211], $\beta$-actin (AR 97Q mouse) [212], and PrP promoter (112Q mouse) [213]. These models reproduce many features of SBMA, including the muscle weakness and atrophy, myelination defects and loss of motor neurons, and testicular pathology. As in previous SBMA models, testosterone deprivation by castration in the AR97Q model significantly improves the SBMA phenotype, demonstrating a direct correlation between the disease phenotype and androgen levels. Conversely, testosterone-treated female mice exhibit a phenotype that is similar to that of non-castrated male mice [212]. In addition, in the $112 \mathrm{Q}$ model, the males predominantly develop an overt phenotype and lose fertility, yet premature death is not present in this model. The mice lacked evidence of muscular atrophy or neuronal loss in the spinal cord while having the general polyQ phenotype [213-216].

\section{Muscle-Specific SBMA Model}

A mouse model, which supports a different, muscle-centric view of SBMA pathogenesis, overexpresses AR and contains 22 CAGs exclusively in skeletal muscle fibers under the control of the human skeletal $\alpha$-actin promoter [217]. Endogenous mouse AR expression is blocked using the testicular feminization mouse ( $\mathrm{Tfm}$ ) genetic background. The resulting mouse strain - with exclusive and extremely high overexpression of AR in the muscles - has a phenotype that is similar to mouse models with much longer CAG repeats; these mice exhibit motor neuron pathology and deficits in muscle strength and motor function that are present in the males but not in the females. This high expression of the transgene in muscle may compensate for the lack of longer CAG repeats and therefore may evoke the disease phenotypes. The loss of motor function is androgendependent because female mice that are treated with testosterone develop the disease, while motor function returns in males after castration [218]. The marked loss of muscle strength and rapid loss of body weight (30\% over 9 days) in testosterone-treated females were quickly reversed when testosterone administration was stopped [218].

\section{The Data Table}

\section{Comparison and Validation of Mouse Models}

The approach of comparison and extrapolation of animal models to human diseases was historically proposed by Paul Willner [219]. He reasoned that the validation of animal models should be conducted according to general validation criteria that are already used in scientific research, namely, construct validity, face validity, and predictive validity [220]. These criteria were originally used for validating psychometric tests or psychiatric diagnoses and were proposed before identification of causative genes in polyQ disorders and also before the creation of the first polyQ mouse models.

\section{Construct Validity}

Construct validity should be assessed to determine whether a mouse model reproduces the molecular mechanisms that are responsible for the development of the human disease. The creation of polyQ mouse models with high construct validity is much easier than modeling complex pathology such as mood disorders, where mouse models have low construct validity [221]. On average, the construct validity 
of polyQ models is relatively high because these diseases have a well-defined etiology related to a specific type of mutation-expansion in known single genes. Although the creation of models of diseases related to single genes is relatively easy, several possible approaches exist. Two examples of such approaches are (1) creating a mouse model that contains a CAG expansion mutation in a mouse gene, such as HD knock-in models (references in "Knock-in HD models"), or (2) transferring the entire human mutant gene into the mouse genome, such as in the YAC128 or BACHD $[27,30]$ models. In the first approach, the mutation is deprived of its original context of the human gene, which may be very important for correct reproduction of the disease. In the second approach, two copies of the endogenous mouse gene are still present in the final mouse model. The additional presence of endogenous mouse genes may ameliorate the disease phenotype, as demonstrated in the YAC128 on the Htt knock-out background [222]. The wild-type huntingtin can also protect neurons from excitotoxicity [223]. The above examples illustrate that it may be difficult to evaluate which of these models has a higher degree of construct validity. The examples of models with relatively low construct validity are R6/2 and N171-82Q mice, which express only fragments of causative proteins and exhibit more features of general polyQ toxicity instead of matching the specific mechanisms of HD in patients.

A theoretical model for the creation of a polyQ mouse with very high construct validity should reflect the genetic features of human patients where one allele contains the copy of the gene with a pathogenic number of CAG repeats and a second allele that contains the same gene with a normal number of repeats. Preferably, it should be a targeted design with a complete human sequence driven by a native promoter that contains all of the appropriate regulatory elements. Unfortunately, it is quite likely that such a model would have a very mild disease phenotype also due to the presence of a CAG repeat number that is within the normal human range. Table 2 summarizes the factors that should be considered when evaluating construct validity. More discussion of construct validity parameters is found in "The promoter, the transgenic sequence, and the number of CAG/Q repeats" and "Mouse genetic background."

\section{Face Validity}

The face validity of an animal model reflects the phenotypic similarity between a mouse model and the associated human condition. It is obvious that a large number of mouse models of polyQ disorders exhibit neurological phenotypes and motor impairments that resemble those of patients suffering from polyQ diseases. However, many of the phenotypes seen in a particular mouse model are not equivalent to any symptom that occurs in human patients. For instance the R6/
Table 2 Construct validity in polyQ models

\begin{tabular}{|c|c|c|}
\hline $\begin{array}{l}\text { Animal model } \\
\text { properties }\end{array}$ & $\begin{array}{l}\text { Higher construct } \\
\text { validity (arbitrary) }\end{array}$ & $\begin{array}{l}\text { Lower construct } \\
\text { validity (arbitrary) }\end{array}$ \\
\hline Mutation & Pure CAG tract & Mixed CAA/CAG tract \\
\hline $\begin{array}{l}\text { Adult length } \\
\text { of polyQ }\end{array}$ & As in human & Longer than in human \\
\hline $\begin{array}{l}\text { Juvenile length } \\
\text { of polyQ }\end{array}$ & As in human & Longer than in human \\
\hline Gene context & Human gene & Nonhuman gene \\
\hline $\begin{array}{l}\text { Translated sequence } \\
\text { (exons) }\end{array}$ & Full gene models & Fragment models \\
\hline $\begin{array}{l}5^{\prime} \mathrm{UTR}, 3^{\prime} \mathrm{UTR}, \\
\text { introns }\end{array}$ & Full gene models & $\begin{array}{l}\text { Fragment and cDNA } \\
\text { models; }\end{array}$ \\
\hline Promoter & PolyQ promoter & Non-polyQ promoter \\
\hline $\begin{array}{l}\text { polyQ mRNA } \\
\text { and protein }\end{array}$ & $\begin{array}{l}\text { Level equal to level } \\
\text { of non-mutant gene } \\
\text { of a host }\end{array}$ & $\begin{array}{l}\text { Much higher or much } \\
\text { lower expression level }\end{array}$ \\
\hline $\begin{array}{l}\text { Number of transgene } \\
\text { copies }\end{array}$ & 1 & 2 or more \\
\hline $\begin{array}{l}\text { Single allele or } \\
\text { biallelic }\end{array}$ & $\begin{array}{l}\text { Two alleles with } \\
\text { various CAG tract } \\
\text { (like in patients) }\end{array}$ & Single allele \\
\hline $\begin{array}{l}\text { Model generation } \\
\text { process }\end{array}$ & Targeted & Random \\
\hline Host species & $\begin{array}{l}\text { Primates }>\text { swine }> \\
\text { mouse } \approx \text { rat }\end{array}$ & $\begin{array}{l}\text { Fruit fly }>\text { C. elegans }> \\
\text { yeast }\end{array}$ \\
\hline
\end{tabular}

2 and N171-82Q models present many phenotypes that are not present in patients, such as an extremely short lifespan or widespread nonspecific neuropathology that includes defects in the cerebellum and other brain regions. In contrast, the R6/2 model also reveals HD-specific pathology in the striatum, cortex, and other tissues. Therefore, it is extremely difficult and probably unnecessary to assess the absolute face validity of a given mouse model, but it is important to identify the validity of certain aspects of a mouse phenotype that would be necessary for conducting particular research tasks. By collecting information about the phenotypes of polyQ mouse models, our data table provides a tool for assessing their face validity. Further discussion of face validity parameters can be found in "Phenotypes, disease onset, progression, and localization of neuropathology in the CNS and other tissues."

\section{Predictive Validity}

The important reason for producing mouse models of human disorders is the evaluation of potential drug candidates. The predictive validity of a mouse model can in principle be defined as its ability to predict the molecular and symptomatic drug responses in a patient. Identifying the predictive validity of a mouse model requires data from testing various drugs in the mouse model and data about the clinical trials of treatments using the same substances in human patients. Our 
second data table and review (Part II) may be very useful for examining the predictive validity of polyQ models because we have collected most of the available data about therapeutic approaches in polyQ mouse models. Unfortunately, clinical trials for most of the drugs collected in the Part II data table have not been conducted so far, and the drugs that have been evaluated, such as CoQ10, ethyl-eicosapentaenoate (ethyl-EPA), tetrabenazine, memantine, phenylbutyrate, dimebolin hydrochloride, and minocycline, either were unsuccessful or produced limited therapeutic benefits [224, 225]. Moreover, all of these substances had been preclinically tested on R6/2 model animals and had shown improvement in the disease phenotype (see the Part II data table). For the reasons described above, the predictive validities of polyQ mouse models are still unknown. Regardless of their low construct validity, low face validity, and unknown predictive validity, the R6/2 and N171-82Q models are the most extensively used models in research on both the HD pathogenesis and therapy.

The Promoter, the Transgenic Sequence, and the Number of CAG/Q Repeats

The promoter, the transgenic sequence, and the number of $\mathrm{CAG} / \mathrm{Q}$ repeats (which are also listed in the data table) influence the effectiveness of reproducing the polyQ disease phenotype in mice. They also provide information about the properties of the transgene cassette and on the resulting expression pattern in mice. This expression pattern is shaped by the transgene promoter, which can drive expression in all cells (pan-cellular promoters), all neuronal cells (pan-neuronal promoters), or specific cell types, such as PCs. To model the disease as accurately as possible, researchers also use native human and mouse promoters for generating knock-in and YAC models. Our data table lists three principal promoters that have been used to create the polyQ models: the PrP promoter, which was used in 21 mouse models; the huntingtin (mouse and human) promoter, used in 19 models; and the Pcp 2 promoter, used for generating 12 models. Together, these promoters were used to generate over half of all polyQ models (Supp. Fig. 3).

\section{The Impact of Promoters and Transgene Sequence in poly $Q$ Mouse Models}

In addition to the PrP promoter, the pan-neuronal and pancellular group of promoters includes the NSE, NFL, CMV, and PDGF-B promoters. The PrP promoter has been widely used to create polyQ models of HD, DRPLA, SCA1, SCA3, SCA7, SCA17, and SBMA. The natural prion protein is expressed in mice ubiquitously throughout the brain; however, its expression in the striatum (caudate and putamen) is quite weak (see, for example, the Allen mouse brain atlas). Moreover, the engineered version of this promoter does not drive expression in PCs, and its expression in the striatum appears to be weak [226, 227]. The expression profile of this promoter has been examined in the mouse brain using PrPLacZ expression. The authors did not detect this promoter activity in MSNs in the striatum and only found expression in interneurons [228]. We can corroborate this finding, as in our hands, the transgenic protein levels and NIIs in the striatum of the PrP-driven N171-82Q model are barely detectable, whereas these inclusions are frequent in the cerebral cortex and hippocampus [169]. The causative proteins huntingtin, ataxins 1, 2, 6, and 7, and atrophin-1 are all naturally expressed in the striatum and PCs.

Moreover, although the PrP-based models express different proteins with polyQ tracts, the resulting mice present a very similar set of phenotypes in which the severity of the phenotype and shortened lifespan are characteristic hallmarks. For example, the PrP promoter has also been used to create the SBMA model (PrP112) [202], which exhibits a very strong phenotype that resembles the phenotype observed in N171-82Q mice but has an even shorter lifespan. The PrP112 model reveals more severe general impairment and lacks slowly progressing SBMA phenotypes, such as weak hind limbs and weak gait. In general, many PrP-based models with long pathogenic CAG tracts have a dramatically decreased lifespan and severe impairments. It is likely that the cellular effects of the polyQ tracts and similar expression patterns of the transgenes in various PrP mice strongly contribute to the disease phenotype, whereas differences in protein context have a weaker influence on the disease. A somewhat stronger manifestation of protein context is present in some PrP models, such as models of SCA3 and SCA7. Ataxin-3 is expressed ubiquitously in the mouse brain, including the cell soma of PCs. Interestingly, although the PrP promoter is not expressed in PCs, the transgenic models that express full-length human mutant ataxin-3 under the PrP promoter exhibit a loss of the dendritic tree in the Purkinje cell layer. However, in transgenic animals, $\operatorname{PrP} /$ expanded ataxin-3 is expressed in similar brain regions to AR in the SBMA PrP112 model and the huntingtin fragment in the N171-82Q model, yet the pathogenic effects are clearly distinct, indicating an influence of ataxin-3 protein context. The influence of AR protein context can be observed in the SBMA 112Q model, which is the full-length AR PrP-driven model [213]. The influence of protein context is also evident in the PrP/SCA7 model with 92Q, in which the mice develop a loss of vision that is similar to that of human patients. However, this is accompanied by a very severe phenotype and premature death, which are much like the PrP112/SBMA and N171 models. We conclude that the PrP promoter has the potential to reproduce some of the protein-specific symptoms of human polyQ diseases. Unfortunately, it also promotes many severe and nonspecific phenotypes that may be attributed to general polyQ effects; 
therefore, it is uncertain which kind of disease the resulting mice really mimic.

The cell-specific group of polyQ transgenic constructs uses the Pcp2 (L7) promoter for PCs, the dopamine- and cAMP-regulated neuronal phosphoprotein (DARPP32) promoter for MSNs in the striatum, the GFAP (Gfa2) promoter for various populations of astrocytes, including Bergmann glia, the nestin and Emx1 neuronal promoters for Creinduced animals, and the human skeletal $\alpha$-actin promoter to drive expression in muscle cells. Using the cell-specific promoters to generate animal models has revealed interesting information regarding the cellular pathogenesis of polyQ diseases.

Both ataxin-1 and ataxin-2 are prominently expressed in PCs, and therefore, the Pcp 2 promoter is a good first choice for several SCA1 (and one SCA2) mouse models that show degeneration of PCs as the most striking event in SCA pathology. In patients, the degeneration of PCs is present, but the most prominent disease marker, NIIs, are barely detectable in these cells. We also know from the conditional SCA1/Prp-tTA and SCA3 PrP/MJD77 mouse models that PCs degenerate without transgene expression because the PrP promoter does not drive expression in PCs [229, 230]. This finding suggests that the damage of PCs in SCA may be non-cell-autonomous and may be the result of some primary pathogenic condition instead. These conditions may be the result of the pathologic influence of other cells or lack of the physiologic influence of these cells because of their damage or loss. This model of nonautonomous degeneration was recently proposed for other polyQ diseases. It has been demonstrated (using the GFAP promoter) that Bergmann glia may play an important role in the pathogenesis of SCA7 [177]. In addition, the GFAP promoter and mutant HTT fragment were recently expressed in transgenic mice, which resulted in an HD-like phenotype [231] in addition to exacerbating HD neuropathology in the N17182Q model [232]. These mice have provided evidence for the involvement of astrocytes and the strong contribution of aberrant glutamate uptake in SCA7 and HD. This finding suggests that excitotoxic death of neurons in cerebral cortex may lead to loss of connectivity to striatum and thus may play role in evoking HD. This hypothesis is in agreement with results that were obtained from mouse models that restricted the expression of the HTT transgene to the striatum and MSNs with either a conditional model or the DARPP32 promoter [23, 36, 233]. In those models, the striatum and MSNs are the only affected populations in the mouse brain; however, this does not produce a drastic phenotype compared to the pan-neuronal models of HD.

Recently, it has been confirmed that in addition to glia and neurons also endothelial cells in the brain and the abnormal vasculature investigated in YAC128 model may participate in pathogenesis of HD [234]. Another example of redefining the pathogenesis of polyQ disorders is SBMA. It has been demonstrated that the mouse model that uses the HSA promoter to express the transgene in muscle cells can elicit SBMA-like phenotypes in mice [217]. This finding suggests that the degeneration of motor neurons in SBMA may be secondary (non-autonomous pathogenesis) and dependent on primary muscle degeneration. The SBMA phenotype in mice also appears to rely heavily on both the mutant polyQ tract and its expression pattern because mice that have an AR promoter driving the expression of a protein composed exclusively of 239 glutamines show SBMA-like phenotypes [203].

The mouse and human versions of native promoters for polyQ genes have been used in knock-in models and in transgenic R6/2, YAC, BAC, and Cosmid models. Generally, the knock-in and YAC models of polyQ disorders produce no phenotype, a weak phenotype or develop the disease much more slowly than the simple transgenic models and this applies to HD models in particular. The random transgenic models often contain many transgene copies that result in very strong transgene expression. However, the slow phenotype cannot simply be explained by the number of integrated transgenes because the phenotype severity does not always increase with an increase in the number of transgene copies. For example, in the R6 lines, although the $\mathrm{R} 6 / 5$ has five transgene copies and the R6/1 and R6/2 lines have only one copy each, the phenotype severity does not mirror this difference [19]. Similar observations were also made among the SCA1 B0X lines [14]. Nevertheless, mice that have been bred to homozygosity, like HD knock-ins or SCA6_84Q [17], are more affected. Their severe phenotype may result from either increased mutant protein expression from two alleles or the lack of mitigating activity of a wildtype allele, which was investigated in a study of YAC128 mice on an Htt-knock-out background. In YACs, BACs, and knock-in models, the protein expression level is usually lower than that of the endogenous allele. Moreover, these discrepancies exist despite high levels of mRNA expression. For example, in the YAC128 model, which has transgene mRNA expression several orders of magnitude higher than WT mRNA expression, the level of transgene protein expression is only $75 \%$ of the WT level [30]. Similar puzzling discrepancies concerning the expression of the Htt gene were identified in the $\mathrm{Hdh}(\mathrm{CAG}) 150$ knock-in mouse mod$\mathrm{el}$, in which the expression of mutant protein is variable and lower compared to that of the WT allele [235]. It has also been postulated that the length of the transgene protein contributes to the severity of the disease in HD models. Models with a short mutant protein, such as the R6/2 and N171-82Q models, show phenotypes much earlier because of the skipping of a putative protein-processing step that would otherwise delay the onset of the disease in animals that have longer proteins. Moreover, the N-terminal 586 
caspase- 6 fragment seems to be just the intermediate step in HD patogenesis since the 586-82Q models $[236,237]$ exhibit milder phenotypes than R6/2 and N171-82Q. The neurons from 586-82Q models contain predominantly cytoplasmic agregates and such localization may suggest that the pathogenic accumulation of HTT fragments in nucleus is delayed. However, the transgene length hypothesis is not supported by the Shortstop model, which contains a short protein but does not show an HD-like phenotype [20]. Recent work concludes that the lack of such a phenotype cannot be completely explained by the properties of the mutant N118 htt protein fragment because the mice containing this protein under the PrP promoter had pronounced phenotypes [24]. The clear differences between the Shortstop model and the R6/2 or N118 models are the 5' sequences and promoter sequences that are present in these models. The Shortstop model contains large flanking sequences from the $5^{\prime}$ end, along with the entire HTT promoter; together, these comprise $24 \mathrm{~kb}$ of upstream human sequence, whereas the R6/2 contains only $1 \mathrm{~kb}$ of the HTT promoter. YAC and knock-in models also contain entire $H T T$ and $H t t$ genes with flanking sequences and therefore preserve the endogenous signals and gene vicinity that influence the regulation of HTT and Htt gene expression. Interestingly, it has been postulated that nongenetic factors influence the regulation of the expression of HTT and $\mathrm{Htt}$ [235]. These nongenetic factors, such as chromatin remodeling, can modulate the expression of HTT and Htt genes by driving the expression in defined cell types and tissues such as the brain and the testes [235]. Perhaps, the deletion of the entire $3^{\prime}$ sequence in the Shortstop model may cause gene regulation via epigenetic chromatin remodeling or antisense HTT transcripts [238] that results in the selective silencing of the shortstop protein in certain neuronal cell types that are particularly involved in pathogenesis of HD. According to such hypothesis, the $5^{\prime}$ untranslated region and the promoter of the HTT gene would be responsible for the severity of disease in mouse models, and probably also in patients.

\section{The Impact of CAG Repeat/polyQ Tract}

Unlike patients who suffer from polyQ disorders, the mouse models are not very sensitive to the number of CAG repeats in the transgenes. To evoke a phenotype in mice, the average number of repeats in the transgene needs to be higher than in humans. Mice have a relatively short lifespan, and it is likely that the accumulation of the pathogenic events is sometimes insufficient to evoke the phenotype. Moreover, the positive correlation between the number of repeats and disease severity that is present in human patients is not as apparent in mice. This correlation can be observed in HD YAC, HD knock-ins, and SCA1 knock-ins, which have similar model variants with increasing numbers of CAG repeats.
Unfortunately, this positive correlation cannot be confirmed for transgenic, high copy integration mouse models because of expression levels that "balance" the CAG counts. The phenotypes in transgenic mice are strongly influenced by expression level. For example, two copies of a transgene may have a dramatic effect, whereas one copy may leave the mouse healthy, as occurs in some HD knock-ins, Sca3Q71$\mathrm{b}$, and PrP/MJD77 models. In addition, the increased number of repeats may sometimes ameliorate the disease phenotype rather than accelerating it, as in the case of R6/2 mice variants with very long CAG tracts [38, 39]. Moreover, it is quite puzzling that the expression of the protein containing expanded polyQ tract does not always elicit a diseased phenotype. For instance, the Shortstop HD animals contain both inclusions and mutant protein expression, but show no signs of disease [20]. Similarly, full-length ataxin-3 expression in PCs produces no phenotype, but a fragment of ataxin-3 does produce a phenotype [154]. Moreover, HD models that express either the caspase-site-mutated [26] or phosphomimetic [239] versions of huntingtin are rescued from the disease despite having an expanded polyQ tract. Similarly, a recent YAC128 model that completely lacks caspase-2 expression does not show the behavioral changes that are typical in HD models despite exhibiting neurodegenerative alterations such as reduction in striatal volume [240]. Conversely, the polyQ tract is not always needed to evoke the disease, as in the SCA model, which has a substitution of Ser776 with a phosphomimicking Asp residue [138].

In summary, properties of the transgenic cassette and the promoter type that is used in a transgenic construct have a prominent impact on the disease phenotype. Additional features that were not included in the transgenic properties section of our data table are the transgene's mRNA and protein levels and the number of transgene copies that are integrated into the mouse model. This omission is mainly due to a lack of data. The few studies that report precise values of transgene expression levels in relation to endogenous levels would not significantly enrich the data table. However, gathering such data from all of the polyQ models would be useful for standardizing the phenotypes and investigating the outcomes of therapeutic approaches.

\section{Mouse Genetic Background}

The careful selection of genetic background for maintaining transgenic mice is important for the reliable characterization and comparison of mouse models because various strains exhibit differences in physiological, motor, and cognitive traits [97, 241-245]. The genetic background can influence a number of features, including breeding qualities, behavioral responses to changes in environmental conditions [246-248], and testing paradigms [249-251], all of which may generate lab-to-lab variability in phenotypic outcomes 
[252]. Thus, the performance of the background strain in a particular test can influence the performance of a transgenic model maintained on this background. For example, some popular strains $(\mathrm{C} 3 \mathrm{H}, \mathrm{CBA} / \mathrm{J}, \mathrm{FVB} / \mathrm{NJ}$, and $\mathrm{SJL} / \mathrm{J})$ are homozygous for the retinal degeneration allele $\mathrm{rd} 1$, which results in blindness [253] at a young age. These strains are not optimal backgrounds for modeling diseases with visual impairment, such as SCA7, where testing of visual performance is essential. Visual impairment may influence the outcome of spatial learning in the Morris water maze [254], or it may influence strategy-shifting tasks that are based on visual discrimination. Similarly, the hearing loss in 129/SvJ, DBA/2J or older C57BL/6J [255] strains may influence performance on acoustic startle and PPI tests [256].

Our data table includes information about the genetic background of the models, and we have presented it according to the Jackson Laboratory nomenclature for mouse strains. The models were often characterized based on different backgrounds and stages of backcrossing.

Most of the information about the influence of genetic background in polyQ diseases is again related to HD mouse models. The R6/2 model is generally bred using the F1 hybrid of the C57BL/6J strain with either UK-bred CBA or CBA/J animals [45]. The two substrains are significantly different because they reject skin grafts between each other [257], and, unlike the UK substrain, the CBA/J animals carry a homozygous rd 1 allele, thereby contributing a $25 \%$ chance of blindness to the R6/2. UK- and US-bred R6/2 animals show differences in acoustic startle performance, PPI performance and body weight loss $[42,45]$. However, it is presently uncertain whether the difference in genetic background contributes to phenotype discrepancies between UK- and US-bred mice because the existing data either are based on separate studies with different methodologies [38, 45, 258] or compare mice with different lengths of the polyQ tract [45]. Therefore, a more systematic comparison among R6/2 variants with shorter and longer CAG tracts on hybrid and pure C57BL/6J backgrounds is needed.

Like the R6/2 mice, R6/1 mice show differences in acoustic startle and PPI performance, body weight loss, and locomotor activity depending on their genetic background [41, 259-261]. This issue also requires further clarification.

In the case of the YAC 128 model, different genetic backgrounds have been compared in cross-sectional studies $[45,93]$. The most popular YAC128/FVB/N combination has a more pronounced phenotype than the less affected YAC128 on $129 / \mathrm{SvJ}$ or C $57 \mathrm{BL} / 6 \mathrm{~J}$ backgrounds. The YAC128/129/SvJ strain also lacks the hypoactivity [93] phenotype, which is probably related to increased anxiety, pronounced hypoactivity, and lack of motivation in the 129/ SvJ strain [245].

In the HdhQ111 model, intergenerational and somatic stability of CAG expansions are affected by the genetic background, as is the formation of polyQ NIIs. HdhQ111 mice on a $\mathrm{C} 57 \mathrm{BL} / 6 \mathrm{NCrl}$ congenic background develop the most pronounced CAG tract instability and the greatest number of NIIs, whereas the CAG tracts were rather stable, and few NIIs were observed in HdhQ111 on a 129/SvCrl background. The phenotype on an $\mathrm{FVB} / \mathrm{NCrl}$ background is placed in the middle of C57BL/6NCrl and 129/SvCrl strains [262].

Similar to HdhQ111 model, greater CAG tract instability was observed in the SCA3 CMVMJD94 mouse model on a $\mathrm{C} 57 \mathrm{BL} / 6 \mathrm{~J}$ background than on an FVB/N congenic background [168]. Another study of SCA1 78Q mice revealed that backcrossing from a mixed C57BL/6J;129/SvEv background to a pure $\mathrm{C} 57 \mathrm{BL} / 6 \mathrm{~J}$ background is able to rescue the rotarod deficit [145]. The SCA1 B05 model on the mixed FVB/N;129/SvEv background had a slower progression of phenotype development compared to mice that were backcrossed to a FVB/N [145] background. Like in Sca1 78Q mice, backcrossing the SCA7 B7E2 mice from a (C57BL/ $6 \mathrm{~J} \times \mathrm{SJL}) \mathrm{F} 1$ background to a pure $\mathrm{C} 57 \mathrm{Bl} / 6 \mathrm{~J}$ background ameliorated the phenotype [171].

Phenotypes, Disease Onset, Progression, and Localization of Neuropathology in the CNS and Other Tissues

In our data table of mouse models and phenotypes, we collected 41 groups of "phenotypes" (Table 3), including almost 200 "detailed phenotypes" in 107 mouse models and variants that model nine polyQ diseases. Both a detailed description of a system for describing the phenotypes in our data table and the data table itself are available online as Supplementary material.

Table 3 summarizes the 41 phenotypes that belong to motor (M), neuropathological $(\mathrm{N})$, cognitive $(\mathrm{C})$, and other (O) "general phenotypes". A large portion of these phenotypes (approximately $32 \%$ ) are polyQ protein aggregates. Because the mice have aggregates in multiple tissues, nuclear inclusions are listed in the data table repeatedly for different tissues and brain regions. The detailed phenotypes in the polyQ protein aggregates group are aggregates, aggresomes, amyloid-like inclusions, cytoplasmic aggregation foci (AF), diffuse cytoplasmic staining, diffuse nuclear staining, extranuclear aggregates, nuclear inclusions, and nuclear microaggregates. Neuronal morphology alterations occur frequently in the mouse models and contain detailed phenotypes, including abnormal cell morphology, cell size decrease, dark cell degeneration, and dendritic degeneration. Locomotor impairment was measured as the frequency of grooming, rearing, and motor and exploratory activity, and the balance and coordination alterations category included observations of rotarod or beam walk impairment.

We investigated whether we could identify groups of detailed phenotypes that are universal and phenotypes that are unique to mouse models of different disorders. Using the 
Table 3 The 41 groups of "phenotypes" identified in polyQ models belonging to "general phenotypes" categories [neuropathological (N), cognitive $(\mathrm{C})$, motor $(\mathrm{M})$ and other $(\mathrm{O})]$ : the number indicates the amount of records that are present for every "phenotype" in the data table

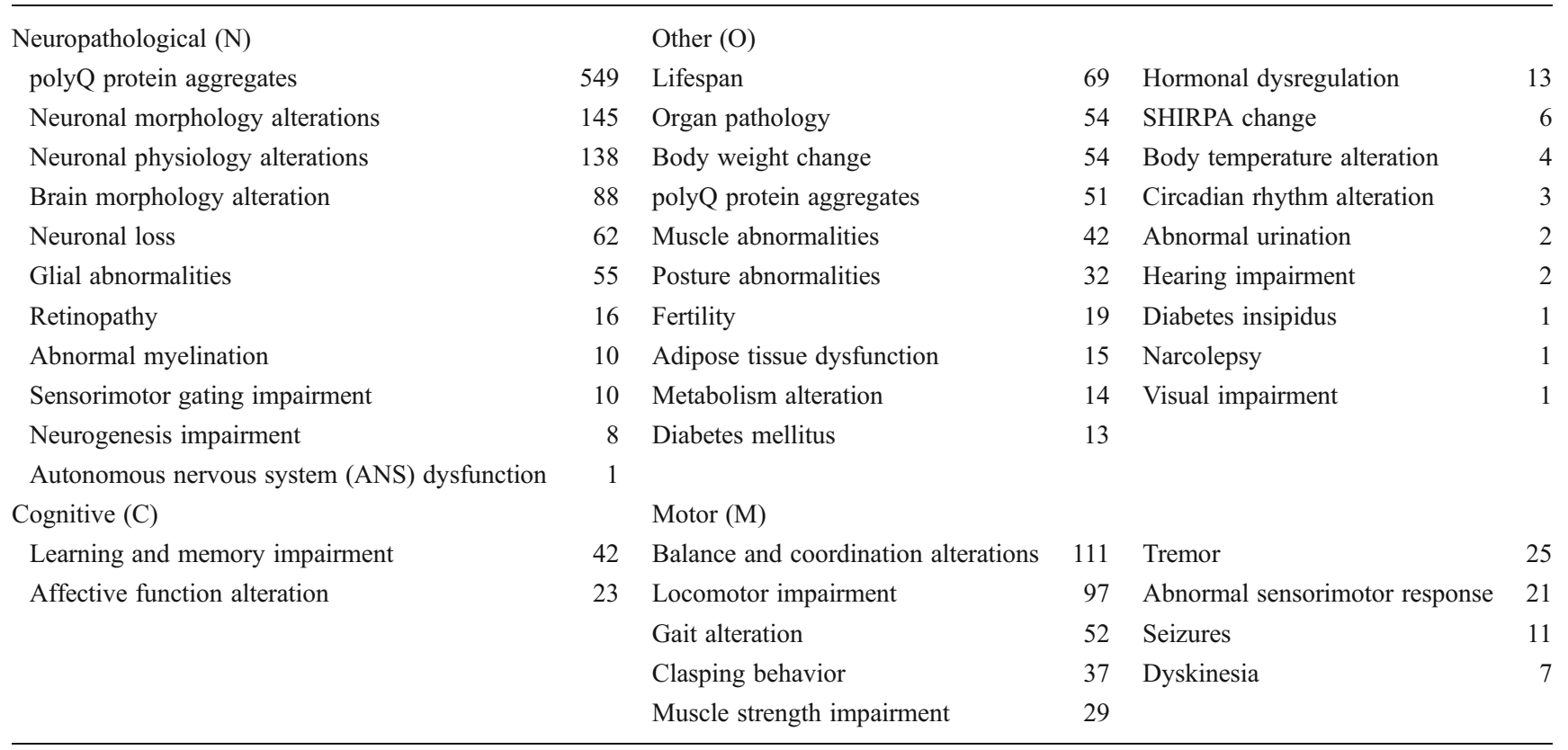

data in our data table and pivot table tools in Excel, we pooled detailed phenotypes from all mouse models of a particular disease and investigated the overall similarities and differences among phenotypes associated with diseases that were reproduced in mouse models.

We identified 21 detailed phenotypes that were present in mouse models that represented at least 6 diseases and 17 detailed phenotypes that are common to mouse models that represent 4 or 5 diseases (Table 4 ). We identified a third group of 33 detailed phenotypes that are present in mouse models that represent 2 or 3 polyQ diseases. Finally, 124 different detailed phenotypes are unique to a single polyQ disease model or to a single disease. The phenotype that is present in the mouse models of all diseases is rotarod impairment. The cell size decrease, clasping behavior, and gait abnormality phenotypes are present in all of the mouse models except models of SCA6.

Ataxia, body weight loss, decreased lifespan, diffused nuclear staining, gene expression alteration, and nuclear inclusions are detected in all mouse models except SCA2 and SCA6. In contrast, diffused cytoplasmic staining or extranuclear inclusions phenotypes are found in both the SCA2 and SCA6 models. The dendritic degeneration phenotype was not reported for SBMA mouse models, but other phenotypes, such as cell loss and dark cell degeneration, were present in SBMA models, indicating that also dendritic degeneration is part of the pathogenesis of SBMA. The cell loss phenotype was not present for the DRPLA and SCA6 models, indicating that these mouse models involve cell dysfunction without the loss of neurons. Tremor (which is a symptom that originates in the peripheral nervous system) was not present for SCA1, SCA2, or SCA6 mice, which is surprising for SCA1 models because of the involvement of the PNS. Although normal lifespan is not a phenotype per se, it was listed in the data table for many mouse models that exhibit neurological phenotypes. Moreover, a number of mouse models present only mild disease phenotypes and have only a slightly affected lifespan.

Unique phenotypes account for more than half of the phenotypes that have been identified in polyQ mice. For instance, the SBMA models display muscle pathology, while some cognitive phenotypes are specific to HD models.

In summary, many of the phenotypes that are associated with a given polyQ disease are common to mouse models of different polyQ diseases, which may indicate that the polyQ diseases are really similar disorders with many common aspects of pathogenesis. In addition, the models also reproduce many unique features of human polyQ diseases. The existing similarities between disease models may also indicate that we need more sophisticated and accurate mouse models to study polyQ disorders because some common phenotypes between current polyQ disease models may result from the way in which the transgenic mice were created (random integration, genetic background, and regulatory sequences).

Defining the Onset and Progression of the Disease in PolyQ Mouse Models

Our data table also lists "age of earliest detection (age I, weeks)" and "age of latest detection (age II, weeks)", which 
Table 4 The phenotypes overlapping across mouse models and diseases

\begin{tabular}{|c|c|c|c|c|c|c|c|c|c|c|}
\hline & Detailed phenotypes & Diseases & & & & & & & & \\
\hline \multirow{21}{*}{$\begin{array}{l}\text { Common for } 6 \text { or } \\
\text { more diseases }\end{array}$} & Rotarod impairment & DRPLA & $\mathrm{HD}$ & SBMA & SCA1 & SCA2 & SCA3 & SCA6 & SCA7 & SCA17 \\
\hline & Abnormal gait & DRPLA & $\mathrm{HD}$ & SBMA & SCA1 & SCA2 & SCA3 & & SCA7 & SCA17 \\
\hline & Cell size decrease & DRPLA & $\mathrm{HD}$ & SBMA & SCA1 & SCA2 & SCA3 & & SCA7 & SCA17 \\
\hline & Clasping & DRPLA & $\mathrm{HD}$ & SBMA & SCA1 & SCA2 & SCA3 & & SCA7 & SCA17 \\
\hline & Ataxia & DRPLA & $\mathrm{HD}$ & SBMA & SCA1 & & SCA3 & & SCA7 & SCA17 \\
\hline & Body weight loss & DRPLA & $\mathrm{HD}$ & SBMA & SCA1 & & SCA3 & & SCA7 & SCA17 \\
\hline & Cell loss & & $\mathrm{HD}$ & SBMA & SCA1 & SCA2 & SCA3 & & SCA7 & SCA17 \\
\hline & Decreased lifespan & DRPLA & $\mathrm{HD}$ & SBMA & SCA1 & & SCA3 & & SCA7 & SCA17 \\
\hline & Dendritic degeneration & DRPLA & $\mathrm{HD}$ & & SCA1 & SCA2 & SCA3 & & SCA7 & SCA17 \\
\hline & Diffused nuclear staining & DRPLA & $\mathrm{HD}$ & SBMA & SCA1 & & SCA3 & & SCA7 & SCA17 \\
\hline & Electrophysiology alteration & DRPLA & $\mathrm{HD}$ & SBMA & SCA1 & & SCA3 & SCA6 & SCA7 & \\
\hline & Gene expression alteration & DRPLA & HD & SBMA & SCA1 & & SCA3 & & SCA7 & SCA17 \\
\hline & Motor and exploratory activity decrease & & HD & SBMA & SCA1 & & SCA3 & SCA6 & SCA7 & SCA17 \\
\hline & Nuclear inclusions & DRPLA & HD & SBMA & SCA1 & & SCA3 & & SCA7 & SCA17 \\
\hline & Abnormal cell morphology & DRPLA & HD & SBMA & SCA1 & & SCA3 & & SCA7 & \\
\hline & Brain volume decrease & DRPLA & HD & SBMA & & & SCA3 & & SCA7 & SCA17 \\
\hline & Brain weight loss & DRPLA & HD & SBMA & SCA1 & & SCA3 & & & SCA17 \\
\hline & Diffused cytoplasmic staining & & $\mathrm{HD}$ & SBMA & SCA1 & SCA2 & SCA3 & & SCA7 & \\
\hline & Kyphosis & & $\mathrm{HD}$ & SBMA & SCA1 & & SCA3 & & SCA7 & SCA17 \\
\hline & Seizures/evoked seizures & DRPLA & $\mathrm{HD}$ & SBMA & & & SCA3 & & SCA7 & SCA17 \\
\hline & Tremor & DRPLA & $\mathrm{HD}$ & SBMA & & & SCA3 & & SCA7 & SCA17 \\
\hline \multirow{17}{*}{$\begin{array}{l}\text { Common for } 4 \\
\text { or } 5 \text { diseases }\end{array}$} & Apoptosis increase & & $\mathrm{HD}$ & SBMA & & & SCA3 & & SCA7 & SCA17 \\
\hline & Dark cell degeneration & & $\mathrm{HD}$ & SBMA & & & SCA3 & & SCA7 & SCA17 \\
\hline & Loss of calbindin & & & & SCA1 & SCA2 & SCA3 & & SCA7 & SCA17 \\
\hline & Reactive gliosis & & $\mathrm{HD}$ & & SCA1 & & SCA3 & & SCA7 & SCA17 \\
\hline & Reduced fertility & DRPLA & $\mathrm{HD}$ & SBMA & & & SCA3 & & SCA7 & \\
\hline & Axonal degeneration & DRPLA & $\mathrm{HD}$ & SBMA & & & & & & SCA17 \\
\hline & Demyelination/thin myelin & & $\mathrm{HD}$ & SBMA & & & SCA3 & & & SCA17 \\
\hline & General incoordination & DRPLA & $\mathrm{HD}$ & & SCA1 & & & & SCA7 & \\
\hline & Grooming activity decrease & & $\mathrm{HD}$ & & & & SCA3 & SCA6 & & SCA17 \\
\hline & Hindlimb dragging & & HD & SBMA & & SCA2 & SCA3 & & & \\
\hline & $\begin{array}{l}\text { Hypothalamic-pituitary-adrenal } \\
\text { axis alteration }\end{array}$ & DRPLA & HD & SBMA & & & SCA3 & & & \\
\hline & Infertility & & HD & SBMA & & & SCA3 & & SCA7 & \\
\hline & Layer thickness decrease (cerebellum) & & & & SCA1 & & SCA3 & & SCA7 & SCA17 \\
\hline & Motor and exploratory activity increase & DRPLA & $\mathrm{HD}$ & & SCA1 & & SCA3 & & & \\
\hline & Muscle atrophy & & $\mathrm{HD}$ & SBMA & SCA1 & & SCA3 & & & \\
\hline & Nuclear microaggregates & & $\mathrm{HD}$ & SBMA & & & & & SCA7 & SCA17 \\
\hline & Simple motor learning deficit & & HD & & SCA1 & & SCA3 & & SCA7 & \\
\hline
\end{tabular}

The 21 "detailed phenotypes" (light gray) that are present in mouse models representing at least 6 diseases and 17 "detailed phenotypes" (dark gray) that are common for mouse models representing four or five diseases. For the number of "detailed phenotypes" in mouse models, see also Supp. Fig. 2

indicate the ages at which an alteration was documented for the first or last time, respectively. The research works that were the sources of data for these columns were preselected; in the case of the column labeled age of earliest detection, the research works that reported the youngest mouse with a documented alteration in phenotypes that have a simple non-statistical nature, such as nuclear inclusions (present/ not present), were selected. If the alterations were subjected to statistical analyses (for example, as in the case of behavioral tests, such as the rotarod, open field assays, cognitive tests, and brain volume assays), then the data were based on the youngest mice that had a documented, statistically significant alteration. The selection of data for the age of latest detection column was based on reports of the ages of the 
oldest mice with documented alterations that were statistically significant in the case of experiments that involved statistical analyses. One caveat is that the phenotypes obviously do not have endpoints, as a measure of the time of the last investigation might suggest, but the phenotypes may undergo transitions, such as a transition from hyper- to hypoactivity. Other example of such transition is the conversion of mutant polyQ proteins from diffused to aggregated forms. Obviously, this column contains fewer data, and the data are less reliable because researchers do not always follow the development of all phenotypes until very late ages in mice. The major reason for this lack of data is the fact that the model animals should not be tested too frequently because testing per se influences the phenotype and therefore precludes the accurate assessment of natural disease progression.

Based on the data collected in our data table, we have investigated the disease onset and progression in mouse models. The definition of disease onset in mouse models can be expressed as the single age of an animal when the first change in phenotype was detected. This definition has several drawbacks. First, this definition assumes that a deficit or phenotype begins when it is first detected or investigated, not when it actually appears in the animal. At present, researchers cannot avoid making this assumption; however, they must always realize that the age of disease onset in mice is an approximation that can always be refined by more intensive research and the use of more sensitive methods. The second disadvantage is that this definition limits the description of onset to a single time point at which either a limited number of phenotypes or only one phenotype starts to occur. However, disease onset and pathogenesis result from several events that initiate the development of phenotype. Therefore, the age of disease onset in mice can be investigated as a time frame that encompasses the earliest onsets of phenotypes from three major groups of phenotypes, including motor, neuropathological, and cognitive phenotypes. These data are collected in our data table. To investigate this time frame in different models, we have prepared Table 5, which lists the ages of onset for motor, neuropathological, and cognitive phenotypes.

We also asked whether it would be possible to use our data table to construct a normalized value that would both describe the progression of the disease in a given mouse model and allow for comparison between mouse models. Every model in the data table contains a set of phenotypes, the majority of which have a specified age of earliest detection. For instance, the R6/2 model on the hybrid background contains 164 phenotypes, and the age of earliest detection is specified for 158 of them. The age at which $50 \%$ of these phenotypes have been detected in a particular model reflects the dynamics of disease progression in that model (Fig. 5). We have excluded the "polyQ protein aggregates" phenotype from this analysis for reasons described below. Thus, $50 \%$ of the number of specified phenotypes would be 67 for the R6/2 model and 19 for the YAC128 (FVB/N) model. Therefore, the $50 \%$ of phenotypes can be used as a normalizing value for the different number of phenotypes described in various polyQ mouse models (Fig. 4). Thus, we propose a parameter AD50 (age at $50 \%$ detected phenotypes), which is defined as the age at which $50 \%$ of the number of phenotypes for a particular mouse model have been detected. The AD50 is the median of the values collected in the column age of earliest detection for each analyzed mouse model. The AD50 for the R6/2 model is 8 weeks, and the AD50 for the YAC128 model is 35 weeks reflecting the different speed of disease progression in the two models. The above analysis was based on a number of assumptions. The first is that the disease in a mouse model is progressive and the number of phenotypes gradually increases. The second is that the mice are well-studied at every possible age and that a sufficient number of phenotypes were identified. Although none of the mouse models follows these rules completely, some are close. The AD50 will certainly need to be recalculated frequently in the future. Additionally, the polyQ protein aggregates phenotypes were not used for these analyses since the 600 records related to aggregates formation constitute approximately one third of the data reported in the data table. The inclusion of these data would shift the AD50 balance to a value that demonstrates the progression of aggregate formation. A very important parameter of disease progression is the lifespan of the model animals. Table 5 presents both the lifespan and the AD50 for selected models. Figure 5 additionally demonstrates that progression of the disease can be presented on the graph by plotting the increasing (cumulative) number of phenotypes against age of earliest detection. For example, Fig. $5 \mathrm{c}$ demonstrates progression curves and AD50 values for R6/2 and YAC128 models.

\section{Neuropathology in the CNS and Non-CNS Phenotypes}

A question that has frequently emerged in research on polyQ disorders is the famous "If polyQ proteins are widely expressed in virtually every cell in an organism, why are neurons in the CNS particularly vulnerable to polyQmediated toxicity?" To examine the issue of CNS versus non-CNS phenotypes more closely, we analyzed the localization of neuropathology in the CNS for the various polyQ mouse models. We selected the most important neuropathology phenotypes, namely, neuronal loss, neuronal morphology alteration, neuronal physiology alteration, glia abnormalities, retinopathy, neurogenesis impairment, and abnormal myelination. These neuropathology phenotypes comprise over 430 records that include data on brain location across mouse models. Additionally, we investigated 


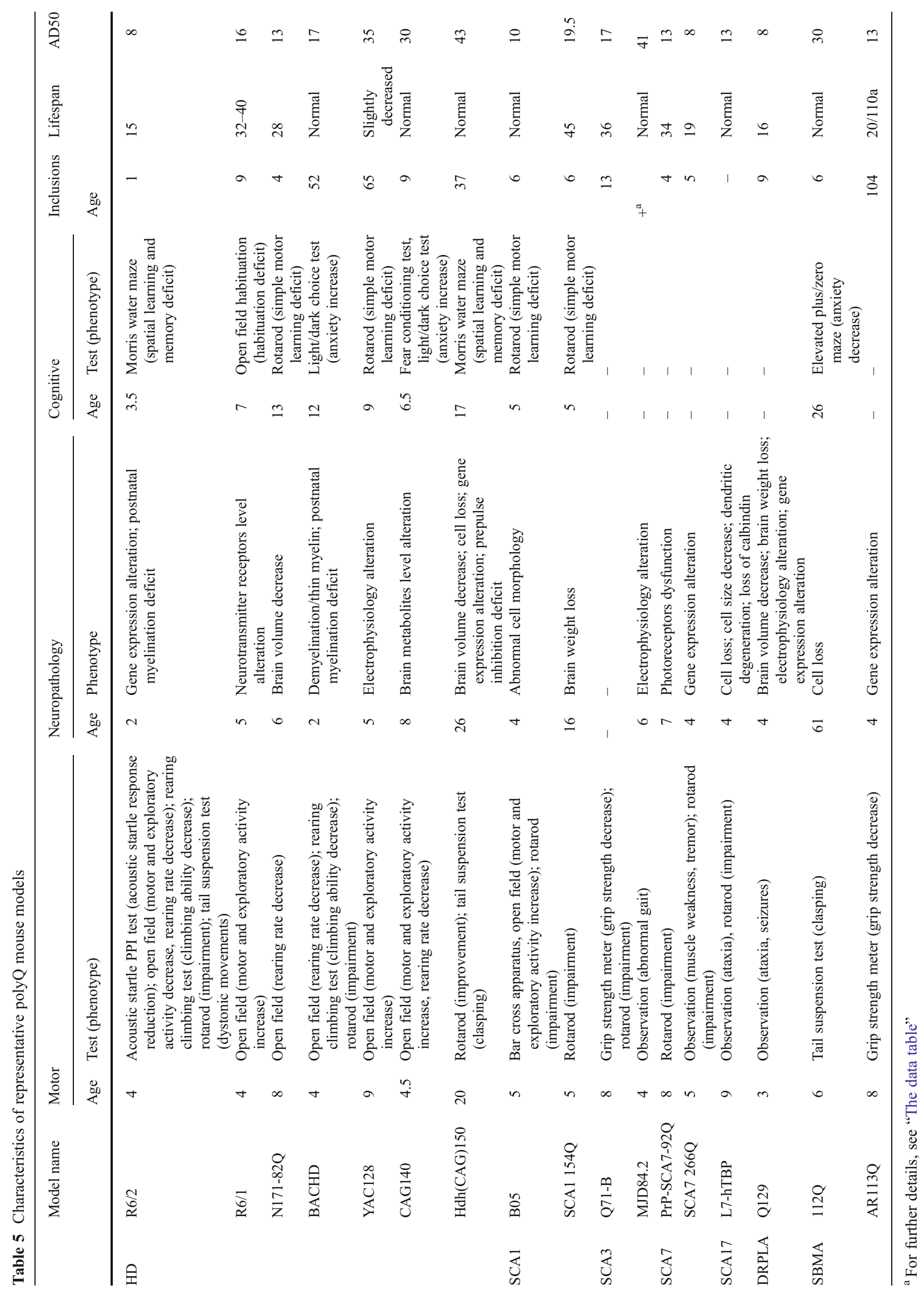


Fig. 4 Diagrams of brain, spinal cord, and retina neuropathology in polyQ models that use the PrP promoters. As in previous figures, the phenotypes and brain regions were marked with colors on a schematic sagittal section of the mouse brain. Because multiple PrP polyQ models were available for some diseases, the data from multiple models for each disease were pooled to increase the total information content. The PrP promoter produces a pattern of neuropathology that is different from that produced in models that use native promoters. The PrP promoter tends to produce neuropathological outcomes in the cerebral cortex $(C T X)$, cerebellum $(C B)$, and striatum $(S T R)$, but, unlike the native promoters (Fig. 3), the PrP promoter does not tend to produce pathology in the hippocampus $(H P)$
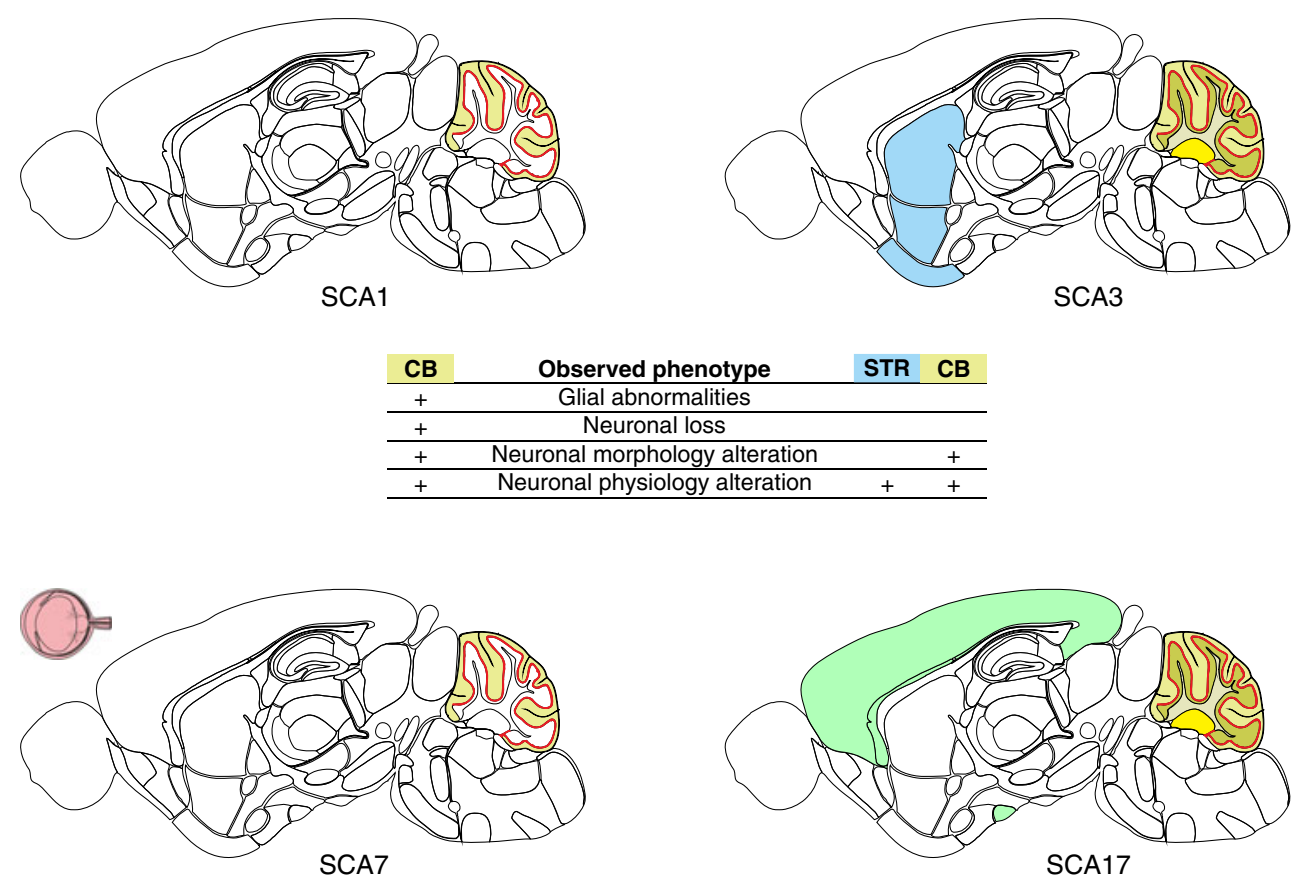

\begin{tabular}{ccccc} 
RETINA & CB & Observed phenotype & CTX & CB \\
\hline \multicolumn{4}{c}{ Abnormal myelination } & + \\
\hline+ & + & Glial abnormalities & + \\
\hline+ & \multicolumn{4}{c}{ Neuronal loss } \\
\hline & + & Neuronal morphology alteration & + \\
\hline & + & Neuronal physiology alteration & + \\
\hline+ & \multicolumn{4}{c}{ Retinopathy } \\
\hline \multicolumn{4}{c}{}
\end{tabular}
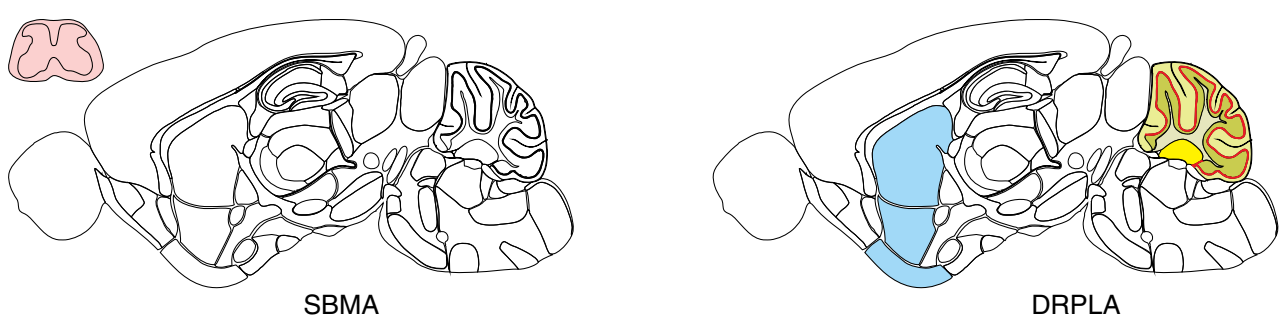

\begin{tabular}{cccc} 
SC & Observed phenotype & STR & CB \\
\hline+ & Neuronal loss & & \\
\hline & Neuronal physiology alteration & + & + \\
\hline
\end{tabular} separately the representative models of HD (Fig. 2), models of different polyQ disorders using native promoters (mouse or human) (Fig. 3), and the PrP promoter (Fig. 4; if more than one PrP models of the same disease were available, the neuropathology data were combined for these models). The figures depict the locations of neuropathology using diagrams of a sagittal section of the mouse brain, the spinal cord, and the eye; the brain regions that were affected by neuropathology are marked with colors. This analysis indicates that although the neuropathological phenotypes in polyQ mouse models cover many different CNS regions, they share some similarities. The profile of the neuropathology associated with any given mouse model is influenced by the promoter used for transgene expression.
The HD models are very well studied and probably also for this reason they present the broadest spectrum of brain regions and tissues that are affected by neuropathology. The main brain regions listed in our data table for HD models are obviously the striatum and the cerebral cortex. Both the R6/ 2 and YAC128 models also show the involvement of the hippocampus listed as neurogenesis impairment. Other brain regions and tissues involved in R6/2 are the hypothalamus, cerebellum, spinal cord, and eye retina. The $\mathrm{Hdh}(\mathrm{CAG}) 150$ knock-in model does not have any of the selected neuropathologies associated with the cerebral cortex. In this model, NIIs are detected in brain regions across the brain and in the cerebral cortex. With the exception of SBMA, the consistent involvement of cerebellar neuropathology in models 
A

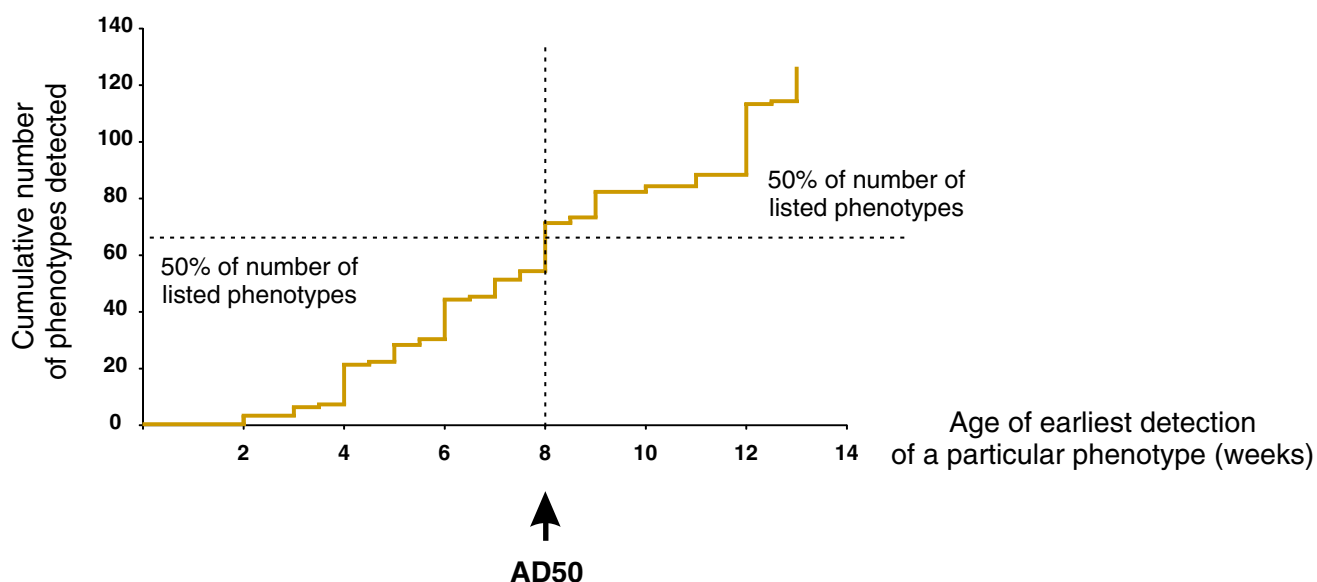

Age when $50 \%$ of number of phenotypes listed in the data table are already detected

\section{B}

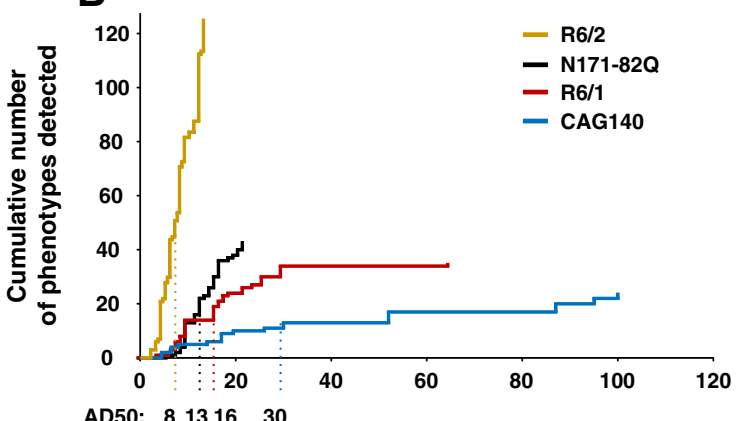

AD50: $81316 \quad 30$

\section{D}

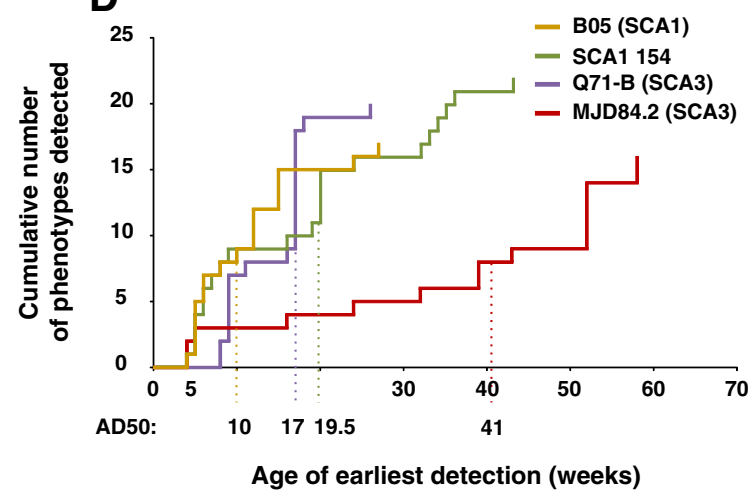

Fig. 5 Graphs of disease progression in polyQ mouse models and the AD50 parameter. We have constructed a normalized value that describes the progression of the disease in a mouse model and that allows for comparison between mouse models. This is the AD50 (age at $50 \%$ detected phenotypes), which represents the median of the values from the "age at earliest detection" column of the data table for an analyzed mouse model. The AD50 is the age at which $50 \%$ of the total number of phenotypes for a particular mouse model has been detected and reflects the dynamics of disease progression in that model. The $50 \%$ of number of phenotypes is a normalizing value for the different numbers of phenotypes described in various polyQ mouse models. a An example graph that shows how the graphs of disease

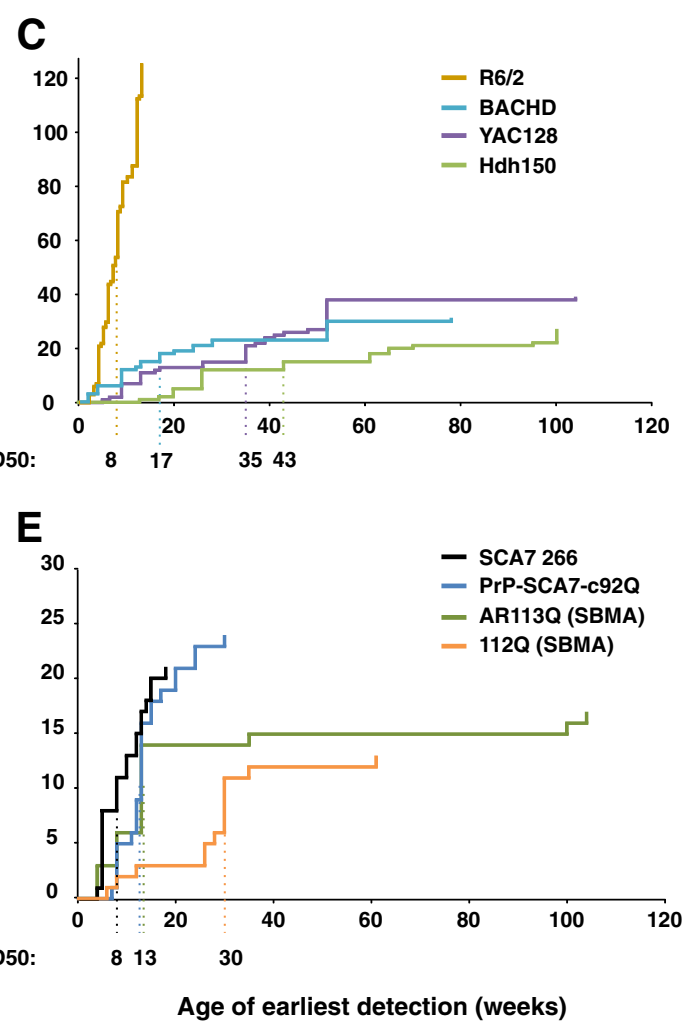

progression are constructed for various models and where the AD50 is located on the graph for the models. b-e The graphs of progression of the disease for various models representing various polyQ diseases. The R6/2 contains 134 "detailed phenotypes" in the data table (after excluding polyQ aggregates and some phenotypes without an "age of earliest detection"). Thus, $50 \%$ of the number of phenotypes equals 67 for the R6/2 model and 19 for the YAC128 model. The AD50 for the $\mathrm{R} 6 / 2$ model is 8 weeks and that for the YAC128 model is 35 weeks. Thus, the AD50 values reflect the different speed of disease progression in each model. The analysis excludes the "polyQ protein aggregates" phenotypes for reasons that are described in the main text 
Table 6 The non-CNS phenotypes in poly Q diseases mouse models cover a vast majority of tissues

\begin{tabular}{|c|c|c|c|}
\hline Tissue/organ & Phenotype & Mouse models & References \\
\hline \multirow[t]{2}{*}{ Adipose tissue } & Adipose tissue dysfunction & $\begin{array}{l}\text { BACHD,CAG140, N171- } \\
\text { 82Q-81, R6/2 }\end{array}$ & {$[67,294,302,337,368]$} \\
\hline & PolyQ protein aggregates & $\mathrm{R} 6 / 2$ & {$[34]$} \\
\hline \multirow[t]{3}{*}{ Adrenal gland } & Hormonal dysregulation & $\mathrm{R} 6 / 2$ & {$[67]$} \\
\hline & Organ pathology & $\mathrm{R} 6 / 2$ & {$[67]$} \\
\hline & PolyQ protein aggregates & $\operatorname{Hdh}(\mathrm{CAG}) 150, \mathrm{R} 6 / 2$ & {$[34,349]$} \\
\hline Bones & Organ pathology & $\mathrm{R} 6 / 2$ & {$[67]$} \\
\hline \multirow[t]{3}{*}{ Gastrointestinal tract } & Hormonal dysregulation & $\mathrm{R} 6 / 2$ & [258] \\
\hline & Organ pathology & PrP-SCA7-c92Q, R6/2 & {$[183,258]$} \\
\hline & PolyQ protein aggregates & $\operatorname{Hdh}(\mathrm{CAG}) 150, \mathrm{R} 6 / 2$ & {$[34,349]$} \\
\hline \multirow[t]{3}{*}{ Heart } & Muscle abnormalities & $\mathrm{R} 6 / 2$ & [349] \\
\hline & Organ pathology & BACHD, R6/2, YAC128 & {$[68,87,351]$} \\
\hline & polyQ protein aggregates & AR-97Q, R6/2 & {$[68,212]$} \\
\hline Immune system & Increased level of cytokines & Hdh(CAG)150, R6/2, YAC128 & [269] \\
\hline Inner ear & PolyQ protein aggregates & $\operatorname{Hdh}(\mathrm{CAG}) 150, \mathrm{R} 6 / 2$ & [319] \\
\hline \multirow[t]{2}{*}{ Kidneys } & Organ pathology & Hdh(CAG)150, R6/2, YAC128 & {$[34,87,349]$} \\
\hline & PolyQ protein aggregates & $\operatorname{Hdh}(\mathrm{CAG}) 150, \mathrm{R} 6 / 2$ & {$[34,349]$} \\
\hline \multirow[t]{3}{*}{ Liver } & Metabolism alteration & $\mathrm{R} 6 / 2$ & [308] \\
\hline & Organ pathology & $\mathrm{R} 6 / 2, \mathrm{YAC} 128$ & {$[87,298]$} \\
\hline & PolyQ protein aggregates & AR100, Hdh(CAG)150, R6/2 & {$[34,204,349]$} \\
\hline Lung & Organ pathology & AR239Q & [203] \\
\hline \multirow[t]{4}{*}{ Pancreas } & Hormonal dysregulation & $\mathrm{R} 6 / 2$ & {$[67,272]$} \\
\hline & Organ pathology & N171-82Q-81, R6/1, R6/2 & {$[65,307,325]$} \\
\hline & PolyQ protein aggregates & $\begin{array}{l}\text { AR-97Q, AR239Q, Hdh(CAG)150, } \\
\text { N171-82Q-81, R6/1, R6/2 }\end{array}$ & {$[34,203,212,307,325,349]$} \\
\hline & Diabetes mellitus & $\begin{array}{l}\text { BACHD, Hdh(CAG)150, N171- } \\
\text { 82Q-81, R6/1, R6/2 }\end{array}$ & {$[77,272,302,307,357]$} \\
\hline \multirow[t]{4}{*}{ Peripheral nervous system } & Neuronal morphology alterations & PrP-SCA7-c92Q, R6/2 & {$[183,364]$} \\
\hline & Neuronal loss & PrP-SCA7-c92Q & [183] \\
\hline & PolyQ protein aggregates & PrP-SCA7-c92Q & {$[183]$} \\
\hline & Abnormal myelination & MJD84.2 & [164] \\
\hline \multirow[t]{2}{*}{ Skeletal muscle } & Muscle abnormalities & $\begin{array}{l}\text { AR-97Q, AR100, AR113Q, AR120, } \\
\text { Hdh(CAG)150, HSA-AR-141, } \\
\text { NLS-N171-82Q, R6/1, R6/2 }\end{array}$ & $\begin{array}{l}{[34,204,209,211,212,217,281,} \\
\quad 298,345,346,349]\end{array}$ \\
\hline & PolyQ protein aggregates & $\begin{array}{l}\text { AR-97Q, AR100, AR113Q, } \\
\text { Hdh(CAG)150, HSA-AR-141, R6/2 }\end{array}$ & {$[34,204,208,212,217,349]$} \\
\hline Skin & PolyQ protein aggregates & AR239Q & [203] \\
\hline Spleen & Organ pathology & YAC128 & {$[87]$} \\
\hline Testes & Fertility & AR120, Q71-B, R6/2 & {$[157,211,335]$} \\
\hline
\end{tabular}

of other polyQ disorders is clear regardless of whether a native or non-native (such as $\operatorname{PrP}$ ) promoter is used. The SCA3 MJD84.2 and DRPLA Q129 models with native promoters present broader spectrum of brain regions involved. The MJD84.2 reveals neuropathology in the cerebral cortex, pons, midbrain, and cerebellum that resembles the human pathology. The neuropathology map of PrP models (Fig. 4) depicts the involvement of striatum in PrP mouse models of SCA3. The neuropathology in this brain region has also been observed in patients [263-265]. The DRPLA Q129 model exhibits neuropathology in the cerebral cortex, pallidum, hippocampus, medulla oblongata, and cerebellum; this pattern of neuropathology is unique and is not present in other disorders and models (Fig. 2). The SCA1 154Q and SCA7 266Q models show the involvement of both the cerebellum and the hippocampus (Fig. 3), and this hippocampal neuropathology is also mapped in several HD models (Fig. 2).

Because HD is modeled in mice so extensively, we also asked how the HD mouse models compare to the human pathology. The use of MRI [266, 267] to image and investigate inflammatory processes in HD brains [268] demonstrates that the disease affects nearly the entire brain in patient. The 
specific brain regions that are affected comprise many lobes of the cerebral cortex, the caudate, putamen, globus pallidus, red nucleus, substantia nigra, thalamus, hippocampus, amygdala, brain stem, and cerebellum. Many of these brain regions are equivalent to sites of neuropathology in HD models. The models also show polyQ aggregates and brain morphology alterations that are detected in an even broader spectrum of regions and tissues. Taken together, the coverage of HD in mouse brain regions nicely matches the coverage in the human brain.

Furthermore, our data table shows that defects in the brain and the CNS do not necessarily result in the most severe phenotypes (such as a shortened lifespan). For example, mouse models with mutant polyQ expression that is selectively localized to the PCs or the striatum do not have life-threatening phenotypes. Instead, the data table shows that there are many phenotypes that are characteristic for other organs and tissues outside of the brain or the CNS. Table 6 demonstrates that NIIs are present in the vast majority of non-CNS tissues, such as the endocrine tissues (e.g., pancreas, adrenal glands, and testes), skeletal muscle, heart, lungs, liver, kidneys, skin, stomach, and duodenum. Although it is presently unclear whether these NIIs contribute to the pathogenesis, they are certainly a sign of that the disease is present in tissues other than the CNS.

We also retrieved data regarding non-CNS phenotypes other than NIIs that are present in the polyQ mouse models (Table 6). A detailed list of non-CNS phenotypes is provided in the data table and includes changes in organs such as the heart, kidneys, liver, pancreas, spleen, stomach, testes, bones, pituitary gland, skeletal muscle, epididymis, brown fat, adrenal glands, and peripheral nervous system. This list clearly indicates that many organs and systems are affected in polyQ diseases. The majority of non-CNS organs and tissues that exhibit pathology show, e.g., organ enlargement, altered morphology, muscle abnormalities, and many other features. This finding may indicate that the most severe phenotypes that lead to the deaths of these transgenic model animals are located outside of the brain and CNS. One exciting finding is the demonstration of immune system involvement in mouse models of HD [269]. The R6/2, $\operatorname{Hdh}(\mathrm{CAG}) 150$, and YAC128 model animals show increased levels of serum IL-6 and other cytokines, along with excessive activation of stimulated monocytes, macrophages, and microglia [270]. Similar findings on the contribution of immune system were confirmed in HD patients [270]. Another issue is that the dysfunction of neurons that are located outside of the brain or the CNS may lead to extremely severe phenotypes. Gastrointestinal abnormalities in the PrP-SCA7-c92Q mouse are related to the degeneration of enteric neurons and may contribute to decreased lifespan in this model [183]. Another example is the SCA1 154Q knock-in mouse, which has breath-control abnormalities that probably lead to death [149], and this phenotype may well be related to defects in neurons that are not directly located in the brain but in the nuclei of the medulla.

Therefore, we should not ask "Why the brain?" or "Why the CNS?" Rather, we should analyze the broader context of polyQ disorders, wherein pathogenesis may be located throughout the organs and tissues of the entire body. Therefore, we should ask, "Which tissues and why these tissues?," "Why neurons and why these particular neurons?," and "Why neurons outside the CNS?"

The references used to construct the data table I that are not directly cited in the publication text are [271-373].

Acknowledgments This work was supported by the European Regional Development Fund within the Innovative Economy Programme (grant numbers POIG.01.03.01-30-049/09 and POIG.01.03.01-30-098/ 08 ) and the grant of Polish Ministry of Science and Higher Education (grant number N N302 299536).

Open Access This article is distributed under the terms of the Creative Commons Attribution License which permits any use, distribution, and reproduction in any medium, provided the original author(s) and the source are credited.

\section{References}

1. The Huntington's Disease Collaborative Research Group (1993) A novel gene containing a trinucleotide repeat that is expanded and unstable on Huntington's disease chromosomes. Cell 72(6):971-983

2. Fischbeck KH, Souders D, La Spada A (1991) A candidate gene for X-linked spinal muscular atrophy. Adv Neurol 56:209-213

3. La Spada AR, Wilson EM, Lubahn DB, Harding AE, Fischbeck KH (1991) Androgen receptor gene mutations in X-linked spinal and bulbar muscular atrophy. Nature 352(6330):77-79

4. Orr HT, Chung MY, Banfi S, Kwiatkowski TJ Jr, Servadio A, Beaudet AL, McCall AE, Duvick LA, Ranum LP, Zoghbi HY (1993) Expansion of an unstable trinucleotide CAG repeat in spinocerebellar ataxia type 1 . Nat Genet 4(3):221-226

5. Pulst SM, Nechiporuk A, Nechiporuk T et al (1996) Moderate expansion of a normally biallelic trinucleotide repeat in spinocerebellar ataxia type 2. Nat Genet 14(3):269-276

6. Kawaguchi Y, Okamoto T, Taniwaki M, Aizawa M, Inoue M, Katayama S, Kawakami H, Nakamura S, Nishimura M, Akiguchi I (1994) CAG expansions in a novel gene for Machado-Joseph disease at chromosome 14q32.1. Nat Genet 8(3):221-228

7. Zhuchenko O, Bailey J, Bonnen P, Ashizawa T, Stockton DW, Amos C, Dobyns WB, Subramony SH, Zoghbi HY, Lee CC (1997) Autosomal dominant cerebellar ataxia (SCA6) associated with small polyglutamine expansions in the alpha 1A-voltagedependent calcium channel. Nat Genet 15(1):62-69

8. Lindblad K, Savontaus ML, Stevanin G et al (1996) An expanded CAG repeat sequence in spinocerebellar ataxia type 7. Genome Res 6(10):965-971

9. Koide R, Kobayashi S, Shimohata T, Ikeuchi T, Maruyama M, Saito M, Yamada M, Takahashi H, Tsuji S (1999) A neurological disease caused by an expanded CAG trinucleotide repeat in the TATA-binding protein gene: a new polyglutamine disease? Hum Mol Genet 8(11):2047-2053

10. Nakamura K, Jeong SY, Uchihara T, Anno M, Nagashima K, Nagashima T, Ikeda S, Tsuji S, Kanazawa I (2001) SCA17, a 
novel autosomal dominant cerebellar ataxia caused by an expanded polyglutamine in TATA-binding protein. Hum Mol Genet 10 (14): $1441-1448$

11. Koide R, Ikeuchi T, Onodera O, Tanaka H, Igarashi S, Endo K, Takahashi H, Kondo R, Ishikawa A, Hayashi T (1994) Unstable expansion of CAG repeat in hereditary dentatorubralpallidoluysian atrophy (DRPLA). Nat Genet 6(1):9-13

12. Nagafuchi S, Yanagisawa H, Sato K, Shirayama T, Ohsaki E, Bundo M, Takeda T, Tadokoro K, Kondo I, Murayama N (1994) Dentatorubral and pallidoluysian atrophy expansion of an unstable CAG trinucleotide on chromosome 12p. Nat Genet 6(1):14-18

13. Orr HT, Zoghbi HY (2007) Trinucleotide repeat disorders. Annu Rev Neurosci 30:575-621

14. Burright EN, Clark HB, Servadio A, Matilla T, Feddersen RM, Yunis WS, Duvick LA, Zoghbi HY, Orr HT (1995) SCA1 transgenic mice: a model for neurodegeneration caused by an expanded CAG trinucleotide repeat. Cell 82(6):937-948

15. Crook ZR, Housman D (2011) Huntington's disease: can mice lead the way to treatment? Neuron 69(3):423-435

16. Saegusa H, Wakamori M, Matsuda Y, Wang J, Mori Y, Zong S, Tanabe T (2007) Properties of human Cav2.1 channel with a spinocerebellar ataxia type 6 mutation expressed in Purkinje cells. Mol Cell Neurosci 34(2):261-270

17. Watase K, Barrett CF, Miyazaki T et al (2008) Spinocerebellar ataxia type 6 knockin mice develop a progressive neuronal dysfunction with age-dependent accumulation of mutant CaV2.1 channels. Proc Natl Acad Sci USA 105(33):11987-11992

18. Grubb SC, Maddatu TP, Bult CJ, Bogue MA (2009) Mouse phenome database. Nucleic Acids Res 37(Database issue): D720-D730

19. Mangiarini L, Sathasivam K, Seller M et al (1996) Exon 1 of the HD gene with an expanded CAG repeat is sufficient to cause a progressive neurological phenotype in transgenic mice. Cell 87(3):493-506

20. Slow EJ, Graham RK, Osmand AP et al (2005) Absence of behavioral abnormalities and neurodegeneration in vivo despite widespread neuronal huntingtin inclusions. Proc Natl Acad Sci USA 102(32):11402-11407

21. Schilling G, Becher MW, Sharp AH et al (1999) Intranuclear inclusions and neuritic aggregates in transgenic mice expressing a mutant $\mathrm{N}$-terminal fragment of huntingtin. Hum Mol Genet 8 (3):397-407

22. Schilling G, Savonenko AV, Klevytska A et al (2004) Nucleartargeting of mutant huntingtin fragments produces Huntington's disease-like phenotypes in transgenic mice. Hum Mol Genet 13 (15): 1599-1610

23. Brown TB, Bogush AI, Ehrlich ME (2008) Neocortical expression of mutant huntingtin is not required for alterations in striatal gene expression or motor dysfunction in a transgenic mouse. Hum Mol Genet 17(20):3095-3104

24. Tebbenkamp ATN, Swing D, Tessarollo L, Borchelt DR (2011) Premature death and neurologic abnormalities in transgenic mice expressing a mutant huntingtin exon-2 fragment. Hum Mol Genet 20(8):1633-1642

25. Reddy PH, Williams M, Charles V, Garrett L, Pike-Buchanan L, Whetsell WO Jr, Miller G, Tagle DA (1998) Behavioural abnormalities and selective neuronal loss in HD transgenic mice expressing mutated full-length HD cDNA. Nat Genet 20(2):198-202

26. Graham RK, Deng Y, Slow EJ et al (2006) Cleavage at the caspase- 6 site is required for neuronal dysfunction and degeneration due to mutant huntingtin. Cell 125(6):1179-1191

27. Gray M, Shirasaki DI, Cepeda C et al (2008) Full-length human mutant huntingtin with a stable polyglutamine repeat can elicit progressive and selective neuropathogenesis in BACHD mice. J Neurosci 28(24):6182-6195

28. Hodgson JG, Smith DJ, McCutcheon K et al (1996) Human huntingtin derived from YAC transgenes compensates for loss of murine huntingtin by rescue of the embryonic lethal phenotype. Hum Mol Genet 5(12):1875-1885

29. Hodgson JG, Agopyan N, Gutekunst CA et al (1999) A YAC mouse model for Huntington's disease with full-length mutant huntingtin, cytoplasmic toxicity, and selective striatal neurodegeneration. Neuron 23(1):181-192

30. Slow EJ, van Raamsdonk J, Rogers D et al (2003) Selective striatal neuronal loss in a YAC128 mouse model of Huntington disease. Hum Mol Genet 12(13):1555-1567

31. Lin CH, Tallaksen-Greene S, Chien WM, Cearley JA, Jackson WS, Crouse AB, Ren S, Li XJ, Albin RL, Detloff PJ (2001) Neurological abnormalities in a knock-in mouse model of Huntington's disease. Hum Mol Genet 10(2):137-144

32. Wheeler VC, Gutekunst C-A, Vrbanac V et al (2002) Early phenotypes that presage late-onset neurodegenerative disease allow testing of modifiers in Hdh CAG knock-in mice. Hum Mol Genet 11(6):633-640

33. Menalled LB, Sison JD, Dragatsis I, Zeitlin S, Chesselet M-F (2003) Time course of early motor and neuropathological anomalies in a knock-in mouse model of Huntington's disease with 140 CAG repeats. J Comp Neurol 465(1):11-26

34. Moffitt H, McPhail GD, Woodman B, Hobbs C, Bates GP (2009) Formation of polyglutamine inclusions in a wide range of nonCNS tissues in the HdhQ150 knock-in mouse model of Huntington's disease. PLoS One 4(11):e8025

35. Yamamoto A, Lucas JJ, Hen R (2000) Reversal of neuropathology and motor dysfunction in a conditional model of Huntington's disease. Cell 101(1):57-66

36. Gu X, Li C, Wei W et al (2005) Pathological cell-cell interactions elicited by a neuropathogenic form of mutant Huntingtin contribute to cortical pathogenesis in HD mice. Neuron 46(3):433-444

37. Tanaka Y, Igarashi S, Nakamura M et al (2006) Progressive phenotype and nuclear accumulation of an amino-terminal cleavage fragment in a transgenic mouse model with inducible expression of full-length mutant huntingtin. Neurobiol Dis 21(2):381391

38. Morton AJ, Glynn D, Leavens W, Zheng Z, Faull RLM, Skepper JN, Wight JM (2009) Paradoxical delay in the onset of disease caused by super-long CAG repeat expansions in R6/2 mice. Neurobiol Dis 33(3):331-341

39. Dragatsis I, Goldowitz D, Del Mar N, Deng YP, Meade CA, Liu L, Sun Z, Dietrich P, Yue J, Reiner A (2009) CAG repeat lengths $>$ or $=335$ attenuate the phenotype in the R6/2 Huntington's disease transgenic mouse. Neurobiol Dis 33(3):315-330

40. Gil JM, Rego AC (2009) The R6 lines of transgenic mice: a model for screening new therapies for Huntington's disease. Brain Res Rev 59(2):410-431

41. Brooks SP, Janghra N, Workman VL, Bayram-Weston Z, Jones L, Dunnett SB (2012) Longitudinal analysis of the behavioural phenotype in R6/1 (C57BL/6J) Huntington's disease transgenic mice. Brain Res Bull 88(2-3):94-103

42. Carter RJ, Lione LA, Humby T, Mangiarini L, Mahal A, Bates GP, Dunnett SB, Morton AJ (1999) Characterization of progressive motor deficits in mice transgenic for the human Huntington's disease mutation. J Neurosci 19(8):3248-3257

43. Hickey MA, Gallant K, Gross GG, Levine MS, Chesselet M-F (2005) Early behavioral deficits in R6/2 mice suitable for use in preclinical drug testing. Neurobiol Dis 20(1):1-11

44. Stack EC, Kubilus JK, Smith K, Cormier K, Del Signore SJ, Guelin E, Ryu H, Hersch SM, Ferrante RJ (2005) Chronology of behavioral symptoms and neuropathological sequela in R6/2 Huntington's disease transgenic mice. J Comp Neurol 490 (4):354-370

45. Menalled L, El-Khodor BF, Patry M et al (2009) Systematic behavioral evaluation of Huntington's disease transgenic and knock-in mouse models. Neurobiol Dis 35(3):319-336 
46. Lione LA, Carter RJ, Hunt MJ, Bates GP, Morton AJ, Dunnett SB (1999) Selective discrimination learning impairments in mice expressing the human Huntington's disease mutation. J Neurosci 19(23):10428-10437

47. Bolivar VJ, Manley K, Messer A (2003) Exploratory activity and fear conditioning abnormalities develop early in R6/2 Huntington's disease transgenic mice. Behav Neurosci 117 (6): 1233-1242

48. Morton AJ, Skillings E, Bussey TJ, Saksida LM (2006) Measuring cognitive deficits in disabled mice using an automated interactive touchscreen system. Nat Methods 3(10):767

49. Ciamei A, Morton AJ (2008) Rigidity in social and emotional memory in the R6/2 mouse model of Huntington's disease. Neurobiol Learn Mem 89(4):533-544

50. Ciamei A, Morton AJ (2009) Progressive imbalance in the interaction between spatial and procedural memory systems in the R6/ 2 mouse model of Huntington's disease. Neurobiol Learn Mem 92(3):417-428

51. Turmaine M, Raza A, Mahal A, Mangiarini L, Bates GP, Davies SW (2000) Nonapoptotic neurodegeneration in a transgenic mouse model of Huntington's disease. Proc Natl Acad Sci USA 97(14):8093-8097

52. Yu Z-X, Li S-H, Evans J, Pillarisetti A, Li H, Li X-J (2003) Mutant huntingtin causes context-dependent neurodegeneration in mice with Huntington's disease. J Neurosci 23(6):2193-2202

53. Klapstein GJ, Fisher RS, Zanjani H, Cepeda C, Jokel ES, Chesselet MF, Levine MS (2001) Electrophysiological and morphological changes in striatal spiny neurons in R6/2 Huntington's disease transgenic mice. J Neurophysiol 86(6):2667-2677

54. Cepeda C, Hurst RS, Calvert CR, Hernández-Echeagaray E, Nguyen OK, Jocoy E, Christian LJ, Ariano MA, Levine MS (2003) Transient and progressive electrophysiological alterations in the corticostriatal pathway in a mouse model of Huntington's disease. J Neurosci 23(3):961-969

55. Starling AJ, André VM, Cepeda C, de Lima M, Chandler SH, Levine MS (2005) Alterations in N-methyl-D-aspartate receptor sensitivity and magnesium blockade occur early in development in the R6/2 mouse model of Huntington's disease. J Neurosci Res 82(3):377-386

56. Davies SW, Turmaine M, Cozens BA, DiFiglia M, Sharp AH, Ross CA, Scherzinger E, Wanker EE, Mangiarini L, Bates GP (1997) Formation of neuronal intranuclear inclusions underlies the neurological dysfunction in mice transgenic for the $\mathrm{HD} \mathrm{mu-}$ tation. Cell 90(3):537-548

57. Meade CA, Deng Y-P, Fusco FR, Del Mar N, Hersch S, Goldowitz D, Reiner A (2002) Cellular localization and development of neuronal intranuclear inclusions in striatal and cortical neurons in R6/2 transgenic mice. J Comp Neurol 449(3):241-269

58. Woodman B, Butler R, Landles C, Lupton MK, Tse J, Hockly E, Moffitt H, Sathasivam K, Bates GP (2007) The Hdh(Q150/Q150) knock-in mouse model of HD and the R6/2 exon 1 model develop comparable and widespread molecular phenotypes. Brain Res Bull 72(2-3):83-97

59. Ferrante RJ, Andreassen OA, Jenkins BG, Dedeoglu A, Kuemmerle S, Kubilus JK, Kaddurah-Daouk R, Hersch SM, Beal MF (2000) Neuroprotective effects of creatine in a transgenic mouse model of Huntington's disease. J Neurosci 20 (12):4389-4397

60. Zhang J, Peng Q, Li Q et al (2010) Longitudinal characterization of brain atrophy of a Huntington's disease mouse model by automated morphological analyses of magnetic resonance images. Neuroimage 49(3):2340-2351

61. Sun Z, Del Mar N, Meade C, Goldowitz D, Reiner A (2002) Differential changes in striatal projection neurons in R6/2 transgenic mice for Huntington's disease. Neurobiol Dis 11(3):369 385
62. Giampà C, Laurenti D, Anzilotti S, Bernardi G, Menniti FS, Fusco FR (2010) Inhibition of the striatal specific phosphodiesterase PDE10A ameliorates striatal and cortical pathology in R6/2 mouse model of Huntington's disease. PLoS One 5(10):e13417

63. Helmlinger D, Yvert G, Picaud S, Merienne K, Sahel J, Mandel JL, Devys D (2002) Progressive retinal degeneration and dysfunction in R6 Huntington's disease mice. Hum Mol Genet 11 (26):3351-3359

64. Hurlbert MS, Zhou W, Wasmeier C, Kaddis FG, Hutton JC, Freed CR (1999) Mice transgenic for an expanded CAG repeat in the Huntington's disease gene develop diabetes. Diabetes 48(3):649651

65. Björkqvist M, Fex M, Renström E et al (2005) The R6/2 transgenic mouse model of Huntington's disease develops diabetes due to deficient beta-cell mass and exocytosis. Hum Mol Genet 14(5):565-574

66. Lüesse HG, Schiefer J, Spruenken A, Puls C, Block F, Kosinski CM (2001) Evaluation of R6/2 HD transgenic mice for therapeutic studies in Huntington's disease: behavioral testing and impact of diabetes mellitus. Behav Brain Res 126(1-2):185-195

67. Björkqvist M, Petersén A, Bacos K et al (2006) Progressive alterations in the hypothalamic-pituitary-adrenal axis in the R6/ 2 transgenic mouse model of Huntington's disease. Hum Mol Genet 15(10):1713-1721

68. Mihm MJ, Amann DM, Schanbacher BL, Altschuld RA, Bauer JA, Hoyt KR (2007) Cardiac dysfunction in the R6/2 mouse model of Huntington's disease. Neurobiol Dis 25(2):297-308

69. Morton AJ, Wood NI, Hastings MH, Hurelbrink C, Barker RA, Maywood ES (2005) Disintegration of the sleep-wake cycle and circadian timing in Huntington's disease. J Neurosci 25(1):157163

70. Kudo T, Schroeder A, Loh DH, Kuljis D, Jordan MC, Roos KP, Colwell CS (2011) Dysfunctions in circadian behavior and physiology in mouse models of Huntington's disease. Exp Neurol 228 (1):80-90

71. Wang C-E, Tydlacka S, Orr AL, Yang S-H, Graham RK, Hayden MR, Li S, Chan AWS, Li X-J (2008) Accumulation of N-terminal mutant huntingtin in mouse and monkey models implicated as a pathogenic mechanism in Huntington's disease. Hum Mol Genet 17(17):2738-2751

72. Norflus F, Nanje A, Gutekunst C-A, Shi G, Cohen J, Bejarano M, Fox J, Ferrante RJ, Hersch SM (2004) Anti-inflammatory treatment with acetylsalicylate or rofecoxib is not neuroprotective in Huntington's disease transgenic mice. Neurobiol Dis 17(2):319325

73. Klivenyi P, Bende Z, Hartai Z, Penke Z, Nemeth H, Toldi J, Vecsei L (2006) Behaviour changes in a transgenic model of Huntington's disease. Behav Brain Res 169(1):137-141

74. Southwell AL, Ko J, Patterson PH (2009) Intrabody gene therapy ameliorates motor, cognitive, and neuropathological symptoms in multiple mouse models of Huntington's disease. J Neurosci 29 (43): 13589-13602

75. Schilling G, Coonfield ML, Ross CA, Borchelt DR (2001) Coenzyme Q10 and remacemide hydrochloride ameliorate motor deficits in a Huntington's disease transgenic mouse model. Neurosci Lett 315(3):149-153

76. Li H, Wyman T, Yu Z-X, Li S-H, Li X-J (2003) Abnormal association of mutant huntingtin with synaptic vesicles inhibits glutamate release. Hum Mol Genet 12(16):2021-2030

77. Duan W, Guo Z, Jiang H, Ware M, Li X-J, Mattson MP (2003) Dietary restriction normalizes glucose metabolism and BDNF levels, slows disease progression, and increases survival in huntingtin mutant mice. Proc Natl Acad Sci USA 100(5):2911-2916

78. Stack C, Ho D, Wille E, Calingasan NY, Williams C, Liby K, Sporn M, Dumont M, Beal MF (2010) Triterpenoids CDDOethyl amide and CDDO-trifluoroethyl amide improve the 
behavioral phenotype and brain pathology in a transgenic mouse model of Huntington's disease. Free Radic Biol Med 49(2):147158

79. Cheng Y, Peng Q, Hou Z, Aggarwal M, Zhang J, Mori S, Ross CA, Duan W (2011) Structural MRI detects progressive regional brain atrophy and neuroprotective effects in N171-82Q Huntington's disease mouse model. Neuroimage 56(3):10271034

80. Mughal MR, Baharani A, Chigurupati S, Son TG, Chen E, Yang P, Okun E, Arumugam T, Chan SL, Mattson MP (2011) Electroconvulsive shock ameliorates disease processes and extends survival in huntingtin mutant mice. Hum Mol Genet 20 (4):659-669

81. Vamos E, Voros K, Zadori D, Vecsei L, Klivenyi P (2009) Neuroprotective effects of probenecid in a transgenic animal model of Huntington's disease. J Neural Transm 116(9):10791086

82. Panov AV, Gutekunst C-A, Leavitt BR, Hayden MR, Burke JR, Strittmatter WJ, Greenamyre JT (2002) Early mitochondrial calcium defects in Huntington's disease are a direct effect of polyglutamines. Nat Neurosci 5(8):731-736

83. Zeron MM, Hansson O, Chen N, Wellington CL, Leavitt BR, Brundin P, Hayden MR, Raymond LA (2002) Increased sensitivity to N-methyl-D-aspartate receptor-mediated excitotoxicity in a mouse model of Huntington's disease. Neuron 33(6):849-860

84. Li L, Murphy TH, Hayden MR, Raymond LA (2004) Enhanced striatal NR2B-containing N-methyl-D-aspartate receptormediated synaptic currents in a mouse model of Huntington disease. J Neurophysiol 92(5):2738-2746

85. Van Raamsdonk JM, Warby SC, Hayden MR (2007) Selective degeneration in YAC mouse models of Huntington disease. Brain Res Bull 72(2-3):124-131

86. Van Raamsdonk JM, Murphy Z, Slow EJ, Leavitt BR, Hayden MR (2005) Selective degeneration and nuclear localization of mutant huntingtin in the YAC128 mouse model of Huntington disease. Hum Mol Genet 14(24):3823-3835

87. Van Raamsdonk JM, Gibson WT, Pearson J, Murphy Z, Lu G, Leavitt BR, Hayden MR (2006) Body weight is modulated by levels of full-length huntingtin. Hum Mol Genet 15(9):15131523

88. Van Raamsdonk JM, Pearson J, Slow EJ, Hossain SM, Leavitt BR, Hayden MR (2005) Cognitive dysfunction precedes neuropathology and motor abnormalities in the YAC128 mouse model of Huntington's disease. J Neurosci 25(16):4169-4180

89. Brooks SP, Higgs G, Janghra N, Jones L, Dunnett SB (2012) Longitudinal analysis of the behavioural phenotype in YAC128 (C57BL/6 J) Huntington's disease transgenic mice. Brain Res Bull 88(2-3):113-120

90. Brooks SP, Janghra N, Higgs GV, Bayram-Weston Z, Heuer A, Jones L, Dunnett SB (2012) Selective cognitive impairment in the YAC128 Huntington's disease mouse. Brain Res Bull 88(23):121-129

91. Brooks SP, Jones L, Dunnett SB (2012) Longitudinal analyses of operant performance on the serial implicit learning task (SILT) in the YAC128 Huntington's disease mouse line. Brain Res Bull 88 (2-3):130-136

92. Lerch JP, Carroll JB, Spring S, Bertram LN, Schwab C, Hayden MR, Henkelman RM (2008) Automated deformation analysis in the YAC128 Huntington disease mouse model. Neuroimage 39 (1):32-39

93. Van Raamsdonk JM, Metzler M, Slow E, Pearson J, Schwab C, Carroll J, Graham RK, Leavitt BR, Hayden MR (2007) Phenotypic abnormalities in the YAC128 mouse model of Huntington disease are penetrant on multiple genetic backgrounds and modulated by strain. Neurobiol Dis 26(1):189200
94. Bayram-Weston Z, Jones L, Dunnett SB, Brooks SP (2012) Light and electron microscopic characterization of the evolution of cellular pathology in YAC128 Huntington's disease transgenic mice. Brain Res Bull 88(2-3):137-147

95. Graham RK, Pouladi MA, Joshi P et al (2009) Differential susceptibility to excitotoxic stress in YAC128 mouse models of Huntington disease between initiation and progression of disease. J Neurosci 29(7):2193-2204

96. Hansson O, Petersén A, Leist M, Nicotera P, Castilho RF, Brundin P (1999) Transgenic mice expressing a Huntington's disease mutation are resistant to quinolinic acid-induced striatal excitotoxicity. Proc Natl Acad Sci USA 96(15):8727-8732

97. Hansson O, Guatteo E, Mercuri NB, Bernardi G, Li XJ, Castilho RF, Brundin P (2001) Resistance to NMDA toxicity correlates with appearance of nuclear inclusions, behavioural deficits and changes in calcium homeostasis in mice transgenic for exon 1 of the huntington gene. Eur J Neurosci 14(9):1492-1504

98. Jarabek BR, Yasuda RP, Wolfe BB (2004) Regulation of proteins affecting NMDA receptor-induced excitotoxicity in a Huntington's mouse model. Brain 127(Pt 3):505-516

99. Petersén A, Hansson O, Puschban Z et al (2001) Mice transgenic for exon 1 of the Huntington's disease gene display reduced striatal sensitivity to neurotoxicity induced by dopamine and 6 hydroxydopamine. Eur J Neurosci 14(9):1425-1435

100. Petersén A, Puschban Z, Lotharius J, NicNiocaill B, Wiekop P, O'Connor WT, Brundin P (2002) Evidence for dysfunction of the nigrostriatal pathway in the R6/1 line of transgenic Huntington's disease mice. Neurobiol Dis 11(1):134-146

101. Cepeda C, Wu N, André VM, Cummings DM, Levine MS (2007) The corticostriatal pathway in Huntington's disease. Prog Neurobiol 81(5-6):253-271

102. Cummings DM, André VM, Uzgil BO, Gee SM, Fisher YE, Cepeda C, Levine MS (2009) Alterations in cortical excitation and inhibition in genetic mouse models of Huntington's disease. J Neurosci 29(33):10371-10386

103. Cummings DM, Cepeda C, Levine MS (2010) Alterations in striatal synaptic transmission are consistent across genetic mouse models of Huntington's disease. ASN Neuro 2(3):e00036

104. Joshi PR, Wu N-P, André VM et al (2009) Age-dependent alterations of corticostriatal activity in the YAC128 mouse model of Huntington disease. J Neurosci 29(8):2414-2427

105. André VM, Cepeda C, Levine MS (2010) Dopamine and glutamate in Huntington's disease: a balancing act. CNS Neurosci Ther 16(3):163-178

106. Milnerwood AJ, Gladding CM, Pouladi MA et al (2010) Early increase in extrasynaptic NMDA receptor signaling and expression contributes to phenotype onset in Huntington's disease mice. Neuron 65(2): 178-190

107. Shehadeh J, Fernandes HB, Zeron Mullins MM, Graham RK, Leavitt BR, Hayden MR, Raymond LA (2006) Striatal neuronal apoptosis is preferentially enhanced by NMDA receptor activation in YAC transgenic mouse model of Huntington disease. Neurobiol Dis 21(2):392-403

108. White JK, Auerbach W, Duyao MP, Vonsattel JP, Gusella JF, Joyner AL, MacDonald ME (1997) Huntingtin is required for neurogenesis and is not impaired by the Huntington's disease CAG expansion. Nat Genet 17(4):404-410

109. Wheeler VC, Auerbach W, White JK et al (1999) Lengthdependent gametic CAG repeat instability in the Huntington's disease knock-in mouse. Hum Mol Genet 8(1):115-122

110. Trueman RC, Brooks SP, Jones L, Dunnett SB (2009) Rule learning, visuospatial function and motor performance in the Hdh(Q92) knock-in mouse model of Huntington's disease. Behav Brain Res 203(2):215-222

111. Brooks SP, Higgs G, Jones L, Dunnett SB (2012) Longitudinal analysis of the behavioural phenotype in Hdh 
(Q92) Huntington's disease knock-in mice. Brain Res Bull 88(2-3):148-155

112. Brustovetsky N, LaFrance R, Purl KJ, Brustovetsky T, Keene CD, Low WC, Dubinsky JM (2005) Age-dependent changes in the calcium sensitivity of striatal mitochondria in mouse models of Huntington's disease. J Neurochem 93(6):1361-1370

113. Trueman RC, Brooks SP, Jones L, Dunnett SB (2007) The operant serial implicit learning task reveals early onset motor learning deficits in the Hdh knock-in mouse model of Huntington's disease. Eur J Neurosci 25(2):551-558

114. Trueman RC, Brooks SP, Jones L, Dunnett SB (2008) Time course of choice reaction time deficits in the Hdh(Q92) knockin mouse model of Huntington's disease in the operant serial implicit learning task (SILT). Behav Brain Res 189(2):317-324

115. Trueman RC, Dunnett SB, Jones L, Brooks SP (2012) Five choice serial reaction time performance in the $\operatorname{Hdh}(\mathrm{Q} 92)$ mouse model of Huntington's disease. Brain Res Bull 88(2-3):163-170

116. Trueman RC, Jones L, Dunnett SB, Brooks SP (2012) Early onset deficits on the delayed alternation task in the Hdh(Q92) knock-in mouse model of Huntington's disease. Brain Res Bull 88(23):156-162

117. Wheeler VC, White JK, Gutekunst CA et al (2000) Long glutamine tracts cause nuclear localization of a novel form of huntingtin in medium spiny striatal neurons in HdhQ92 and HdhQ111 knock-in mice. Hum Mol Genet 9(4):503-513

118. Bayram-Weston Z, Jones L, Dunnett SB, Brooks SP (2012) Light and electron microscopic characterization of the evolution of cellular pathology in Hdh(Q92) Huntington's disease knock-in mice. Brain Res Bull 88(2-3):171-181

119. Levine MS, Klapstein GJ, Koppel A et al (1999) Enhanced sensitivity to N-methyl-D-aspartate receptor activation in transgenic and knockin mouse models of Huntington's disease. J Neurosci Res 58(4):515-532

120. Menalled LB, Sison JD, Wu Y, Olivieri M, Li X-J, Li H, Zeitlin S, Chesselet M-F (2002) Early motor dysfunction and striosomal distribution of huntingtin microaggregates in Huntington's disease knock-in mice. J Neurosci 22(18):8266-8276

121. Dorner JL, Miller BR, Barton SJ, Brock TJ, Rebec GV (2007) Sex differences in behavior and striatal ascorbate release in the 140 CAG knock-in mouse model of Huntington's disease. Behav Brain Res 178(1):90-97

122. Hickey MA, Kosmalska A, Enayati J, Cohen R, Zeitlin S, Levine MS, Chesselet M-F (2008) Extensive early motor and non-motor behavioral deficits are followed by striatal neuronal loss in knock-in Huntington's disease mice. Neuroscience 157(1):280-295

123. Rising AC, Xu J, Carlson A, Napoli VV, Denovan-Wright EM, Mandel RJ (2011) Longitudinal behavioral, cross-sectional transcriptional and histopathological characterization of a knock-in mouse model of Huntington's disease with 140 CAG repeats. Exp Neurol 228(2):173-182

124. Heng MY, Tallaksen-Greene SJ, Detloff PJ, Albin RL (2007) Longitudinal evaluation of the $\mathrm{Hdh}(\mathrm{CAG}) 150$ knock-in murine model of Huntington's disease. J Neurosci 27(34):8989-8998

125. Brooks SP, Betteridge H, Trueman RC, Jones L, Dunnett SB (2006) Selective extra-dimensional set shifting deficit in a knock-in mouse model of Huntington's disease. Brain Res Bull 69(4):452-457

126. Brooks SP, Higgs G, Jones L, Dunnett SB (2012) Longitudinal analysis of the behavioural phenotype in $\mathrm{Hdh}((\mathrm{CAG}) 150)$ Huntington's disease knock-in mice. Brain Res Bull 88(23): $182-188$

127. Bayram-Weston Z, Torres EM, Jones L, Dunnett SB, Brooks SP (2012) Light and electron microscopic characterization of the evolution of cellular pathology in the $\mathrm{Hdh}((\mathrm{CAG}) 150)$ Huntington's disease knock-in mouse. Brain Res Bull 88(23):189-198
128. Heng MY, Duong DK, Albin RL, Tallaksen-Greene SJ, Hunter JM, Lesort MJ, Osmand A, Paulson HL, Detloff PJ (2010) Early autophagic response in a novel knock-in model of Huntington disease. Hum Mol Genet 19(19):3702-3720

129. Spampanato J, Gu X, Yang XW, Mody I (2008) Progressive synaptic pathology of motor cortical neurons in a BAC transgenic mouse model of Huntington's disease. Neuroscience 157(3):606620

130. André VM, Fisher YE, Levine MS (2011) Altered balance of activity in the striatal direct and indirect pathways in mouse models of Huntington's disease. Front Syst Neurosci 5:46

131. Clark HB, Burright EN, Yunis WS, Larson S, Wilcox C, Hartman B, Matilla A, Zoghbi HY, Orr HT (1997) Purkinje cell expression of a mutant allele of SCA1 in transgenic mice leads to disparate effects on motor behaviors, followed by a progressive cerebellar dysfunction and histological alterations. J Neurosci 17(19):73857395

132. Inoue T, Lin X, Kohlmeier KA, Orr HT, Zoghbi HY, Ross WN (2001) Calcium dynamics and electrophysiological properties of cerebellar Purkinje cells in SCA1 transgenic mice. J Neurophysiol 85(4):1750-1760

133. Barnes JA, Ebner BA, Duvick LA, Gao W, Chen G, Orr HT, Ebner TJ (2011) Abnormalities in the climbing fiber-Purkinje cell circuitry contribute to neuronal dysfunction in ATXN1[82Q] mice. J Neurosci 31(36):12778-12789

134. Skinner PJ, Koshy BT, Cummings CJ, Klement IA, Helin K, Servadio A, Zoghbi HY, Orr HT (1997) Ataxin-1 with an expanded glutamine tract alters nuclear matrix-associated structures. Nature 389(6654):971-974

135. Lin X, Antalffy B, Kang D, Orr HT, Zoghbi HY (2000) Polyglutamine expansion down-regulates specific neuronal genes before pathologic changes in SCA1. Nat Neurosci 3(2):157-163

136. Serra HG, Byam CE, Lande JD, Tousey SK, Zoghbi HY, Orr HT (2004) Gene profiling links SCA1 pathophysiology to glutamate signaling in Purkinje cells of transgenic mice. Hum Mol Genet 13 (20):2535-2543

137. Oz G, Nelson CD, Koski DM, Henry P-G, Marjanska M, Deelchand DK, Shanley R, Eberly LE, Orr HT, Clark HB (2010) Noninvasive detection of presymptomatic and progressive neurodegeneration in a mouse model of spinocerebellar ataxia type 1. J Neurosci 30(10):3831-3838

138. Duvick L, Barnes J, Ebner B, Agrawal S, Andresen M, Lim J, Giesler GJ, Zoghbi HY, Orr HT (2010) SCA1-like disease in mice expressing wild-type ataxin-1 with a serine to aspartic acid replacement at residue 776. Neuron 67(6):929-935

139. Emamian ES, Kaytor MD, Duvick LA, Zu T, Tousey SK, Zoghbi HY, Clark HB, Orr HT (2003) Serine 776 of ataxin-1 is critical for polyglutamine-induced disease in SCA1 transgenic mice. Neuron 38(3):375-387

140. Klement IA, Skinner PJ, Kaytor MD, Yi H, Hersch SM, Clark HB, Zoghbi HY, Orr HT (1998) Ataxin-1 nuclear localization and aggregation: role in polyglutamine-induced disease in SCA1 transgenic mice. Cell 95(1):41-53

141. Skinner PJ, Vierra-Green CA, Emamian E, Zoghbi HY, Orr HT (2002) Amino acids in a region of ataxin-1 outside of the polyglutamine tract influence the course of disease in SCA1 transgenic mice. Neuromolecular Med 1(1):33-42

142. Zu T, Duvick LA, Kaytor MD, Berlinger MS, Zoghbi HY, Clark HB, Orr HT (2004) Recovery from polyglutamine-induced neurodegeneration in conditional SCA1 transgenic mice. J Neurosci 24(40):8853-8861

143. Serra HG, Duvick L, Zu T et al (2006) RORalpha-mediated Purkinje cell development determines disease severity in adult SCA1 mice. Cell 127(4):697-708

144. Oz G, Vollmers ML, Nelson CD, Shanley R, Eberly LE, Orr HT, Clark HB (2011) In vivo monitoring of recovery from 
neurodegeneration in conditional transgenic SCA1 mice. Exp Neurol 232(2):290-298

145. Lorenzetti D, Watase K, Xu B, Matzuk MM, Orr HT, Zoghbi HY (2000) Repeat instability and motor incoordination in mice with a targeted expanded CAG repeat in the Sca1 locus. Hum Mol Genet 9(5):779-785

146. Watase K, Weeber EJ, Xu B et al (2002) A long CAG repeat in the mouse Scal locus replicates SCA1 features and reveals the impact of protein solubility on selective neurodegeneration. Neuron 34(6):905-919

147. Watase K, Venken KJT, Sun Y, Orr HT, Zoghbi HY (2003) Regional differences of somatic CAG repeat instability do not account for selective neuronal vulnerability in a knock-in mouse model of SCA1. Hum Mol Genet 12(21):2789-2795

148. Fryer JD, Yu P, Kang H et al (2011) Exercise and genetic rescue of SCA1 via the transcriptional repressor Capicua. Science 334 (6056):690-693

149. Jafar-Nejad P, Ward CS, Richman R, Orr HT, Zoghbi HY (2011) Regional rescue of spinocerebellar ataxia type 1 phenotypes by 14-3-3epsilon haploinsufficiency in mice underscores complex pathogenicity in neurodegeneration. Proc Natl Acad Sci USA 108(5):2142-2147

150. Cvetanovic M, Patel JM, Marti HH, Kini AR, Opal P (2011) Vascular endothelial growth factor ameliorates the ataxic phenotype in a mouse model of spinocerebellar ataxia type 1. Nat Med 17(11):1445-1447

151. Huynh DP, Figueroa K, Hoang N, Pulst SM (2000) Nuclear localization or inclusion body formation of ataxin-2 are not necessary for SCA2 pathogenesis in mouse or human. Nat Genet 26(1):44-50

152. Liu J, Tang T-S, Tu H, Nelson O, Herndon E, Huynh DP, Pulst SM, Bezprozvanny I (2009) Deranged calcium signaling and neurodegeneration in spinocerebellar ataxia type 2. J Neurosci 29(29):9148-9162

153. Aguiar J, Fernández J, Aguilar A et al (2006) Ubiquitous expression of human SCA2 gene under the regulation of the SCA2 self promoter cause specific Purkinje cell degeneration in transgenic mice. Neurosci Lett 392(3):202-206

154. Ikeda H, Yamaguchi M, Sugai S, Aze Y, Narumiya S, Kakizuka A (1996) Expanded polyglutamine in the Machado-Joseph disease protein induces cell death in vitro and in vivo. Nat Genet 13 (2):196-202

155. Torashima T, Koyama C, Iizuka A, Mitsumura K, Takayama K, Yanagi S, Oue M, Yamaguchi H, Hirai H (2008) Lentivectormediated rescue from cerebellar ataxia in a mouse model of spinocerebellar ataxia. EMBO Rep 9(4):393-399

156. Goti D, Katzen SM, Mez J et al (2004) A mutant ataxin-3 putative-cleavage fragment in brains of Machado-Joseph disease patients and transgenic mice is cytotoxic above a critical concentration. J Neurosci 24(45):10266-10279

157. Colomer Gould VF, Goti D, Kiluk J (2006) A neuroendocrine dysfunction, not testicular mutant ataxin-3 cleavage fragment or aggregate, causes cell death in testes of transgenic mice. Cell Death Differ 13(3):524-526

158. Colomer Gould VF, Goti D, Pearce D, Gonzalez GA, Gao H, Bermudez de Leon M, Jenkins NA, Copeland NG, Ross CA, Brown DR (2007) A mutant ataxin-3 fragment results from processing at a site N-terminal to amino acid 190 in brain of Machado-Joseph disease-like transgenic mice. Neurobiol Dis 27 (3):362-369

159. Bichelmeier U, Schmidt T, Hübener J et al (2007) Nuclear localization of ataxin-3 is required for the manifestation of symptoms in SCA3: in vivo evidence. J Neurosci 27 (28):7418-7428

160. Menzies FM, Huebener J, Renna M, Bonin M, Riess O, Rubinsztein DC (2010) Autophagy induction reduces mutant ataxin-3 levels and toxicity in a mouse model of spinocerebellar ataxia type 3. Brain 133(Pt 1):93-104

161. Hübener J, Riess O (2010) Polyglutamine-induced neurodegeneration in SCA3 is not mitigated by non-expanded ataxin-3: conclusions from double-transgenic mouse models. Neurobiol Dis $38(1): 116-124$

162. Chou A-H, Yeh T-H, Ouyang P, Chen Y-L, Chen S-Y, Wang H-L (2008) Polyglutamine-expanded ataxin-3 causes cerebellar dysfunction of SCA3 transgenic mice by inducing transcriptional dysregulation. Neurobiol Dis 31(1):89-101

163. Chou A-H, Chen S-Y, Yeh T-H, Weng Y-H, Wang H-L (2011) HDAC inhibitor sodium butyrate reverses transcriptional downregulation and ameliorates ataxic symptoms in a transgenic mouse model of SCA3. Neurobiol Dis 41(2):481-488

164. Cemal CK, Carroll CJ, Lawrence L, Lowrie MB, Ruddle P, AlMahdawi S, King RHM, Pook MA, Huxley C, Chamberlain S (2002) YAC transgenic mice carrying pathological alleles of the MJD1 locus exhibit a mild and slowly progressive cerebellar deficit. Hum Mol Genet 11(9):1075-1094

165. Chen X, Tang T-S, Tu H, Nelson O, Pook M, Hammer R, Nukina N, Bezprozvanny I (2008) Deranged calcium signaling and neurodegeneration in spinocerebellar ataxia type 3. J Neurosci 28 (48):12713-12724

166. Shakkottai VG, do Carmo Costa M, Dell'Orco JM, Sankaranarayanan A, Wulff H, Paulson HL (2011) Early changes in cerebellar physiology accompany motor dysfunction in the polyglutamine disease spinocerebellar ataxia type 3. J Neurosci 31(36):13002-13014

167. Boy J, Schmidt T, Schumann U et al (2010) A transgenic mouse model of spinocerebellar ataxia type 3 resembling late disease onset and gender-specific instability of CAG repeats. Neurobiol Dis 37(2):284-293

168. Silva-Fernandes A, do Carmo Costa M, Duarte-Silva $S$ et al (2010) Motor uncoordination and neuropathology in a transgenic mouse model of Machado-Joseph disease lacking intranuclear inclusions and ataxin-3 cleavage products. Neurobiol Dis 40 (1):163-176

169. Switonski PM, Fiszer A, Kazmierska K, Kurpisz M, Krzyzosiak WJ, Figiel M (2011) Mouse ataxin-3 functional knock-out model. Neuromolecular Med 13(1):54-65

170. Yvert G, Lindenberg KS, Picaud S, Landwehrmeyer GB, Sahel JA, Mandel JL (2000) Expanded polyglutamines induce neurodegeneration and trans-neuronal alterations in cerebellum and retina of SCA7 transgenic mice. Hum Mol Genet 9(17):2491-2506

171. Yvert G, Lindenberg KS, Devys D, Helmlinger D, Landwehrmeyer GB, Mandel JL (2001) SCA7 mouse models show selective stabilization of mutant ataxin-7 and similar cellular responses in different neuronal cell types. Hum Mol Genet 10(16):1679-1692

172. Helmlinger D, Abou-Sleymane G, Yvert G, Rousseau S, Weber C, Trottier Y, Mandel J-L, Devys D (2004) Disease progression despite early loss of polyglutamine protein expression in SCA7 mouse model. J Neurosci 24(8):1881-1887

173. Helmlinger D, Hardy S, Abou-Sleymane G et al (2006) Glutamine-expanded ataxin-7 alters TFTC/STAGA recruitment and chromatin structure leading to photoreceptor dysfunction. PLoS Biol 4(3):e67

174. Yefimova MG, Messaddeq N, Karam A, Jacquard C, Weber C, Jonet L, Wolfrum U, Jeanny J-C, Trottier Y (2010) Polyglutamine toxicity induces rod photoreceptor division, morphological transformation or death in spinocerebellar ataxia 7 mouse retina. Neurobiol Dis 40(1):311-324

175. Abou-Sleymane G, Chalmel F, Helmlinger D et al (2006) Polyglutamine expansion causes neurodegeneration by altering the neuronal differentiation program. Hum Mol Genet 15 (5):691-703 
176. Brenner M, Kisseberth WC, Su Y, Besnard F, Messing A (1994) GFAP promoter directs astrocyte-specific expression in transgenic mice. J Neurosci 14(3 Pt 1):1030-1037

177. Custer SK, Garden GA, Gill N et al (2006) Bergmann glia expression of polyglutamine-expanded ataxin-7 produces neurodegeneration by impairing glutamate transport. Nat Neurosci 9 (10):1302-1311

178. Figiel M, Engele J (2000) Pituitary adenylate cyclase-activating polypeptide (PACAP), a neuron-derived peptide regulating glial glutamate transport and metabolism. J Neurosci 20(10):35963605

179. Figiel M, Maucher T, Rozyczka J, Bayatti N, Engele J (2003) Regulation of glial glutamate transporter expression by growth factors. Exp Neurol 183(1):124-135

180. La Spada AR, Fu YH, Sopher BL et al (2001) Polyglutamineexpanded ataxin-7 antagonizes CRX function and induces conerod dystrophy in a mouse model of SCA7. Neuron 31(6):913-927

181. Garden GA, Libby RT, Fu Y-H et al (2002) Polyglutamineexpanded ataxin-7 promotes non-cell-autonomous purkinje cell degeneration and displays proteolytic cleavage in ataxic transgenic mice. J Neurosci 22(12):4897-4905

182. Grote SK, La Spada AR (2003) Insights into the molecular basis of polyglutamine neurodegeneration from studies of a spinocerebellar ataxia type 7 mouse model. Cytogenet Genome Res 100 (1-4):164-174

183. Clarke CM, Plata C, Cole B, Tsuchiya K, La Spada AR, Kapur RP (2007) Visceral neuropathy and intestinal pseudo-obstruction in a murine model of a nuclear inclusion disease. Gastroenterology 133 (6):1971-1978

184. Yoo SY, Pennesi ME, Weeber EJ, Xu B, Atkinson R, Chen S, Armstrong DL, Wu SM, Sweatt JD, Zoghbi HY (2003) SCA7 knockin mice model human SCA7 and reveal gradual accumulation of mutant ataxin-7 in neurons and abnormalities in short-term plasticity. Neuron 37(3):383-401

185. Noma S, Ohya-Shimada W, Kanai M, Ueda K, Nakamura T, Funakoshi H (2012) Overexpression of HGF attenuates the degeneration of Purkinje cells and Bergmann glia in a knockin mouse model of spinocerebellar ataxia type 7. Neurosci Res 73 (2):115-121

186. Chou A-H, Chen C-Y, Chen S-Y, Chen W-J, Chen Y-L, Weng YS, Wang H-L (2010) Polyglutamine-expanded ataxin-7 causes cerebellar dysfunction by inducing transcriptional dysregulation. Neurochem Int 56(2):329-339

187. Furrer SA, Mohanachandran MS, Waldherr SM, Chang C, Damian VA, Sopher BL, Garden GA, La Spada AR (2011) Spinocerebellar ataxia type 7 cerebellar disease requires the coordinated action of mutant ataxin- 7 in neurons and glia, and displays non-cell-autonomous bergmann glia degeneration. J Neurosci 31(45):16269-16278

188. Friedman MJ, Shah AG, Fang Z-H, Ward EG, Warren ST, Li S, Li X-J (2007) Polyglutamine domain modulates the TBP-TFIIB interaction: implications for its normal function and neurodegeneration. Nat Neurosci 10(12):1519-1528

189. Lima FRS, Arantes CP, Muras AG, Nomizo R, Brentani RR, Martins VR (2007) Cellular prion protein expression in astrocytes modulates neuronal survival and differentiation. J Neurochem 103(6):2164-2176

190. Friedman MJ, Wang C-E, Li X-J, Li S (2008) Polyglutamine expansion reduces the association of TATA-binding protein with DNA and induces DNA binding-independent neurotoxicity. J Biol Chem 283(13):8283-8290

191. Chang Y-C, Lin C-Y, Hsu C-M, Lin H-C, Chen Y-H, Lee-Chen G-J, Su M-T, Ro L-S, Chen C-M, Hsieh-Li HM (2011) Neuroprotective effects of granulocyte-colony stimulating factor in a novel transgenic mouse model of SCA17. J Neurochem 118 (2):288-303
192. Huang S, Ling JJ, Yang S, Li X-J, Li S (2011) Neuronal expression of TATA box-binding protein containing expanded polyglutamine in knock-in mice reduces chaperone protein response by impairing the function of nuclear factor-Y transcription factor. Brain 134(Pt 7):1943-1958

193. Moretti P, Bouwknecht JA, Teague R, Paylor R, Zoghbi HY (2005) Abnormalities of social interactions and home-cage behavior in a mouse model of Rett syndrome. Hum Mol Genet 14 (2):205-220

194. Schilling G, Wood JD, Duan K et al (1999) Nuclear accumulation of truncated atrophin-1 fragments in a transgenic mouse model of DRPLA. Neuron 24(1):275-286

195. Ying M, Xu R, Wu X, Zhu H, Zhuang Y, Han M, Xu T (2006) Sodium butyrate ameliorates histone hypoacetylation and neurodegenerative phenotypes in a mouse model for DRPLA. J Biol Chem 281(18):12580-12586

196. Sato T, Oyake M, Nakamura K et al (1999) Transgenic mice harboring a full-length human mutant DRPLA gene exhibit agedependent intergenerational and somatic instabilities of CAG repeats comparable with those in DRPLA patients. Hum Mol Genet 8(1):99-106

197. Sakai K, Yamada M, Sato T, Yamada M, Tsuji S, Takahashi H (2006) Neuronal atrophy and synaptic alteration in a mouse model of dentatorubral-pallidoluysian atrophy. Brain 129(Pt 9):2353-2362

198. Sato T, Miura M, Yamada M et al (2009) Severe neurological phenotypes of Q129 DRPLA transgenic mice serendipitously created by en masse expansion of CAG repeats in Q76 DRPLA mice. Hum Mol Genet 18(4):723-736

199. Suzuki K, Zhou J, Sato T et al (2012) DRPLA transgenic mouse substrains carrying single copy of full-length mutant human DRPLA gene with variable sizes of expanded CAG repeats exhibit CAG repeat length- and age-dependent changes in behavioral abnormalities and gene expression profiles. Neurobiol Dis 46(2):336-350

200. Bingham PM, Scott MO, Wang S, McPhaul MJ, Wilson EM, Garbern JY, Merry DE, Fischbeck KH (1995) Stability of an expanded trinucleotide repeat in the androgen receptor gene in transgenic mice. Nat Genet 9(2):191-196

201. La Spada AR, Peterson KR, Meadows SA et al (1998) Androgen receptor YAC transgenic mice carrying CAG 45 alleles show trinucleotide repeat instability. Hum Mol Genet 7(6):959-967

202. Abel A, Walcott J, Woods J, Duda J, Merry DE (2001) Expression of expanded repeat androgen receptor produces neurologic disease in transgenic mice. Hum Mol Genet 10(2):107116

203. Adachi H, Kume A, Li M, Nakagomi Y, Niwa H, Do J, Sang C, Kobayashi Y, Doyu M, Sobue G (2001) Transgenic mice with an expanded CAG repeat controlled by the human AR promoter show polyglutamine nuclear inclusions and neuronal dysfunction without neuronal cell death. Hum Mol Genet 10(10):1039-1048

204. Sopher BL, Thomas PS Jr, LaFevre-Bernt MA, Holm IE, Wilke SA, Ware CB, Jin L-W, Libby RT, Ellerby LM, La Spada AR (2004) Androgen receptor YAC transgenic mice recapitulate SBMA motor neuronopathy and implicate VEGF164 in the motor neuron degeneration. Neuron 41(5):687-699

205. Malik B, Nirmalananthan N, Bilsland LG, La Spada AR, Hanna MG, Schiavo G, Gallo J-M, Greensmith L (2011) Absence of disturbed axonal transport in spinal and bulbar muscular atrophy. Hum Mol Genet 20(9):1776-1786

206. Oosthuyse B, Moons L, Storkebaum E et al (2001) Deletion of the hypoxia-response element in the vascular endothelial growth factor promoter causes motor neuron degeneration. Nat Genet 28 (2):131-138

207. Thomas PS Jr, Fraley GS, Damian V, Damien V, Woodke LB, Zapata F, Sopher BL, Plymate SR, La Spada AR (2006) Loss of 
endogenous androgen receptor protein accelerates motor neuron degeneration and accentuates androgen insensitivity in a mouse model of X-linked spinal and bulbar muscular atrophy. Hum Mol Genet 15(14):2225-2238

208. Yu Z, Dadgar N, Albertelli M, Scheller A, Albin RL, Robins DM, Lieberman AP (2006) Abnormalities of germ cell maturation and sertoli cell cytoskeleton in androgen receptor 113 CAG knock-in mice reveal toxic effects of the mutant protein. Am J Pathol 168 (1):195-204

209. Yu Z, Dadgar N, Albertelli M, Gruis K, Jordan C, Robins DM, Lieberman AP (2006) Androgen-dependent pathology demonstrates myopathic contribution to the Kennedy disease phenotype in a mouse knock-in model. J Clin Invest 116(10):2663-2672

210. Ranganathan S, Harmison GG, Meyertholen K, Pennuto M, Burnett BG, Fischbeck KH (2009) Mitochondrial abnormalities in spinal and bulbar muscular atrophy. Hum Mol Genet 18(1):27-42

211. McManamny P, Chy HS, Finkelstein DI et al (2002) A mouse model of spinal and bulbar muscular atrophy. Hum Mol Genet 11 (18):2103-2111

212. Katsuno M, Adachi H, Kume A, Li M, Nakagomi Y, Niwa H, Sang C, Kobayashi Y, Doyu M, Sobue G (2002) Testosterone reduction prevents phenotypic expression in a transgenic mouse model of spinal and bulbar muscular atrophy. Neuron 35(5):843854

213. Chevalier-Larsen ES, O'Brien CJ, Wang H, Jenkins SC, Holder L, Lieberman AP, Merry DE (2004) Castration restores function and neurofilament alterations of aged symptomatic males in a transgenic mouse model of spinal and bulbar muscular atrophy. J Neurosci 24(20):4778-4786

214. Li M, Chevalier-Larsen ES, Merry DE, Diamond MI (2007) Soluble androgen receptor oligomers underlie pathology in a mouse model of spinobulbar muscular atrophy. J Biol Chem 282(5):3157-3164

215. Montie HL, Cho MS, Holder L, Liu Y, Tsvetkov AS, Finkbeiner S, Merry DE (2009) Cytoplasmic retention of polyglutamineexpanded androgen receptor ameliorates disease via autophagy in a mouse model of spinal and bulbar muscular atrophy. Hum Mol Genet 18(11):1937-1950

216. Acevedo SF, Tittle S, Raber J (2008) Transgenic expression of androgen receptors improves spatial memory retention in both sham-irradiated and $137 \mathrm{Cs}$ gamma-irradiated female mice. Radiat Res 170(5):572-578

217. Monks DA, Johansen JA, Mo K, Rao P, Eagleson B, Yu Z, Lieberman AP, Breedlove SM, Jordan CL (2007) Overexpression of wild-type androgen receptor in muscle recapitulates polyglutamine disease. Proc Natl Acad Sci USA 104 (46):18259-18264

218. Johansen JA, Yu Z, Mo K, Monks DA, Lieberman AP, Breedlove SM, Jordan CL (2009) Recovery of function in a myogenic mouse model of spinal bulbar muscular atrophy. Neurobiol Dis 34(1):113-120

219. Willner P (1984) The validity of animal models of depression. Psychopharmacology (Berl) 83(1):1-16

220. Willner P (1991) Methods for assessing the validity of animal models of human psychopathology. Animal models in psychiatry. I. Humana, New Jersey, pp 1-24

221. Cryan JF, Slattery DA (2007) Animal models of mood disorders: recent developments. Curr Opin Psychiatry 20(1):1-7

222. Van Raamsdonk JM, Pearson J, Rogers DA, Bissada N, Vogl AW, Hayden MR, Leavitt BR (2005) Loss of wild-type huntingtin influences motor dysfunction and survival in the YAC128 mouse model of Huntington disease. Hum Mol Genet 14(10):1379-1392

223. Leavitt BR, van Raamsdonk JM, Shehadeh J, Fernandes H, Murphy Z, Graham RK, Wellington CL, Raymond LA, Hayden MR (2006) Wild-type huntingtin protects neurons from excitotoxicity. J Neurochem 96(4):1121-1129
224. Morse RJ, Leeds JM, Macdonald D, Park L, Toledo-Sherman L, Pacifici R (2011) Pharmaceutical development for Huntington's disease. In: Lo DC, Hughes RE (eds) Neurobiology of Huntington's disease: applications to drug discovery. CRC Press, Boca Raton, pp 197-224

225. Wagner LA, Menalled L, Gomeniouk AD, Brunner D, Leavitt BR (2008) Huntington disease. In: McArthur RA, Borsini F (eds) Animal and translational models for CNS drug discovery, vol II. Elsevier, Amsterdam, pp 207-266

226. Borchelt DR, Davis J, Fischer M et al (1996) A vector for expressing foreign genes in the brains and hearts of transgenic mice. Genet Anal 13(6):159-163

227. Fischer M, Rülicke T, Raeber A, Sailer A, Moser M, Oesch B, Brandner S, Aguzzi A, Weissmann C (1996) Prion protein (PrP) with amino-proximal deletions restoring susceptibility of $\operatorname{PrP}$ knockout mice to scrapie. EMBO J 15(6):1255-1264

228. Boy J, Leergaard TB, Schmidt T et al (2006) Expression mapping of tetracycline-responsive prion protein promoter: digital atlasing for generating cell-specific disease models. Neuroimage 33 (2):449-462

229. Giovannoni R, Maggio N, Rosaria Bianco M, Cavaliere C, Cirillo G, Lavitrano M, Papa M (2007) Reactive astrocytosis and glial glutamate transporter clustering are early changes in a spinocerebellar ataxia type 1 transgenic mouse model. Neuron Glia Biol 3 (4):335-351

230. Boy J, Schmidt T, Wolburg H et al (2009) Reversibility of symptoms in a conditional mouse model of spinocerebellar ataxia type 3. Hum Mol Genet 18(22):4282-4295

231. Bradford J, Shin J-Y, Roberts M, Wang C-E, Li X-J, Li S (2009) Expression of mutant huntingtin in mouse brain astrocytes causes age-dependent neurological symptoms. Proc Natl Acad Sci USA 106(52):22480-22485

232. Bradford J, Shin J-Y, Roberts M, Wang C-E, Sheng G, Li S, Li X$\mathrm{J}$ (2010) Mutant huntingtin in glial cells exacerbates neurological symptoms of Huntington disease mice. J Biol Chem 285 (14):10653-10661

233. Gu X, André VM, Cepeda C, Li S-H, Li X-J, Levine MS, Yang XW (2007) Pathological cell-cell interactions are necessary for striatal pathogenesis in a conditional mouse model of Huntington's disease. Mol Neurodegener 2:8

234. Franciosi S, Ryu JK, Shim Y, Hill A, Connolly C, Hayden MR, McLarnon JG, Leavitt BR (2012) Age-dependent neurovascular abnormalities and altered microglial morphology in the YAC128 mouse model of Huntington disease. Neurobiol Dis 45(1):438-449

235. Dixon KT, Cearley JA, Hunter JM, Detloff PJ (2004) Mouse Huntington's disease homolog mRNA levels: variation and allele effects. Gene Expr 11(5-6):221-231

236. Tebbenkamp ATN, Green C, Xu G et al (2011) Transgenic mice expressing caspase-6-derived $\mathrm{N}$-terminal fragments of mutant huntingtin develop neurologic abnormalities with predominant cytoplasmic inclusion pathology composed largely of a smaller proteolytic derivative. Hum Mol Genet 20 (14):2770-2782

237. Waldron-Roby E, Ratovitski T, Wang X et al (2012) Transgenic mouse model expressing the caspase 6 fragment of mutant huntingtin. J Neurosci 32(1):183-193

238. Chung DW, Rudnicki DD, Yu L, Margolis RL (2011) A natural antisense transcript at the Huntington's disease repeat locus regulates HTT expression. Hum Mol Genet 20(17):3467-3477

239. Gu X, Greiner ER, Mishra R, Kodali R, Osmand A, Finkbeiner S, Steffan JS, Thompson LM, Wetzel R, Yang XW (2009) Serines 13 and 16 are critical determinants of full-length human mutant huntingtin induced disease pathogenesis in HD mice. Neuron 64 (6):828-840

240. Carroll JB, Lerch JP, Franciosi S, Spreeuw A, Bissada N, Henkelman RM, Hayden MR (2011) Natural history of disease 
in the YAC128 mouse reveals a discrete signature of pathology in Huntington disease. Neurobiol Dis 43(1):257-265

241. Crawley JN, Belknap JK, Collins A et al (1997) Behavioral phenotypes of inbred mouse strains: implications and recommendations for molecular studies. Psychopharmacology (Berl) 132 (2):107-124

242. Logue SF, Owen EH, Rasmussen DL, Wehner JM (1997) Assessment of locomotor activity, acoustic and tactile startle, and prepulse inhibition of startle in inbred mouse strains and F1 hybrids: implications of genetic background for single gene and quantitative trait loci analyses. Neuroscience 80(4):1075-1086

243. Brooks SP, Pask T, Jones L, Dunnett SB (2004) Behavioural profiles of inbred mouse strains used as transgenic backgrounds. I: motor tests. Genes Brain Behav 3(4):206-215

244. Brooks SP, Pask T, Jones L, Dunnett SB (2005) Behavioural profiles of inbred mouse strains used as transgenic backgrounds. II: cognitive tests. Genes Brain Behav 4(5):307-317

245. Bothe GWM, Bolivar VJ, Vedder MJ, Geistfeld JG (2005) Behavioral differences among fourteen inbred mouse strains commonly used as disease models. Comp Med 55(4):326-334

246. Võikar V, Polus A, Vasar E, Rauvala H (2005) Long-term individual housing in $\mathrm{C} 57 \mathrm{BL} / 6 \mathrm{~J}$ and $\mathrm{DBA} / 2$ mice: assessment of behavioral consequences. Genes Brain Behav 4(4):240-252

247. Tucci V, Lad HV, Parker A, Polley S, Brown SDM, Nolan PM (2006) Gene-environment interactions differentially affect mouse strain behavioral parameters. Mamm Genome 17(11):1113-1120

248. Abramov U, Puussaar T, Raud S, Kurrikoff K, Vasar E (2008) Behavioural differences between C57BL/6 and 129 S6/SvEv strains are reinforced by environmental enrichment. Neurosci Lett 443(3):223-227

249. McIlwain KL, Merriweather MY, Yuva-Paylor LA, Paylor R (2001) The use of behavioral test batteries: effects of training history. Physiol Behav 73(5):705-717

250. Võikar V, Vasar E, Rauvala H (2004) Behavioral alterations induced by repeated testing in C57BL/6J and 129S2/Sv mice: implications for phenotyping screens. Genes Brain Behav 3 (1):27-38

251. Lad HV, Liu L, Paya-Cano JL, Parsons MJ, Kember R, Fernandes C, Schalkwyk LC (2010) Behavioural battery testing: evaluation and behavioural outcomes in 8 inbred mouse strains. Physiol Behav 99(3):301-316

252. Wahlsten D, Metten P, Phillips TJ et al (2003) Different data from different labs: lessons from studies of gene-environment interaction. J Neurobiol 54(1):283-311

253. Chang B, Hawes NL, Hurd RE, Davisson MT, Nusinowitz S, Heckenlively JR (2002) Retinal degeneration mutants in the mouse. Vision Res 42(4):517-525

254. Brown RE, Wong AA (2007) The influence of visual ability on learning and memory performance in 13 strains of mice. Learn Mem 14(3):134-144

255. Zheng QY, Johnson KR, Erway LC (1999) Assessment of hearing in 80 inbred strains of mice by ABR threshold analyses. Hear Res 130(1-2):94-107

256. Willott JF, Tanner L, O'Steen J, Johnson KR, Bogue MA, Gagnon L (2003) Acoustic startle and prepulse inhibition in 40 inbred strains of mice. Behav Neurosci 117(4):716-727

257. Green MC, Kaufer KA (1965) A test for histocompatibility between sublines of the CBA strain of mice. Transplantation 3 (6):766-768

258. van der Burg JMM, Bacos K, Wood NI et al (2008) Increased metabolism in the R6/2 mouse model of Huntington's disease. Neurobiol Dis 29(1):41-51

259. Naver B, Stub C, Møller M, Fenger K, Hansen AK, Hasholt L, Sørensen SA (2003) Molecular and behavioral analysis of the R6/ 1 Huntington's disease transgenic mouse. Neuroscience 122 (4):1049-1057
260. Bolivar VJ, Manley K, Messer A (2004) Early exploratory behavior abnormalities in R6/1 Huntington's disease transgenic mice. Brain Res 1005(1-2):29-35

261. Hodges A, Hughes G, Brooks S, Elliston L, Holmans P, Dunnett SB, Jones L (2008) Brain gene expression correlates with changes in behavior in the R6/1 mouse model of Huntington's disease. Genes Brain Behav 7(3):288-299

262. Lloret A, Dragileva E, Teed A, Espinola J, Fossale E, Gillis T, Lopez E, Myers RH, MacDonald ME, Wheeler VC (2006) Genetic background modifies nuclear mutant huntingtin accumulation and HD CAG repeat instability in Huntington's disease knock-in mice. Hum Mol Genet 15(12):2015-2024

263. Taniwaki T, Sakai T, Kobayashi T, Kuwabara Y, Otsuka M, Ichiya Y, Masuda K, Goto I (1997) Positron emission tomography (PET) in Machado-Joseph disease. J Neurol Sci 145(1):6367

264. Yen T-C, Tzen K-Y, Chen M-C, Chou Y-HW, Chen R-S, Chen CJ, Wey S-P, Ting G, Lu C-S (2002) Dopamine transporter concentration is reduced in asymptomatic Machado-Joseph disease gene carriers. J Nucl Med 43(2):153-159

265. Alves S, Régulier E, Nascimento-Ferreira I et al (2008) Striatal and nigral pathology in a lentiviral rat model of Machado-Joseph disease. Hum Mol Genet 17(14):2071-2083

266. Fennema-Notestine C, Archibald SL, Jacobson MW, CoreyBloom J, Paulsen JS, Peavy GM, Gamst AC, Hamilton JM, Salmon DP, Jernigan TL (2004) In vivo evidence of cerebellar atrophy and cerebral white matter loss in Huntington disease. Neurology 63(6):989-995

267. Bohanna I, Georgiou-Karistianis N, Hannan AJ, Egan GF (2008) Magnetic resonance imaging as an approach towards identifying neuropathological biomarkers for Huntington's disease. Brain Res Rev 58(1):209-225

268. Politis M, Pavese N, Tai YF, Kiferle L, Mason SL, Brooks DJ, Tabrizi SJ, Barker RA, Piccini P (2011) Microglial activation in regions related to cognitive function predicts disease onset in Huntington's disease: a multimodal imaging study. Hum Brain Mapp 32(2):258-270

269. Dalrymple A, Wild EJ, Joubert R et al (2007) Proteomic profiling of plasma in Huntington's disease reveals neuroinflammatory activation and biomarker candidates. J Proteome Res 6 (7):2833-2840

270. Björkqvist M, Wild EJ, Thiele J et al (2008) A novel pathogenic pathway of immune activation detectable before clinical onset in Huntington's disease. J Exp Med 205(8):1869-1877

271. Albertelli MA, Scheller A, Brogley M, Robins DM (2006) Replacing the mouse androgen receptor with human alleles demonstrates glutamine tract length-dependent effects on physiology and tumorigenesis in mice. Mol Endocrinol 20(6):1248-1260

272. Andreassen OA, Dedeoglu A, Stanojevic V, Hughes DB, Browne SE, Leech CA, Ferrante RJ, Habener JF, Beal MF, Thomas MK (2002) Huntington's disease of the endocrine pancreas: insulin deficiency and diabetes mellitus due to impaired insulin gene expression. Neurobiol Dis 11(3):410-424

273. Ariano MA, Aronin N, Difiglia M, Tagle DA, Sibley DR, Leavitt BR, Hayden MR, Levine MS (2002) Striatal neurochemical changes in transgenic models of Huntington's disease. J Neurosci Res 68(6):716-729

274. Bayram-Weston Z, Jones L, Dunnett SB, Brooks SP (2012) Light and electron microscopic characterization of the evolution of cellular pathology in the R6/1 Huntington's disease transgenic mice. Brain Res Bull 88(2-3):104-112

275. Becanovic K, Pouladi MA, Lim RS, Kuhn A, Pavlidis P, LuthiCarter R, Hayden MR, Leavitt BR (2010) Transcriptional changes in Huntington disease identified using genome-wide expression profiling and cross-platform analysis. Hum Mol Genet 19(8):1438-1452 
276. Benn CL, Landles C, Li H et al (2005) Contribution of nuclear and extranuclear polyQ to neurological phenotypes in mouse models of Huntington's disease. Hum Mol Genet 14(20):30653078

277. Callahan JW, Abercrombie ED (2011) In vivo dopamine efflux is decreased in striatum of both fragment (R6/2) and full-length (YAC128) transgenic mouse models of Huntington's disease. Front Syst Neurosci 5:61

278. Cayzac S, Delcasso S, Paz V, Jeantet Y, Cho YH (2011) Changes in striatal procedural memory coding correlate with learning deficits in a mouse model of Huntington disease. Proc Natl Acad Sci USA 108(22):9280-9285

279. Cha JH, Kosinski CM, Kerner JA, Alsdorf SA, Mangiarini L, Davies SW, Penney JB, Bates GP, Young AB (1998) Altered brain neurotransmitter receptors in transgenic mice expressing a portion of an abnormal human Huntington disease gene. Proc Natl Acad Sci USA 95(11):6480-6485

280. Chan EYW, Luthi-Carter R, Strand A et al (2002) Increased huntingtin protein length reduces the number of polyglutamineinduced gene expression changes in mouse models of Huntington's disease. Hum Mol Genet 11(17):1939-1951

281. Chaturvedi RK, Adhihetty P, Shukla S et al (2009) Impaired PGC-1alpha function in muscle in Huntington's disease. Hum Mol Genet 18(16):3048-3065

282. Cheng P-H, Li C-L, Her L-S, Chang Y-F, Chan AWS, Chen C-M, Yang S-H (2012) Significantly differential diffusion of neuropathological aggregates in the brain of transgenic mice carrying $\mathrm{N}$-terminal mutant huntingtin fused with green fluorescent protein. Brain Struct Funct. doi:10.1007/s00429-012-0401-x

283. Crespo-Barreto J, Fryer JD, Shaw CA, Orr HT, Zoghbi HY (2010) Partial loss of ataxin-1 function contributes to transcriptional dysregulation in spinocerebellar ataxia type 1 pathogenesis. PLoS Genet 6(7):e1001021

284. Cummings DM, Alaghband Y, Hickey MA et al (2012) A critical window of CAG repeat-length correlates with phenotype severity in the R6/2 mouse model of Huntington's disease. J Neurophysiol 107(2):677-691

285. Cummings DM, Milnerwood AJ, Dallérac GM, Waights V, Brown JY, Vatsavayai SC, Hirst MC, Murphy KPSJ (2006) Aberrant cortical synaptic plasticity and dopaminergic dysfunction in a mouse model of Huntington's disease. Hum Mol Genet 15(19):2856-2868

286. Cybulska-Klosowicz A, Mazarakis NK, Van Dellen A, Blakemore C, Hannan AJ, Kossut M (2004) Impaired learningdependent cortical plasticity in Huntington's disease transgenic mice. Neurobiol Dis 17(3):427-434

287. van Dellen A, Blakemore C, Deacon R, York D, Hannan AJ (2000) Delaying the onset of Huntington's in mice. Nature 404 (6779):721-722

288. Denny CA, Desplats PA, Thomas EA, Seyfried TN (2010) Cerebellar lipid differences between R6/1 transgenic mice and humans with Huntington's disease. J Neurochem 115(3):748-758

289. Deschepper M, Hoogendoorn B, Brooks S, Dunnett SB, Jones L (2012) Proteomic changes in the brains of Huntington's disease mouse models reflect pathology and implicate mitochondrial changes. Brain Res Bull 88(2-3):210-222

290. Desplats PA, Denny CA, Kass KE, Gilmartin T, Head SR, Sutcliffe JG, Seyfried TN, Thomas EA (2007) Glycolipid and ganglioside metabolism imbalances in Huntington's disease. Neurobiol Dis 27(3):265-277

291. Desplats PA, Kass KE, Gilmartin T, Stanwood GD, Woodward EL, Head SR, Sutcliffe JG, Thomas EA (2006) Selective deficits in the expression of striatal-enriched mRNAs in Huntington's disease. J Neurochem 96(3):743-757
292. Díaz-Hernández M, Hernández F, Martín-Aparicio E, GómezRamos P, Morán MA, Castaño JG, Ferrer I, Avila J, Lucas JJ (2003) Neuronal induction of the immunoproteasome in Huntington's disease. J Neurosci 23(37):11653-11661

293. Díaz-Hernández M, Torres-Peraza J, Salvatori-Abarca A, Morán MA, Gómez-Ramos P, Alberch J, Lucas JJ (2005) Full motor recovery despite striatal neuron loss and formation of irreversible amyloid-like inclusions in a conditional mouse model of Huntington's disease. J Neurosci 25(42):9773-9781

294. Fain JN, Del Mar NA, Meade CA, Reiner A, Goldowitz D (2001) Abnormalities in the functioning of adipocytes from R6/2 mice that are transgenic for the Huntington's disease mutation. Hum Mol Genet 10(2):145-152

295. File SE, Mahal A, Mangiarini L, Bates GP (1998) Striking changes in anxiety in Huntington's disease transgenic mice. Brain Res 805(1-2):234-240

296. Gibson HE, Reim K, Brose N, Morton AJ, Jones S (2005) A similar impairment in CA3 mossy fibre LTP in the R6/2 mouse model of Huntington's disease and in the complexin II knockout mouse. Eur J Neurosci 22(7):1701-1712

297. Giles P, Elliston L, Higgs GV, Brooks SP, Dunnett SB, Jones L (2012) Longitudinal analysis of gene expression and behaviour in the HdhQ150 mouse model of Huntington's disease. Brain Res Bull 88(2-3):199-209

298. Goodman AOG, Murgatroyd PR, Medina-Gomez G, Wood NI, Finer N, Vidal-Puig AJ, Morton AJ, Barker RA (2008) The metabolic profile of early Huntington's disease-a combined human and transgenic mouse study. Exp Neurol 210(2):691-698

299. Griffin JL, Cemal CK, Pook MA (2004) Defining a metabolic phenotype in the brain of a transgenic mouse model of spinocerebellar ataxia 3. Physiol Genomics 16(3):334-340

300. Guidetti P, Charles V, Chen EY, Reddy PH, Kordower JH, Whetsell WO Jr, Schwarcz R, Tagle DA (2001) Early degenerative changes in transgenic mice expressing mutant huntingtin involve dendritic abnormalities but no impairment of mitochondrial energy production. Exp Neurol 169(2):340-350

301. Hickey MA, Reynolds GP, Morton AJ (2002) The role of dopamine in motor symptoms in the R6/2 transgenic mouse model of Huntington's disease. J Neurochem 81(1):46-59

302. Hult S, Soylu R, Björklund T, Belgardt BF, Mauer J, Brüning JC, Kirik D, Petersén $\AA$ (2011) Mutant huntingtin causes metabolic imbalance by disruption of hypothalamic neurocircuits. Cell Metab 13(4):428-439

303. Iannicola C, Moreno S, Oliverio S, Nardacci R, Ciofi-Luzzatto A, Piacentini M (2000) Early alterations in gene expression and cell morphology in a mouse model of Huntington's disease. J Neurochem 75(2):830-839

304. Ishiguro H, Yamada K, Sawada H et al (2001) Age-dependent and tissue-specific CAG repeat instability occurs in mouse knock-in for a mutant Huntington's disease gene. J Neurosci Res 65(4):289-297

305. Jenkins BG, Andreassen OA, Dedeoglu A, Leavitt B, Hayden M, Borchelt D, Ross CA, Ferrante RJ, Beal MF (2005) Effects of CAG repeat length, HTT protein length and protein context on cerebral metabolism measured using magnetic resonance spectroscopy in transgenic mouse models of Huntington's disease. J Neurochem 95(2):553-562

306. Johnson MA, Rajan V, Miller CE, Wightman RM (2006) Dopamine release is severely compromised in the R6/2 mouse model of Huntington's disease. J Neurochem 97(3):737-746

307. Josefsen K, Nielsen MD, Jørgensen KH, Bock T, Nørremølle A, Sørensen SA, Naver B, Hasholt L (2008) Impaired glucose tolerance in the R6/1 transgenic mouse model of Huntington's disease. J Neuroendocrinol 20(2):165-172 
308. Josefsen K, Nielsen SMB, Campos A, Seifert T, Hasholt L, Nielsen JE, Nørremølle A, Skotte NH, Secher NH, Quistorff B (2010) Reduced gluconeogenesis and lactate clearance in Huntington's disease. Neurobiol Dis 40(3):656-662

309. Keene CD, Rodrigues CMP, Eich T, Chhabra MS, Steer CJ, Low WC (2002) Tauroursodeoxycholic acid, a bile acid, is neuroprotective in a transgenic animal model of Huntington's disease. Proc Natl Acad Sci USA 99(16):10671-10676

310. Kennedy L, Shelbourne PF, Dewar D (2005) Alterations in dopamine and benzodiazepine receptor binding precede overt neuronal pathology in mice modelling early Huntington disease pathogenesis. Brain Res 1039(1-2):14-21

311. Kotliarova S, Jana NR, Sakamoto N et al (2005) Decreased expression of hypothalamic neuropeptides in Huntington disease transgenic mice with expanded polyglutamine-EGFP fluorescent aggregates. J Neurochem 93(3):641-653

312. Kuhn A, Goldstein DR, Hodges A et al (2007) Mutant huntingtin's effects on striatal gene expression in mice recapitulate changes observed in human Huntington's disease brain and do not differ with mutant huntingtin length or wild-type huntingtin dosage. Hum Mol Genet 16(15):1845-1861

313. Laforet GA, Sapp E, Chase K et al (2001) Changes in cortical and striatal neurons predict behavioral and electrophysiological abnormalities in a transgenic murine model of Huntington's disease. J Neurosci 21(23):9112-9123

314. Lastres-Becker I, Berrendero F, Lucas JJ, Martín-Aparicio E, Yamamoto A, Ramos JA, Fernández-Ruiz JJ (2002) Loss of mRNA levels, binding and activation of GTP-binding proteins for cannabinoid CB1 receptors in the basal ganglia of a transgenic model of Huntington's disease. Brain Res 929 (2): $236-242$

315. Lazic SE, Goodman AOG, Grote HE, Blakemore C, Morton AJ, Hannan AJ, van Dellen A, Barker RA (2007) Olfactory abnormalities in Huntington's disease: decreased plasticity in the primary olfactory cortex of R6/1 transgenic mice and reduced olfactory discrimination in patients. Brain Res 1151:219-226

316. Lerner RP, Trejo Martinez LDCG, Zhu C, Chesselet M-F, Hickey MA (2012) Striatal atrophy and dendritic alterations in a knock-in mouse model of Huntington's disease. Brain Res Bull 87(6):571-578

317. Li H, Li SH, Johnston H, Shelbourne PF, Li XJ (2000) Aminoterminal fragments of mutant huntingtin show selective accumulation in striatal neurons and synaptic toxicity. Nat Genet 25 (4):385-389

318. Li H, Li SH, Yu ZX, Shelbourne P, Li XJ (2001) Huntingtin aggregate-associated axonal degeneration is an early pathological event in Huntington's disease mice. J Neurosci 21(21):84738481

319. Lin Y-S, Chen C-M, Soong B et al (2011) Dysregulated brain creatine kinase is associated with hearing impairment in mouse models of Huntington disease. J Clin Invest 121(4):1519-1523

320. Luthi-Carter R, Strand A, Peters NL et al (2000) Decreased expression of striatal signaling genes in a mouse model of Huntington's disease. Hum Mol Genet 9(9):1259-1271

321. Luthi-Carter R, Hanson SA, Strand AD et al (2002) Dysregulation of gene expression in the R6/2 model of polyglutamine disease: parallel changes in muscle and brain. Hum Mol Genet 11(17):1911-1926

322. Luthi-Carter R, Strand AD, Hanson SA et al (2002) Polyglutamine and transcription: gene expression changes shared by DRPLA and Huntington's disease mouse models reveal context-independent effects. Hum Mol Genet 11 (17): 1927-1937

323. Lynch G, Kramar EA, Rex CS, Jia Y, Chappas D, Gall CM, Simmons DA (2007) Brain-derived neurotrophic factor restores synaptic plasticity in a knock-in mouse model of Huntington's disease. J Neurosci 27(16):4424-4434

324. Ma L, Morton AJ, Nicholson LFB (2003) Microglia density decreases with age in a mouse model of Huntington's disease. Glia 43(3):274-280

325. Martin B, Golden E, Carlson OD et al (2009) Exendin-4 improves glycemic control, ameliorates brain and pancreatic pathologies, and extends survival in a mouse model of Huntington's disease. Diabetes 58(2):318-328

326. Martín-Aparicio E, Yamamoto A, Hernández F, Hen R, Avila J, Lucas JJ (2001) Proteasomal-dependent aggregate reversal and absence of cell death in a conditional mouse model of Huntington's disease. J Neurosci 21(22):8772-8781

327. Mazarakis NK, Cybulska-Klosowicz A, Grote H, Pang T, Van Dellen A, Kossut M, Blakemore C, Hannan AJ (2005) Deficits in experience-dependent cortical plasticity and sensorydiscrimination learning in presymptomatic Huntington's disease mice. J Neurosci 25(12):3059-3066

328. Milnerwood AJ, Cummings DM, Dallérac GM, Brown JY, Vatsavayai SC, Hirst MC, Rezaie P, Murphy KPSJ (2006) Early development of aberrant synaptic plasticity in a mouse model of Huntington's disease. Hum Mol Genet 15 (10):1690-1703

329. Mochel F, Durant B, Durr A, Schiffmann R (2011) Altered dopamine and serotonin metabolism in motorically asymptomatic R6/2 mice. PLoS One 6(3):e18336

330. Mochel F, Durant B, Meng X, O'Callaghan J, Yu H, Brouillet E, Wheeler VC, Humbert S, Schiffmann R, Durr A (2012) Early alterations of brain cellular energy homeostasis in Huntington disease models. J Biol Chem 287(2):1361-1370

331. Murphy KP, Carter RJ, Lione LA, Mangiarini L, Mahal A, Bates GP, Dunnett SB, Morton AJ (2000) Abnormal synaptic plasticity and impaired spatial cognition in mice transgenic for exon 1 of the human Huntington's disease mutation. J Neurosci 20 (13):5115-5123

332. Nithianantharajah J, Barkus C, Murphy M, Hannan AJ (2008) Gene-environment interactions modulating cognitive function and molecular correlates of synaptic plasticity in Huntington's disease transgenic mice. Neurobiol Dis 29(3):490-504

333. Pallier PN, Maywood ES, Zheng Z, Chesham JE, Inyushkin AN, Dyball R, Hastings MH, Morton AJ (2007) Pharmacological imposition of sleep slows cognitive decline and reverses dysregulation of circadian gene expression in a transgenic mouse model of Huntington's disease. J Neurosci 27(29):7869-7878

334. Pang TYC, Du X, Zajac MS, Howard ML, Hannan AJ (2009) Altered serotonin receptor expression is associated with depression-related behavior in the R6/1 transgenic mouse model of Huntington's disease. Hum Mol Genet 18(4):753-766

335. Papalexi E, Persson A, Björkqvist M, Petersén A, Woodman B, Bates GP, Sundler F, Mulder H, Brundin P, Popovic N (2005) Reduction of GnRH and infertility in the R6/2 mouse model of Huntington's disease. Eur J Neurosci 22(6):1541-1546

336. Petersén A, Gil J, Maat-Schieman MLC et al (2005) Orexin loss in Huntington's disease. Hum Mol Genet 14(1):39-47

337. Phan J, Hickey MA, Zhang P, Chesselet M-F, Reue K (2009) Adipose tissue dysfunction tracks disease progression in two Huntington's disease mouse models. Hum Mol Genet 18 (6):1006-1016

338. Pietropaolo S, Delage P, Cayzac S, Crusio WE, Cho YH (2011) Sex-dependent changes in social behaviors in motor presymptomatic R6/1 mice. PLoS One 6(5):e19965

339. Pouladi MA, Graham RK, Karasinska JM, Xie Y, Santos RD, Petersén A, Hayden MR (2009) Prevention of depressive 
behaviour in the YAC128 mouse model of Huntington disease by mutation at residue 586 of huntingtin. Brain 132(Pt 4):919932

340. Pouladi MA, Stanek LM, Xie Y et al (2012) Marked differences in neurochemistry and aggregates despite similar behavioural and neuropathological features of Huntington disease in the fulllength BACHD and YAC128 mice. Hum Mol Genet 21 (10):2219-2232

341. Pouladi MA, Xie Y, Skotte NH et al (2010) Full-length huntingtin levels modulate body weight by influencing insulin-like growth factor 1 expression. Hum Mol Genet 19 (8):1528-1538

342. Rebec GV, Barton SJ, Ennis MD (2002) Dysregulation of ascorbate release in the striatum of behaving mice expressing the Huntington's disease gene. J Neurosci 22(2):RC202

343. Rebec GV, Conroy SK, Barton SJ (2006) Hyperactive striatal neurons in symptomatic Huntington R6/2 mice: variations with behavioral state and repeated ascorbate treatment. Neuroscience 137(1):327-336

344. Renoir T, Zajac MS, Du X, Pang TY, Leang L, Chevarin C, Lanfumey L, Hannan AJ (2011) Sexually dimorphic serotonergic dysfunction in a mouse model of Huntington's disease and depression. PLoS One 6(7):e22133

345. Ribchester RR, Thomson D, Wood NI, Hinks T, Gillingwater TH, Wishart TM, Court FA, Morton AJ (2004) Progressive abnormalities in skeletal muscle and neuromuscular junctions of transgenic mice expressing the Huntington's disease mutation. Eur J Neurosci 20(11):3092-3114

346. Rozas JL, Gómez-Sánchez L, Tomás-Zapico C, Lucas JJ, Fernández-Chacón R (2011) Increased neurotransmitter release at the neuromuscular junction in a mouse model of polyglutamine disease. J Neurosci 31(3):1106-1113

347. Rudenko O, Tkach V, Berezin V, Bock E (2009) Detection of early behavioral markers of Huntington's disease in R6/2 mice employing an automated social home cage. Behav Brain Res 203 (2):188-199

348. Sadagurski M, Cheng Z, Rozzo A, Palazzolo I, Kelley GR, Dong X, Krainc D, White MF (2011) IRS2 increases mitochondrial dysfunction and oxidative stress in a mouse model of Huntington disease. J Clin Invest 121(10):4070-4081

349. Sathasivam K, Hobbs C, Turmaine M, Mangiarini L, Mahal A, Bertaux F, Wanker EE, Doherty P, Davies SW, Bates GP (1999) Formation of polyglutamine inclusions in non-CNS tissue. Hum Mol Genet 8(5):813-822

350. Sawada H, Ishiguro $\mathrm{H}$, Nishii $\mathrm{K}$, Yamada $\mathrm{K}$, Tsuchida $\mathrm{K}$, Takahashi H, Goto J, Kanazawa I, Nagatsu T (2007) Characterization of neuron-specific huntingtin aggregates in human huntingtin knock-in mice. Neurosci Res 57(4):559573

351. Schroeder AM, Loh DH, Jordan MC, Roos KP, Colwell CS (2011) Baroreceptor reflex dysfunction in the BACHD mouse model of Huntington's disease. PLoS Curr 3:RRN1266

352. She P, Zhang Z, Marchionini D, Diaz WC, Jetton TJ, Kimball SR, Vary TC, Lang CH, Lynch CJ (2011) Molecular characterization of skeletal muscle atrophy in the R6/2 mouse model of Huntington's disease. Am J Physiol Endocrinol Metab 301(1): E49-E61

353. Shelbourne PF, Killeen N, Hevner RF et al (1999) A Huntington's disease CAG expansion at the murine Hdh locus is unstable and associated with behavioural abnormalities in mice. Hum Mol Genet 8(5):763-774

354. Shin J-Y, Fang Z-H, Yu Z-X, Wang C-E, Li S-H, Li X-J (2005) Expression of mutant huntingtin in glial cells contributes to neuronal excitotoxicity. J Cell Biol 171(6):1001-1012
355. Spires TL, Grote HE, Garry S, Cordery PM, Van Dellen A, Blakemore C, Hannan AJ (2004) Dendritic spine pathology and deficits in experience-dependent dendritic plasticity in R6/1 Huntington's disease transgenic mice. Eur J Neurosci 19 (10):2799-2807

356. Steele AD, Jackson WS, King OD, Lindquist S (2007) The power of automated high-resolution behavior analysis revealed by its application to mouse models of Huntington's and prion diseases. Proc Natl Acad Sci USA 104(6):1983-1988

357. Strand AD, Aragaki AK, Shaw D et al (2005) Gene expression in Huntington's disease skeletal muscle: a potential biomarker. Hum Mol Genet 14(13):1863-1876

358. Tallaksen-Greene SJ, Crouse AB, Hunter JM, Detloff PJ, Albin RL (2005) Neuronal intranuclear inclusions and neuropil aggregates in HdhCAG(150) knockin mice. Neuroscience 131(4):843852

359. Tang B, Seredenina T, Coppola G, Kuhn A, Geschwind DH, Luthi-Carter R, Thomas EA (2011) Gene expression profiling of R6/2 transgenic mice with different $\mathrm{CAG}$ repeat lengths reveals genes associated with disease onset and progression in Huntington's disease. Neurobiol Dis 42(3):459-467

360. Tang T-S, Chen X, Liu J, Bezprozvanny I (2007) Dopaminergic signaling and striatal neurodegeneration in Huntington's disease. J Neurosci 27(30):7899-7910

361. Thomas EA, Coppola G, Tang B, Kuhn A, Kim S, Geschwind DH, Brown TB, Luthi-Carter R, Ehrlich ME (2011) In vivo cellautonomous transcriptional abnormalities revealed in mice expressing mutant huntingtin in striatal but not cortical neurons. Hum Mol Genet 20(6):1049-1060

362. Usdin MT, Shelbourne PF, Myers RM, Madison DV (1999) Impaired synaptic plasticity in mice carrying the Huntington's disease mutation. Hum Mol Genet 8(5):839-846

363. Vatsavayai SC, Dallérac GM, Milnerwood AJ, Cummings DM, Rezaie P, Murphy KPSJ, Hirst MC (2007) Progressive CAG expansion in the brain of a novel R6/1-89Q mouse model of Huntington's disease with delayed phenotypic onset. Brain Res Bull 72(2-3):98-102

364. Wade A, Jacobs P, Morton AJ (2008) Atrophy and degeneration in sciatic nerve of presymptomatic mice carrying the Huntington's disease mutation. Brain Res 1188:61-68

365. Walker AG, Miller BR, Fritsch JN, Barton SJ, Rebec GV (2008) Altered information processing in the prefrontal cortex of Huntington's disease mouse models. J Neurosci 28(36):8973-8982

366. Walker TL, Turnbull GW, Mackay EW, Hannan AJ, Bartlett PF (2011) The latent stem cell population is retained in the hippocampus of transgenic Huntington's disease mice but not wild-type mice. PLoS One 6(3):e18153

367. Wang H-L, Chou A-H, Lin A-C, Chen S-Y, Weng Y-H, Yeh T-H (2010) Polyglutamine-expanded ataxin-7 upregulates Bax expression by activating p53 in cerebellar and inferior olivary neurons. Exp Neurol 224(2):486-494

368. Weydt P, Pineda VV, Torrence AE et al (2006) Thermoregulatory and metabolic defects in Huntington's disease transgenic mice implicate PGC-1alpha in Huntington's disease neurodegeneration. Cell Metab 4(5):349-362

369. Wood NI, Goodman AOG, van der Burg JMM, Gazeau V, Brundin P, Björkqvist M, Petersén A, Tabrizi SJ, Barker RA, Morton AJ (2008) Increased thirst and drinking in Huntington's disease and the R6/2 mouse. Brain Res Bull 76(1-2):70-79

370. Xiang Z, Valenza M, Cui L et al (2011) Peroxisome-proliferatoractivated receptor gamma coactivator $1 \alpha$ contributes to dysmyelination in experimental models of Huntington's disease. J Neurosci 31(26):9544-9553 
371. Yuen EY, Wei J, Zhong P, Yan Z (2012) Disrupted GABA(A)R trafficking and synaptic inhibition in a mouse model of Huntington's disease. Neurobiol Dis 46(2):497-502

372. Zabel C, Mao L, Woodman B et al (2009) A large number of protein expression changes occur early in life and precede phenotype onset in a mouse model for Huntington disease. Mol Cell Proteomics 8(4):720-734

373. Zacharoff L, Tkac I, Song Q, Tang C, Bolan PJ, Mangia S, Henry P-G, Li T, Dubinsky JM (2012) Cortical metabolites as biomarkers in the R6/2 model of Huntington's disease. J Cereb Blood Flow Metab 32(3):502-514

374. Lein ES, Hawrylycz MJ, Ao N et al (2007) Genome-wide atlas of gene expression in the adult mouse brain. Nature 445(7124):168176
375. Gil JMAC, Leist M, Popovic N, Brundin P, Petersén A (2004) Asialoerythropoietin is not effective in the R6/2 line of Huntington's disease mice. BMC Neurosci 5:17

376. Simpson JM, Gil-Mohapel J, Pouladi MA, Ghilan M, Xie Y, Hayden MR, Christie BR (2011) Altered adult hippocampal neurogenesis in the YAC128 transgenic mouse model of Huntington disease. Neurobiol Dis 41(2):249-260

377. Phillips W, Morton AJ, Barker RA (2006) Limbic neurogenesis/ plasticity in the R6/2 mouse model of Huntington's disease. Neuroreport 17(15):1623-1627

378. Kohl Z, Regensburger M, Aigner R, Kandasamy M, Winner B, Aigner L, Winkler J (2010) Impaired adult olfactory bulb neurogenesis in the R6/2 mouse model of Huntington's disease. BMC Neurosci 11:114 